\title{
Internalization of Sociocultural Standards of Beauty, Perception of Career Barriers, Depression, and State Physical Appearance Anxiety Among College Women
}

Adrionia Molder

West Virginia University, ammolder@mix.wvu.edu

Follow this and additional works at: https://researchrepository.wvu.edu/etd

Part of the Counseling Psychology Commons

\author{
Recommended Citation \\ Molder, Adrionia, "Internalization of Sociocultural Standards of Beauty, Perception of Career Barriers, \\ Depression, and State Physical Appearance Anxiety Among College Women" (2020). Graduate Theses, \\ Dissertations, and Problem Reports. 7790. \\ https://researchrepository.wvu.edu/etd/7790
}

This Dissertation is protected by copyright and/or related rights. It has been brought to you by the The Research Repository @ WVU with permission from the rights-holder(s). You are free to use this Dissertation in any way that is permitted by the copyright and related rights legislation that applies to your use. For other uses you must obtain permission from the rights-holder(s) directly, unless additional rights are indicated by a Creative Commons license in the record and/ or on the work itself. This Dissertation has been accepted for inclusion in WVU Graduate Theses, Dissertations, and Problem Reports collection by an authorized administrator of The Research Repository @ WVU. For more information, please contact researchrepository@mail.wvu.edu. 
Internalization of Sociocultural Standards of Beauty, Perception of Career Barriers, Depression, and State Physical Appearance Anxiety Among College Women

Adrionia M. Molder, M.S.

Dissertation submitted

to the College of Education and Human Resources

at West Virginia University

in partial fulfillment of the requirements for the degree of

Doctor of Philosophy in

Counseling Psychology

Lisa Platt, Ph.D., Chair

Jeffrey Daniels, Ph.D., Co-Chair

Sara Troupe, Psy.D.

Christine Schimmel, Ed.D.

Department of Counseling, Rehabilitation Counseling, and Counseling Psychology

Morgantown, West Virgina

2020

Keywords: internalization, sociocultural standards, beauty, anxiety, depression, career barriers

Copyright 2020 Adrionia M. Molder 


\begin{abstract}
Internalization of Sociocultural Standards of Beauty, Perception of Career Barriers, Depression, and State Physical Appearance Anxiety Among College Women
\end{abstract}

\begin{abstract}
Adrionia M. Molder
Women experience barriers that impede progress in a career and career goals, resulting in reduced career-related outcomes. Although gender discrimination has been identified as a contributing factor to the differential career development of men and women in the United States (U.S.), women's career-related outcomes may be better explained by unaccounted for career barriers. Most notably, internalization of sociocultural standards of beauty, depression, and anxiety have been found to reduce women's career-related outcomes. Therefore, the goal of this study was to explore career barriers that currently impact women's career development in the U.S. Based on Social Cognitive Career Theory (Lent, Brown, \& Hackett, 1994) and previous research, it was hypothesized that internalization of sociocultural standards of beauty would predict women's perception of career barriers, as measured by lack of confidence, inadequate preparation, and decision-making difficulties, with state physical appearance anxiety and depression as potential moderators. Results of this study yielded partial support. Internalization of sociocultural standards of beauty predicted perception of career barriers, as measured by lack of confidence and decision-making difficulties, but no moderation effects were found. This study provides groundwork for future research to build upon and further understanding of the career development of women in the U.S. This study also informs clinical work by emphasizing the importance of providing multicultural counseling that integrates personal and career counseling.
\end{abstract}




\section{ACKNOWLEDGEMENTS}

First, I would like to thank my mother for listening to my celebrations and failures without complaint. You somehow always knew the right thing to say (or not to say) when I needed it most. Thank you, Mom. Second, I would like to thank my lifelong friend and partner, Matthew Link, for always having faith in me, even when I did not have faith in myself. Thank you, Matt. Third, I would like to thank my doctoral cohort at West Virginia University. You,

more than anyone else, have understood the struggles that are inherent to pursuing a Ph.D. You were a daily reminder that I was not alone. Thank you, Chelsea Latorre, Connor Fais, Sarah Milam, Tim Swiger, and Ben Darling. Fourth, I would like to thank my dissertation chair for demystifying the dissertation process and pushing me when I got in my own way. Thank you, Dr. Lisa Platt. Fifth, I would like to thank my dissertation committee for providing constructive feedback with the intent to build me up, rather than tear me down. Thank you, Dr. Jeff Daniels, Dr. Chris Schimmel, and Dr. Sara Troupe. 


\section{TABLE OF CONTENTS}

Page

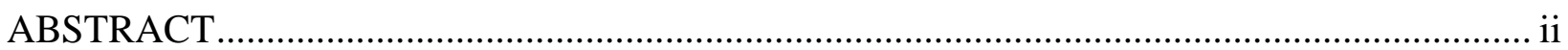

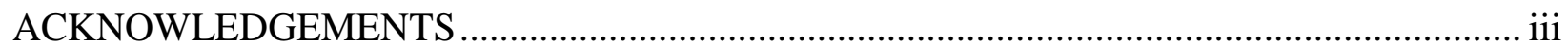

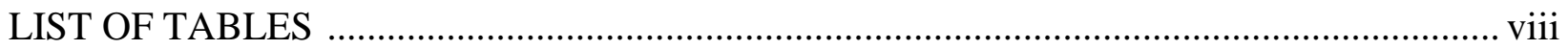

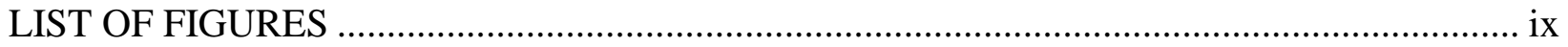

\section{CHAPTER}

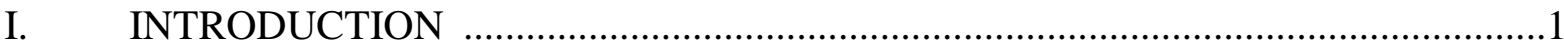

LITERATURE REVIEW .............................................................................

Social Cognitive Career Theory ...................................................................2

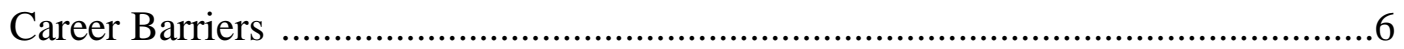

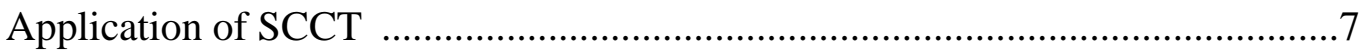

Types of Career Barriers ..............................................................................

Sociocultural Standards of Beauty ..................................................................13

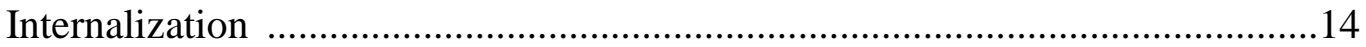

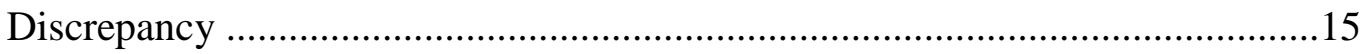

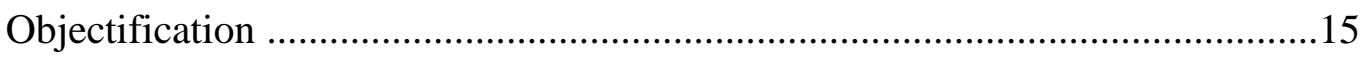

Psychological Consequences ...........................................................................16

Career-Related Outcomes ……………………………………………….....17

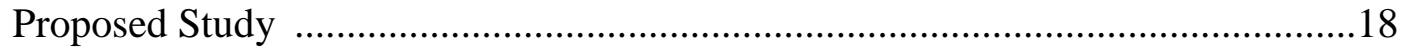

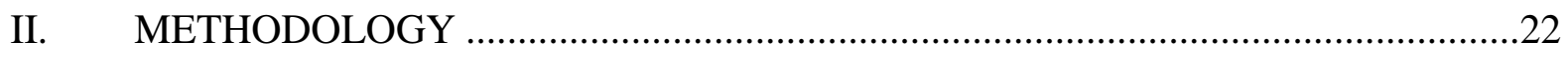

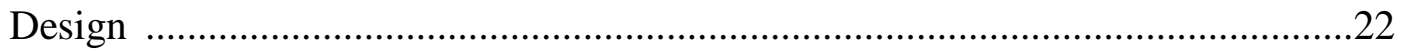

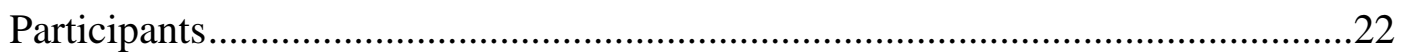


Career Barriers Inventory-Revised ........................................................24

Sociocultural Attitudes Towards Appearance Questionnaire-Internalization ....27

Center for Epidemiologic Studies Depression Scale ...................................28

Physical Appearance State and Trait Anxiety Scale .....................................30

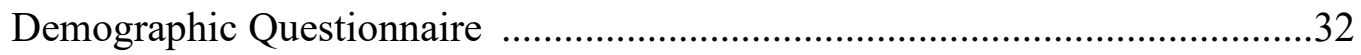

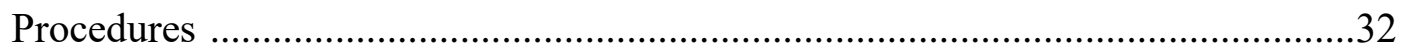

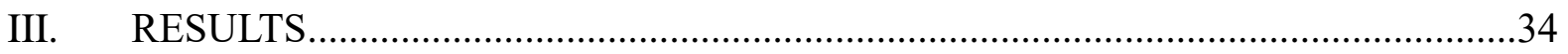

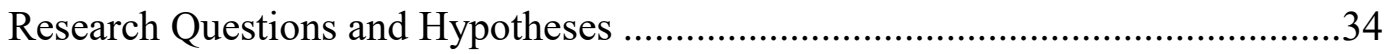

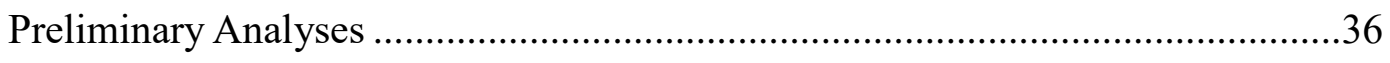

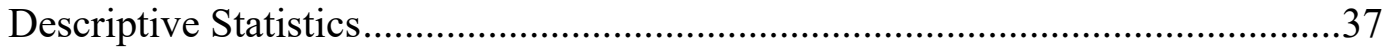

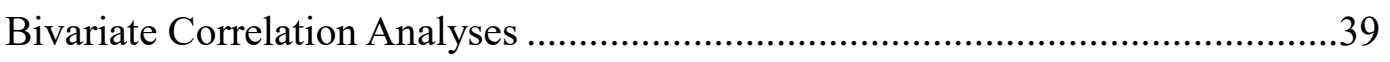

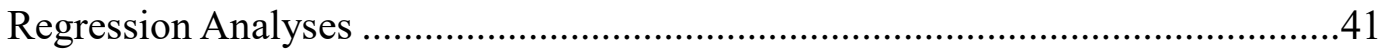

Physical Appearance State Anxiety as a Moderating Variable and Lack of

Confidence as an Outcome Variable.

Physical Appearance State Anxiety as a Mediating Variable and Lack of

Confidence as an Outcome Variable.

Physical Appearance State Anxiety as a Moderating Variable and Inadequate

Preparation as an Outcome Variable ........................................................46

Physical Appearance State Anxiety as a Moderating Variable and Decision-

Making Difficulties as an Outcome Variable

Depression as a Moderating Variable and Lack of Confidence as an Outcome

Variable 
Depression as a Moderating Variable and Inadequate Preparation as an

Outcome Variable

Depression as a Moderating Variable and Decision-Making Difficulties as an

Outcome Variable .54

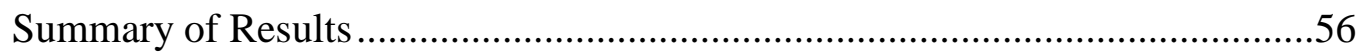

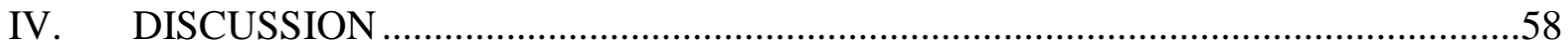

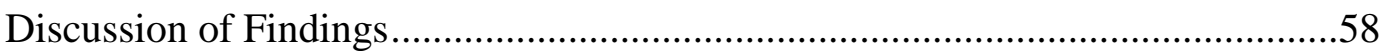

Internalization of Sociocultural Standards of Beauty and Perception of Career

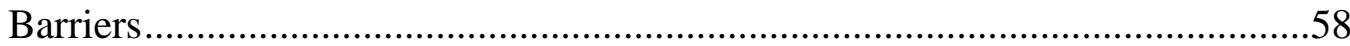

Internalization of Sociocultural Standards of Beauty, Physical Appearance State

Anxiety, and Perception of Career Barriers ................................................62

Internalization of Sociocultural Standards of Beauty, Depression, and

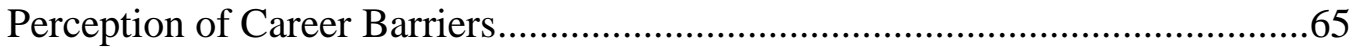

Summary of Findings...........................................................................66

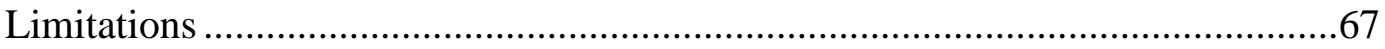

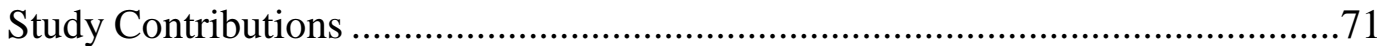

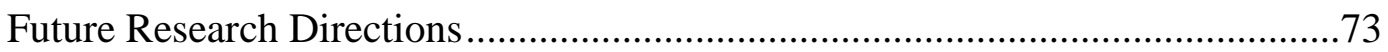

Counseling Psychology and Other Clinical Implications ..................................77

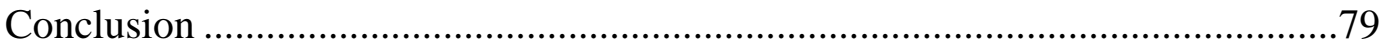

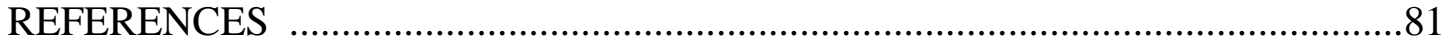

APPENDICES

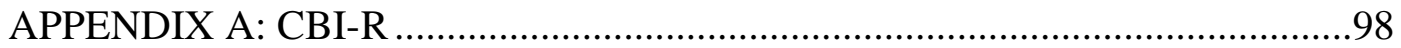

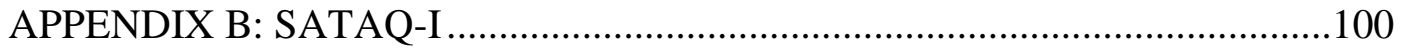


APPENDIX C: CES-D

APPENDIX D: PASTAS-S

103

APPENDIX E: DEMOGRAPHIC QUESTIONNAIRE .104

APPENDIX F: INFORMED CONSENT

107 


\section{LIST OF TABLES}

Table

1. Descriptive Statistics of Participant Demographic Information .38

2. Correlations Among Possible Predictor Variables of Lack of Confidence, Inadequate Preparation, and Decision-Making Difficulties .40

3. Summary of Multiple Regression Analyses for Variables Predicting Lack of Confidence as a Perceived Career Barrier: Physical Appearance State Anxiety as a Moderating Variable

4. PASTAS-S as a Mediating Variable between Predictor Variable SATAQ-I and Outcome Variable Lack of Confidence

5. Summary of Multiple Regression Analyses for Variables Predicting Inadequate Preparation as a Perceived Career Barrier: Physical Appearance State Anxiety as a Moderating Variable

6. Summary of Multiple Regression Analyses for Variables Predicting Decision-Making Difficulties as a Perceived Career Barrier: Physical Appearance State Anxiety as a Moderating Variable

7. Summary of Multiple Regression Analyses for Variables Predicting Lack of Confidence as a Perceived Career Barrier: Depression as a Moderating Variable

8. Summary of Multiple Regression Analyses for Variables Predicting Inadequate Preparation as a Perceived Career Barrier: Depression as a Moderating Variable

9. Summary of Multiple Regression Analyses for Variables Predicting Decision-Making Difficulties as a Perceived Career Barrier: Depression as a Moderating Variable. 


\section{LIST OF FIGURES}

Figure

Page

1. Social Cognitive Career Theory model of social cognitive influence on career development, Adapted from Lent, Brown, and Hackett (1994)

2. A conceptual model of Hypothesis 4 with physical appearance state anxiety as a moderating variable and lack of confidence as an outcome variable.

3. An alternative conceptual model of Hypothesis 4 with physical appearance state anxiety as a mediating variable and lack of confidence as an outcome variable.

4. Standardized regression coefficients for the relationship between internalization of sociocultural standards of beauty and lack of confidence as mediated by physical appearance state anxiety

5. A conceptual model of Hypothesis 5 with physical appearance state anxiety as a moderating variable and inadequate preparation as an outcome variable

6. A conceptual model of Hypothesis 6 with physical appearance state anxiety as a moderating variable and decision-making difficulties as an outcome variable

7. A conceptual model of Hypothesis 7 with depression as a moderating variable and lack of confidence as an outcome variable

8. A conceptual model of Hypothesis 8 with depression as a moderating variable and inadequate preparation as an outcome variable

9. A conceptual model of Hypothesis 9 with depression as a moderating variable and decision-making difficulties as an outcome variable 


\section{CHAPTER I}

Although women in the United States (U.S.) are increasingly represented in economic, political, social, and cultural domains, women continue to experience barriers that impede or prevent progress in a career or career goal(s) (Charles, 2003; Correll, Benard, \& Paik, 2007; Germeijs, Verschueren, \& Soenens, 2006; Freedman, 2010; Lopez \& Anne-Yi, 2006; Lyness \& Heilman, 2006; Newkirk, Perry-Jenkins, \& Sayer, 2017; Phelan, Moss-Racusin, \& Rudman, 2008; Rudman \& Glick, 2001; Swanson, Daniels, \& Tokar, 1996; Yavorsky, Kamp Dush, Schoppe-Sullivan, 2015). Objective and perceived environment-person career barriers, such as gender discrimination, conflict between children and career demands, and job market constraints, influence the development, maintenance, and enactment of career-relevant interests, choices, and action. Furthermore, environment-person career barriers exert significant influence on careerrelated self-efficacy and outcome expectations, which are fundamental to the types of cognitiveperson career barriers that originate, such as lack of confidence, career indecision, and feelings of inadequacy (Lent, Brown, \& Hackett, 2000; Swanson \& Daniels, 1994; Swanson, Daniels, \& Tokar, 1996; Swanson \& Tokar, 1991a; Swanson \& Tokar, 1991b).

The career barriers construct has primarily been examined in relation to the effect of gender discrimination on various career-related outcomes, including hiring, firing, and promotion (Charles, 2003; Freedman, 2010; Hodges \& Parks, 2013; Lyness \& Heilman, 2006; Swanson et al., 1996). However, internalization of sociocultural standards of beauty has also been found to impact women's career-related outcomes (Dipboye, Arvey, \& Terpstra, 1977; Hosoda, Stone-Romero, \& Coats, 2003; Johnson, Podratz, Dipboye, \& Gibbons, 2010; Shahani, Dipboye, \& Gehrlein, 1993). Furthermore, internalization of sociocultural standards of beauty is associated with physiological and psychological consequences, including anxiety and depression, 
for young girls and women (Fredrickson, Roberts, Noll, Quinn, \& Twenge, 1998; Grabe, Ward, \& Hyde, 2008; Moradi, Dirks, \& Matteson, 2005). In addition to reducing career-related outcomes, depression and anxiety weaken career-related self-efficacy and outcome expectations, resulting in the development and maintenance of cognitive-person career barriers (Bianchi, Schonfeld, \& Laurent, 2015; Rottinghaus, Jenkins, \& Jantzer, 2009; Saunders, Peterson, Sampson, \& Reardon, 2000). Although an impediment to women's career development, women's internalization of sociocultural standards of beauty has been mostly excluded from the career barriers literature to date.

Given the status of women in the U.S., it is important to consider the environment-person and cognitive-person career barriers that currently impede women's career development. Similar to other environment-person career barriers, internalization of sociocultural standards of beauty contributes to the development of cognitive-person career barriers and significantly impacts women's career-related outcomes (Baert \& Decuypere, 2014; Bowling et al., 2004; Fredrickson, et al., 1998; Grabe et al., Hosada et al., 2003; 2008; Moradi et al., 2005). To further understand the potential impact of perceived career barriers on women's career development, the current study will examine the relationship between women's perception of career barriers and internalization of sociocultural standards of beauty. Due to establishment as common psychological consequences related to women's internalization of sociocultural standards of beauty, state physical appearance anxiety and depression will be included as potential moderators. The following literature review provides a theoretical and empirical basis for the current study, including a rationale for the inclusion of the variables of interest.

\section{Literature Review}

\section{Social Cognitive Career Theory}


Social Cognitive Career Theory (SCCT) was developed by Lent, Brown, and Hackett (1994) "to understand the processes through which people form interests, make choices, and achieve varying levels of success in educational and occupational pursuits" (Lent et al., 2000, p. 36). Based on the theoretical foundation of Albert Bandura's Social Cognitive Theory (SCT; Bandura, 1977/1986), SCCT highlights the interaction between cognitive-person variables (e.g., self-efficacy, outcome expectations, goals) and environment-person variables (e.g., gender, ethnicity, social supports, barriers) on career development. SCCT is the theoretical basis for the current study.

Per Lent, Brown, and Hackett (2000), the first level of theoretical analysis of SCCT, cognitive-person variables, enables the acquisition and application of personal agency within the career development process. The second level of theoretical analysis, environment-person variables, considers the impact of physical attributes, environmental factors, and previous learning experiences on career-related interests and choices (Lent et al., 2000). Drawing on core assumptions and mechanisms of SCT (Bandura, 1986), Lent et al. (1994) adopted a triadic reciprocal causation model as foundational to SCCT, in which the complex and reciprocal interaction between person, environment, and behavior is considered in relation to career development.

According to Lent and colleagues (1994/2000), career development is influenced by both objective (e.g., quality of educational experience) and perceived environment-person variables (e.g., interpretation of opportunities and barriers). Although objective environment-person variables can impact career development regardless of personal control or awareness, the effect is often dependent on the type of cognitive appraisal and behavioral response that is produced in relation to the environment. SCCT's conceptualization of the perceived environment is based on 
Astin’s (1984) “opportunity structure” and Vondracek, Lerner, and Schulenberg's (1986)

"contextual affordance" constructs, which emphasize "that the opportunities, resources, barriers, and affordances presented by a particular environmental variable may be subject to individual interpretation" (Lent et al., 2000, p. 37). Therefore, SCCT highlights the importance of perception in processing positive and negative environment-person variables in relation to career development.

In addition to the objective and perceived properties of environment-person variables, SCCT emphasizes the importance of temporal proximity of environmental influences on the “career choice-making process" (Lent et al., 2000, p. 37). Lent and colleagues (1994/2000) categorized environment-person variables as distal and proximal influencers (see Figure 1). The first category includes distal, or background, environmental influencers that impact learning via the development and maintenance of career-related self-efficacy and outcome expectations, including exposure to career role models, parental support or opposition of career pursuit, and engagement in career-relevant coursework or extracurricular activities. According to Bandura (1986), self-efficacy refers to "people's judgements of their capabilities to organize and execute courses of action required to attain designated types of performances" (p. 391). Therefore, exposure to distal environmental influencers can impact self-efficacy, which has been associated with choice of career-related activities and environments, as well as persistence, effort, and physiological and emotional arousal in relation to career barriers (Bandura, 1986; BarNir, Watson, \& Hutchins, 2011; Hackett \& Betz, 1981; Lent et al., 1994). Outcome expectations are personal beliefs that a behavior will result in a desired outcome (Bandura, 1977/1986). Although self-efficacy is based on response capabilities, outcome expectations are determined by the 
anticipation of physical, social, and self-evaluative consequences, which may contribute to career-relevant interests and choices (Bandura, 1986; Lent et al., 1994).

The second category includes proximal, or contemporary, environmental influencers that are involved in the "active phases of educational or career decision making," such as inadequacy of networking, job market constraints, and exposure to gender discrimination (Lent et al., 2000, p. 38). Proximal environmental influencers can impose both direct and moderating effects on the development and implementation of career-relevant interests and choices (see Figure 1). In particular, proximal environmental influencers can moderate the relationship between careerrelevant interests, choices, and performance. Career-relevant interests prompt the establishment of a career choice or goal (e.g., medical interests result in intentions to pursue a surgical career), which, in turn, promotes performance, or action, that is consistent with career choice or goal (e.g., applying for entrance into medical school).

However, environmental influencers are instrumental in career development. For example, the transition of career-relevant interests into goals and actions is less likely to occur in the presence of adverse environmental influencers that are perceived to be barriers to progress in a career or career goal(s). In contrast, the perception of environmental influencers as beneficial to career development facilitates the translation of career-relevant interests into career goals and actions. In addition to moderation, environmental influencers can directly influence career development. Specifically, environmental influencers (e.g., inadequate financial resources, familial involvement, acculturation) can direct career-relevant choices and actions regardless of interests. 


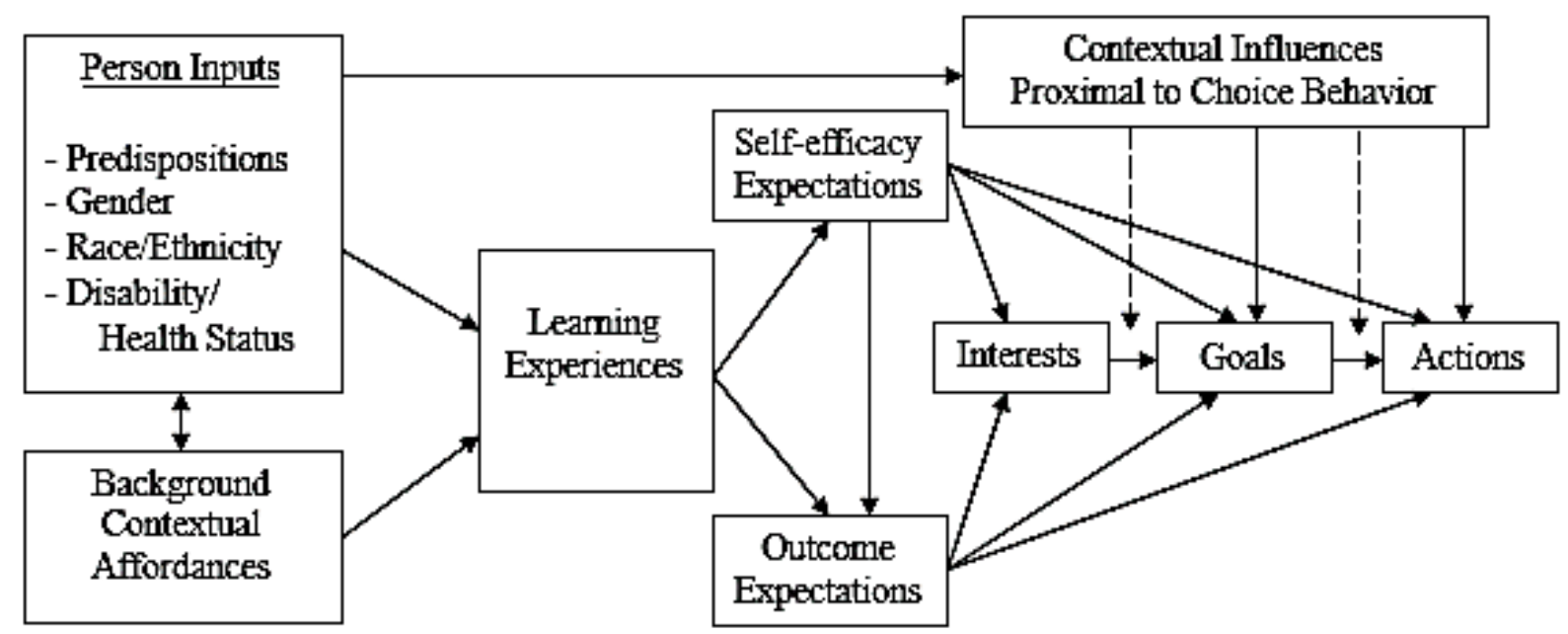

Figure 1. SCCT model of social cognitive influences on career development. The dotted paths indicate moderated effects on interest-goals and goals-actions relationships. Adapted from "Toward a Unifying Social Cognitive Theory of Career and Academic Interest, Choice, and Performance" [Monograph], by R.W. Lent, S. D. Brown, and G. Hackett, 1994, Journal of Vocational Behavior, 45, p. 93. Copyright 1994 by R. W. Lent, S. D. Brown, and G. Hackett.

\section{Career Barriers}

Career barriers are defined by Swanson and colleagues (1996) as "external conditions or internal states that make career progress difficult" (p. 236). The construct of career barriers was originally described by Crites (1969) as "thwarting conditions" that impede career development (p. 52). Crites (1969) differentiated career barriers into internal conflicts (e.g., self-esteem and motivation to achieve) and external frustrations (e.g., workplace discrimination and inadequate wages). Crites' (1969) internal-external dichotomization of career barriers was adopted as the preferred categorization system by subsequent researchers in the field, in which application was primarily circumscribed to the career development of women in the U.S. For example, O'Leary (1974) described six internal (e.g., fear of failure) and four external (e.g., gender-role stereotypes) barriers that impact the formation and maintenance of career aspirations among women. Furthermore, Farmer (1976) identified six internal barriers (e.g., "reduction in academic self-confidence") and three external barriers (e.g., "sex role orientation") to women's career achievement. Similarly, Harmon (1977) conceptualized barriers to women's career development as both psychological and sociological. 
Despite historical precedence, Swanson and Tokar (1991a) challenged the internalexternal dichotomy that had previously been considered foundational to the career barriers construct. For example, in a free-response, thought listing experiment, Swanson and Tokar (1991a) found that male $(n=24)$ and female $(n=24)$ college students perceived 1,098 barriers to career development, which was classified into three categories: social/interpersonal (e.g., multiple-role conflict), attitudinal (e.g., lack of confidence), and interactional (e.g., sex discrimination). Although Swanson and Tokar (1991b) found only modest support for a threeway classification system, the traditional internal-external dichotomy was unsupported and, ultimately, rejected as a suitable classification system for career barriers.

Application of SCCT. According to Swanson and colleagues (1996), the construct of career barriers has been weakened by lack of a theoretical framework that could integrate historical and contemporary research findings and guide the direction and scope of future research. Furthermore, Swanson et al. (1996) argued that empirical approaches to career barriers have been conducted with "idiosyncratic" measures that are specific to a particular study, resulting in limited relevance and consistency in the available body of research (p. 220). Due to ambiguity and incoherence in previous conceptualizations and empirical approaches, Swanson et al. (1996) proposed the application of SCCT as a theoretical framework for understanding career barriers (Lent et al., 1994).

Swanson et al. (1996) reasoned that SCCT provides an "ideal backdrop" for the career barriers construct due to conceptualization of career barriers as either self-reflections (e.g., "Am I capable of succeeding?") or self-referent perceptions of the academic or work environment (“Will I experience discrimination in my pursuit of this career?"; p. 221). Therefore, the career barriers construct is consistent with SCCT (Lent et al., 1994/2000), which emphasizes the 
influence of cognitive appraisal processes on career development. In addition, Swanson et al. (1996) determined that the career barriers construct paralleled sociocognitive mechanisms, namely, self-efficacy beliefs and outcome expectations, hypothesized by Lent et al. (2000) to be especially relevant to career development. Furthermore, Swanson et al. (1996) asserted that perceptions of career barriers may potentially "contribute to, result from, or even represent some of the person, contextual, and experiential inputs" that Lent et al. (1994/2000) hypothesized to moderate key relationships among sociocognitive variables, including career interests, goals, and actions, essential to career development (p. 221). In summary, Swanson et al. (1996) recommended SCCT as an appropriate theoretical framework to conceptualize the career barriers construct and guide future research inquiry (Lent et al., 1994/2000).

Types of career barriers. Although the career barriers construct can be used to understand the types of impediments that detrimentally impact the career development of a variety of populations, career barriers that specifically impact women in the U.S. are reviewed (Cook, Heppner, \& O’Brien, 2002; Rivera, Chen, Flores, Blumberg, \& Ponterotto, 2007). A focus on the types of barriers that hinder the career development of women is consistent with Swanson and colleagues' (1996) conceptualization of a carrier barrier as an explanatory construct that may (a) account for the gap between women's ability and achievement, (b) interact to limit women's career aspirations, and (c) explain the relationship between career aspirations and the restricted range of career options perceived as available and attainable among women.

In a series of studies, Swanson and colleagues (Swanson \& Daniels, 1994; Swanson et al., 1996; Swanson \& Tokar, 1991a; Swanson \& Tokar, 1991b) identified thirteen types of barriers that women perceive as impediments to progress in a career or career goal(s), including sex discrimination, multiple-role conflict, conflict between children and career demands, racial 
discrimination, lack of confidence, inadequate preparation, disapproval by significant others, decision-making difficulties, dissatisfaction with career, discouragement from choosing nontraditional careers, disability/health concerns, job market constraints, and difficulties with networking/socialization. Swanson et al. (1996) found that women most commonly reported inadequate preparation, dissatisfaction with career, lack of confidence, and decision-making difficulties as career barriers, suggesting the importance and relevance of "person factors" in guiding career interests, goals, and actions (p. 239; Swanson \& Daniels, 1994; Swanson \& Tokar, 1991a; Swanson \& Tokar, 1991b). Contextual influences, such as disapproval by significant others, discouragement from choosing nontraditional careers, and difficulty with networking/socialization, were reported by women as least likely to impede career development (Swanson et al., 1996). It is important to note that significant racial/ethnic identity differences have been identified in relation to eight of the thirteen career barriers. Specifically, racial/ethnic minorities were more likely to report racial discrimination as a career barrier, whereas Caucasians were more likely to report lack of confidence, multiple-role conflict, inadequate preparation, disapproval by significant others, dissatisfaction with career, discouragement from choosing nontraditional careers, and disability/health concerns as more likely to limit career development (Swanson et al., 1996).

The prevailing criticism of the career barriers construct is potential irrelevance and limited applicability due to advancement in the economic, political, social, and cultural status of women since original construction in the 1990s (O’Neil \& Bilimoria, 2005). However, career barriers, as defined by Swanson and colleagues (Swanson \& Daniels, 1994; Swanson et al., 1996; Swanson \& Tokar, 1991a; Swanson \& Tokar, 1991b), continue to provide a cogent explanation for the differential career development of men and women in the U.S. (Dahling, 
Melloy, \& Thompson, 2013; Novakovic \& Gnilka, 2015; Watts, Frame, Moffett, Van Hein, \& Hein, 2015). Although an exhaustive review of the career barriers literature is beyond the scope of this study, a brief discussion of key environment-person and cognitive-person career barriers that influence the career development of women in the U.S. is included (Lent et al., 2000).

A primary environment-person career barrier that impacts women's career interests, goals, and actions is occupational segregation, which refers to the distribution of employees across and within careers based on demographic characteristics, including gender, race/ethnicity, sexual orientation, nationality, disability, and age (Charles, 2003). In terms of gender, horizontal occupational segregation, or the distribution of men and women across careers, results in the overrepresentation of women in careers associated with the lowest wages and promotional opportunities in the U.S. (e.g., elementary and secondary education, nursing, leisure and hospitality, accounting; Charles, 2003; U.S. Bureau of Labor Statistics, 2017). Horizontal occupational segregation typically compels women to obtain more than one employment position to achieve financial stability (Freedman, 2010). In a similar manner, vertical occupational segregation, or the distribution of men and women across positions within a career, inhibits the career advancement of women by restricting promotional opportunity. For example, women comprise $4.8 \%$ of Fortune 500 corporate executives, and 12 Fortune 500 companies include no women board members, which emphasizes the preference for men in corporate leadership positions (U.S. Bureau of Labor Statistics, 2017). In combination, horizontal and vertical occupational segregation contribute to the gender wage gap in the U.S., in which women currently earn $82 \%$ of men's median weekly earnings (U.S. Bureau of Labor Statistics, 2017). Lyness and Heilman (2006) explained occupational segregation as a function of perceived lack of person-job fit, or the "perceived incongruity between stereotypically based 
attributes ascribed to women (e.g., kind, caring, and relationship-oriented) and the attributes ascribed to men (e.g., tough, forceful, and achievement-oriented) believed to be necessary" for career success (p. 777). Perceived lack of person-job fit produces the expectation that women will perform poorly in male-dominated careers and positions, resulting in negative performance appraisals that perpetuate and confirm beliefs of incompatibility. However, women's attempts to reduce perceived lack of person-job fit by exhibiting attributes traditionally ascribed to men are associated with a backlash effect, in which perceived competence is increased but likeability is decreased (Phelan, et al., 2008; Rudman \& Glick, 2001). For example, in a study conducted by Rudman and Glick (2001), participants were less likely to hire masculine women job applicants, as compared to feminine women job applicants, based on a tendency to penalize perceived violations of "feminine niceness" prescriptions (p. 743). In addition to decreased hireability, the perception of masculine women as unlikeable or socially deficient results in the reduction of other career-related outcomes, including performance appraisal, promotional opportunity, and social networking/connection (Heilman, Wallen, Fuchs, \& Tamkins, 2004; Phelan et al., 2008).

Perceived lack of person-job fit is even greater and more distinct in relation to women with children. For example, Correll, Benard, and Paik (2007) reported that mothers receive a perchild wage penalty of five percent. Furthermore, in a study conducted by Cuddy, Fiske, and Glick (2004), describing a consultant as a mother resulted in participants rating the employee as less competent than when describing a consultant as not having children. Similarly, other studies have demonstrated that visible pregnancy results in judgment of women managers as less committed, dependable, and authoritative than women managers who are not visibly pregnant (Corse, 1990; Halpert, Wilson, \& Hickman, 1993). Correll and colleagues (2007) hypothesized that the impact of the "motherhood penalty" on wages and performance appraisal is due to 
perceived incompatibility between the motherhood role and the "ideal worker" role, in which mothers are believed to be less committed to the workplace than men and women who do not have children (p. 1298).

Perceived incompatibility between the motherhood role and "ideal worker" role is perpetuated by the maintenance of a traditional division of household and childcare labor, in which women primarily perform household and childcare responsibilities, regardless of employment status (Newkirk, et al., 2017; Yavorsky, et al., 2015). Women's disproportionate performance of career, household, and childcare responsibilities increases women's perception of work-family conflict, which is defined by Greenhaus and Beutell (1985) as, "a form of interrole conflict in which role pressure from the work and family domains are mutually incompatible...participation in the work role is made more difficult by virtue of participation in the family role" (p. 77). In addition to role overload associated with occupying multiple distinct roles, women engage in shifting oppositional identities, in which the assumption of a work or family identity is context-dependent. Due to the cognitive resources required to shift between identities, women experience a variety of psychological and physiological consequences, including stress, fatigue, anxiety, and depression, which significantly reduce career-related outcomes (Hodges \& Park, 2013).

In response to objective and perceived environment-person career barriers, such as occupational segregation, lack of person-job fit, the "motherhood penalty," and role incompatibility, career-related self-efficacy and outcome expectations of women may be negatively impacted, resulting in lack of confidence, indecision, and feelings of inadequacy (Bandura, 1977/1986; Charles, 2003; Correll et al., 2007; Hodges \& Park, 2013; Lent et al., 2000; Lyness \& Heilman, 2006). For example, Betz and Hackett (1981) found that college 
women endorsed significantly lower self-efficacy beliefs than college men in relation to maledominated careers. However, college men demonstrated similar self-efficacy beliefs regardless of career gender distribution. Furthermore, career-related self-efficacy was predictive of differences between men and women in the consideration of career options, in which women exhibited a restricted range of career options, as compared to men (Betz \& Hackett, 1981). In addition, Lopez and Anne-Yi (2006) revealed that perceptions of career barriers, career barrier coping beliefs, and career decision-making self-efficacy were unique predictors of career indecision among women. Career indecision has also been linked to perceived lack of career readiness among college men and women (Gaffner \& Hazler, 2002; Germeijs, et al., 2006; Taylor \& Betz, 1983).

As previously discussed, objective and perceived environment-person career barriers influence women's career development. However, Swanson and colleagues (1996) suggested that cognitive-person career barriers, including inadequate preparation, dissatisfaction with career, lack of confidence, and decision-making difficulties, are more likely to be perceived by women as barriers to career development. Based on the impact of cognitive-person career barriers on women's career interests, goals, and actions, this study limits the focus of career barriers to inadequate preparation, lack of confidence, and decision-making difficulties (Swanson \& Daniels, 1994; Swanson et al., 1996, p. 239; Swanson \& Tokar, 1991a; Swanson \& Tokar, 1991b).

\section{Sociocultural Standards of Beauty}

Sociocultural standards of beauty are culturally prescribed and endorsed physical characteristics that incorporate features of the face and body and "define the standards for physical attractiveness within a culture" (Calogero, Boroughs, \& Thompson, 2007, p. 261; 
Heinberg, Thompson, \& Stormer, 1995). In the U.S., sociocultural standards of beauty for women include thin body shape, fair skin tone, youth, large breast size, flawless skin complexion, muscle definition, and symmetry (Groesz, Levine, \& Murnen, 2002; Harrison, 2003). Media, including television, advertisements, music, movies, video games, magazines, and the Internet, operate as primary mechanisms for the dissemination and integration of the feminine beauty ideal into practices of daily living for young girls and women (Bartlett, \& Harris, 2008; Fardouly, Diedrichs, Vartanian, \& Halliwell, 2015; Grabe et al., 2008; Morry \& Staska, 2001; Tiggeman \& Slater, 2004).

Meta-analytic reviews of experimental and correlational studies examining the relationship between media exposure and body dissatisfaction have suggested that exposure to media images of the feminine beauty ideal is associated with body image concerns for young girls and women (Grabe et al., 2008; Groesz et al., 2002; Myers \& Crowther, 2009). In addition, exposure to non-media communications that affirm sociocultural standards of beauty adversely impact young girls and women. For example, in a study conducted by Stice, Maxfield, and Wells (2003), women reported increased body dissatisfaction following exposure to social pressure to be thin. Similarly, Krones, Stice, Batres, and Orjada (2005) found that in vivo social comparison to a thin body ideal peer resulted in women reporting increased body dissatisfaction.

Internalization. Conformity to sociocultural standards of beauty is associated with morality, or "goodness" (Dion, Berscheid, \& Walster, 1972). For example, the physical attractiveness stereotype, or physical attractiveness bias, is the association of physical attractiveness with socially desirable personality characteristics, including sociability, likeability, independence, happiness, and competence (Eagly, Ashmore, Makhijani, \& Longo, 1991; Shahani et al., 1993). Chronic exposure to sociocultural standards of beauty reinforces the belief that 
beauty equates to social reward. For example, Engeln-Maddox (2006) found that women's internalization of the feminine beauty ideal portrayed in media was related to expectations that beauty would improve important aspects of daily life, including happiness, adjustment, social competency, romantic potential, and career opportunity. The emphasis of social reward as an outcome of adherence to sociocultural standards of beauty encourages personal endorsement and acceptance of the feminine beauty ideal (Heinberg et al., 1995).

Discrepancy. Although sociocultural standards of beauty are prescribed and expected, discrepancy between the feminine beauty ideal and women's bodies is inherent. Specifically, the feminine beauty ideal promotes physically incompatible body proportions, such as thin body shape and large breast size, which are unrealistic and unattainable, given the typical size and shape of women's bodies. For example, the average American woman is 5 feet, 3 inches and 168.5 pounds, but the average American model is 5 feet, 11 inches and 117 pounds (National Eating Disorders Association, 2018). Furthermore, the feminine beauty ideal is only acquired and maintained by $5-10 \%$ of women, suggesting that $90-95 \%$ of women will be unable to conform to sociocultural standards of beauty in the U.S. Due to biological constraint, the feminine beauty ideal is primarily achieved with dangerous methods, such as food restriction, binging, purging, medication, and surgical modification (Dakanalis et al., 2014; Harrison, 2003).

Objectification. Chronic exposure to sociocultural standards of beauty that define the feminine beauty ideal as a limited and exclusive set of physical characteristics is a form of sexual objectification, in which women are constantly reduced to bodies, body parts, or body functions (Moradi et al., 2005). Specifically, Bartky (1990) defined sexual objectification as the reduction of a woman's body to its parts or functions to serve as "mere instruments" or representations of physiological and psychological characteristics of a woman (p. 35). Sexual objectification 
experiences exist on a continuum that ranges from overt and blatant behaviors, such as sexual assault, to covert and subtle behaviors, such as appearance remarks. A frequently cited example of sexual objectification is the objectifying gaze, or "the visual inspection of the body by another person" (Gervais, Vescio, \& Allen, 2011, p. 6), which is a covert form of sexual objectification that occurs during social interaction and is frequently represented in the media (Fredrickson \& Roberts, 1997; Goffman, 1979; Moradi et al., 2005). Although overt forms of sexual objectification occur, daily diary data suggest that women routinely experience covert forms of sexual objectification (e.g., whistles, cat calls, sexual comments or advances) with estimates ranging from one to two times per week (Swim, Hyers, Cohen, \& Ferguson, 2001).

In addition to external observation and experience of sexual objectification, women internalize sociocultural standards of beauty, resulting in self-objectification, in which self-worth is defined as the absence or presence of physical characteristics consistent with the feminine beauty ideal (Fredrickson et al., 1998). Self-objectification refers to the process of adopting a third-person perspective to evaluate observable, or objective, physical characteristics, such as body shape and size, rather than a first-person perspective, which typically includes nonobservable, or subjective, psychological characteristics, such as compassion (Bartky, 1990; Morry \& Staska, 2001). The conversion of the self to an object is manifested by persistent body surveillance (Fredrickson et al., 1998; Moradi et al., 2005).

Psychological consequences. The feminine beauty ideal, as defined by sociocultural standards of beauty, has primarily been associated with body dissatisfaction and eating disturbance among women in the U.S. (Grabe et al., 2008; Groesz et al., 2002; Krones et al., 2005; Stice et al., 2003). However, exposure to the feminine beauty ideal can result in a variety of negative psychological consequences for young girls and women, including body shame, 
general and physical appearance anxiety, depression, anger, and cognitive dysfunction (Calogero et al., 2007; Fredrickson et al., 1998; Moradi et al., 2005; Reed, Thompson, Brannick, \& Sacco, 1991). Internalization of sociocultural standards of beauty increases the risk of negative psychological consequences for young girls and women based on an increased perception of discrepancy between the feminine beauty ideal and current physical appearance and engagement in self-objectification (Cattarin, Thompson, Thomas, \& Williams, 2000; Dittmar \& Howard, 2004; Heinberg et al., 1995).

Career-related outcomes. Sociocultural standards of beauty that define the feminine beauty ideal impact the career development of women in the U.S. For example, perceived physical attractiveness of women job applicants has been implicated as an important contribution in hiring decisions in employment settings (Baert \& Decuypere, 2014; Gilmore, Beehr, \& Love, 1986; Watkins \& Johnston, 2000). Specifically, women job applicants perceived as physically attractive receive more favorable evaluation due to the physical attractiveness stereotype, in which conformity to the feminine beauty ideal is equated to competence, social skill, warmth, happiness, and other positive personality characteristics, resulting in an increased likelihood of hiring (Shahani et al., 1993). In addition to hiring decisions, the physical attractiveness of women has also been found to improve other career-related outcomes, including starting salary, performance appraisal, social networking/connection, and promotion (Bowling et al., 2004; Dipboye et al., 1977; Hosoda et al., 2003; Johnson et al., 2010).

Furthermore, psychological consequences associated with the internalization of sociocultural standards of beauty, such as depression, anxiety, and cognitive dysfunction, reduce career-related outcomes of women due to burnout, dissatisfaction, poor performance appraisal, and social isolation and withdrawal (Bianchi et al., 2015; Cropanzano, Rupp, \& Byrne, 2003; 
Maslach, Schaufeli, \& Leiter, 2001). In particular, depression and anxiety undermine careerrelated self-efficacy and outcome expectations, which contribute to the development and maintenance of cognitive-person career barriers, including lack of confidence, career indecision, and feelings of inadequacy (Campagna \& Curtis, 2007; Lent et al., 2000; Motowidlo, Packard, \& Manning, 1986; Rottinghaus et al., 2009; Saunders et al., 2000; Swanson et al., 1996).

Although sociocultural standards of beauty appear to impede women's career development by influencing various career-related outcomes, including hiring, firing, and promotion, the relationship between women's internalization of sociocultural standards of beauty and perception of career barriers has not been examined. Due to a tendency to identify cognitiveperson career barriers, such as lack of confidence, feelings of inadequacy, and indecision, women may not explicitly identify internalization of sociocultural standards of beauty as a barrier to career development (Swanson et al., 1996). However, internalization of sociocultural standards of beauty may function as both an environment-person and cognitive-person career barrier due to the dual nature of exposure to the feminine beauty ideal and the self-objectification process that occurs in response to internalization of sociocultural standards of beauty.

\section{Proposed Study}

Although women have increasingly become represented in academia and the workforce in the U.S., women continue to disproportionately experience barriers that impede progress in a career or career goal(s) (Charles, 2003; Freedman, 2010; Hodges \& Parks, 2013; Swanson \& Daniels, 1994; Swanson et al., 1996; Swanson \& Tokar, 1991a; Swanson \& Tokar, 1991b). The primary environment-person career barrier that has been identified in the literature is gender discrimination, in which stereotypically ascribed characteristics of women detrimentally impact women's career-related outcomes due to perceived lack of person-job fit (Correll et al., 2007; 
Lyness \& Heilman, 2006; Phelan et al., 2008; Rudman \& Glick, 2001). However, internalization of sociocultural standards of beauty operates in a similar manner by reducing the career-related outcomes of women. Furthermore, internalization of sociocultural standards of beauty is related to women's development of cognitive-person career barriers, such as lack of confidence, career indecision, and feelings of inadequacy, as well as various psychological consequences, including anxiety and depression (Fredrickson et al., 1998; Grabe et al., 2008; Moradi et al., 2005). Despite overlap between internalization of sociocultural standards of beauty and previously identified environment-person and cognitive-person career barriers, the construct has not been included in the career barriers literature to date.

To further understand internalization of sociocultural standards of beauty in relation to women's career development, the relationship between women's internalization of sociocultural standards of beauty and perception of career barriers will be examined. As anxiety and depression are common psychological consequences related to internalization of sociocultural standards of beauty, state physical appearance anxiety and depression will be included as potential moderators of the proposed relationship. To rectify limitations of the current career barriers literature, the following research questions and related hypotheses are addressed:

Research Question 1. Is internalization of sociocultural standards of beauty related to perception of career barriers, as measured by lack of confidence, inadequate preparation, and decision-making difficulties?

Hypothesis 1: Internalization of sociocultural standards of beauty will be a significant, positive predictor of lack of confidence.

Hypothesis 2: Internalization of sociocultural standards of beauty will be a significant, positive predictor of inadequate preparation. 
Hypothesis 3: Internalization of sociocultural standards of beauty will be a significant, positive predictor of decision-making difficulties.

Research Question 2. Is the relationship between internalization of sociocultural standards of beauty and perception of career barriers, as measured by lack of confidence, inadequate preparation, and decision-making difficulties, moderated by physical appearance state anxiety?

Hypothesis 4: The significant, positive relationship between internalization of sociocultural standards of beauty and lack of confidence will be moderated by physical appearance state anxiety.

Hypothesis 5: The significant, positive relationship between internalization of sociocultural standards of beauty and inadequate preparation will be moderated by physical appearance state anxiety.

Hypothesis 6: The significant, positive relationship between internalization of sociocultural standards of beauty and decision-making difficulties will be moderated by physical appearance state anxiety.

Research Question 3. Is the relationship between internalization of sociocultural standards of beauty and perceptions of career barriers, as measured by lack of confidence, inadequate preparation, and decision-making difficulties, moderated by depression?

Hypothesis 7: The significant, positive relationship between internalization of sociocultural standards of beauty and lack of confidence will be moderated by depression. 
Hypothesis 8: The significant, positive relationship between internalization of sociocultural standards of beauty and inadequate preparation will be moderated by depression.

Hypothesis 9: The significant, positive relationship between internalization of sociocultural standards of beauty and decision-making difficulties will be moderated by depression. 


\section{CHAPTER II}

\section{Methodology}

\section{Design}

This study examined the relationship between the outcome variable of perception of career barriers (i.e., lack of confidence, inadequate preparation, and decision-making difficulties) and the predictor variable of internalization of sociocultural standards of beauty with physical appearance state anxiety and depression as two potential moderating variables. Bivariate correlation and multiple regression analyses were conducted to determine relationships among the variables of interest and the potential moderating effect of physical appearance state anxiety and depression on the relationship between internalization of sociocultural standards of beauty and the perception of career barriers. This was a quantitative, correlational, cross-sectional survey research design in which all participants received identical survey material with random variation in survey order.

\section{Participants}

An a priori power analysis was computed using $\mathrm{G}^{*}$ Power software to estimate the sample size for the current study (Faul, Erdfelder, Buchner, \& Lang, 2009; Faul, Erdfelder, Lang, \& Buchner, 2007). The statistical test selected for the estimation was a linear multiple regression, in which one criterion variable (career barriers) and three predictor variables (internalization of sociocultural standards of beauty, depression, and state physical appearance anxiety) were identified. Based on an alpha $(\alpha)$ level of .05 , the power analysis estimated that a minimum of 77 participants would be necessary to obtain adequate statistical power $(1-\beta=.80)$ to obtain a medium effect size $\left(f^{2}=.15\right)$. Based on the power analysis estimate, a convenience sample of 300 graduate and undergraduate students were recruited from the West Virginia University 
(WVU) psychology department subject pool, using SONA, an online participant management system that enables online data collection.

Exclusion criteria for this study included age, gender, and academic disqualifiers.

Specifically, a minimum age of 18 years, a part- or full-time undergraduate or graduate academic status at WVU, and identification as a woman were required to participate in this study. The population of interest was limited to college women due to validation of the career barriers construct with college women (Swanson \& Daniels, 1994; Swanson et al., 1996; Swanson \& Tokar, 1991a; Swanson \& Tokar, 1991b).

A total of 303 undergraduate women at WVU participated in this study; however, 11 participants (3.6\%) were excluded due to missing data. As seen in Table 1, participants ranged in age from 18 to 41 years with a mean age of 19.31 years. The identified race/ethnicity of participants were as follows: $84.6 \%$ Caucasian or White, 3.8\% Asian American or Asian, 3.4\% African American or Black, 3.1\% Hispanic or Latino/a, 0.3\% Native Hawaiian or Pacific Islander, 2.4\% Biracial or Multiracial, and 2.4\% Other. In terms of sexual orientation, participants identified as the following: $84.9 \%$ heterosexual, $8.2 \%$ bisexual, $3.1 \%$ lesbian or gay, $2.7 \%$ questioning, $0.7 \%$ asexual, and $0.3 \%$ pansexual. The majority of participants identified as American (95.5\%) and native English speakers (96.2\%). Participants were primarily freshmen students at WVU (44.5\%) but 35.3\% were sophomores, $14.4 \%$ were juniors, and 5.8\% were seniors. Despite inclusion criteria that allowed graduate students to participate, no graduate students participated in this study. Only $39.4 \%$ of participants were psychology majors. Most participants identified as single, never married (99\%) and with no children (99\%). Total household income of participants were as follows: $20.2 \%$ with less than $\$ 30,000$ per year, $12 \%$ between $\$ 30,000-49,999$ per year, $31.5 \%$, between $\$ 50,000-\$ 99,000$ per year, $30.1 \%$ between 
$\$ 100,000-\$ 249,000$ per year, and $6.2 \%$ with more than $\$ 250,000$ per year. It is important to note that the sample was consistent with the student population from the university sampled (West Virginia Higher Education Policy Commission, 2018).

\section{Measures}

Career Barriers Inventory-Revised. The Career Barriers Inventory-Revised (CBI-R; Appendix A), developed by Swanson and Daniels (1994), is a standardized measurement of career barriers, defined by Swanson, Daniels, and Tokar (1996) as "external or internal states that may make career progress difficult" (p. 236). The CBI-R, originally based on the Career Barriers Inventory (CBI; Swanson et al., 1996), was developed due to identified shortcomings of the CBI, including the length and content of the instrument. The CBI-R consists of 70 items rated on a seven-point Likert scale, ranging from 1 (would not hinder at all) to 7 (would hinder completely), indicating the extent to which each item would hinder progress in a career or career goal(s). None of the items are reverse scored. Higher scores indicate higher perceptions of career barriers.

The CBI-R is comprised of 13 subscales, including Sex Discrimination, Lack of Confidence, Multiple Role Conflict, Conflict between Children and Career Demands, Racial Discrimination, Inadequate Preparation, Disapproval by Significant Others, Decision-Making Difficulties, Dissatisfaction with Career, Discouraged from Choosing Nontraditional Careers, Disability/Health Concerns, Job Market Constraints, and Difficulties with Networking/Socializing (Swanson et al., 1996). The current study included only three subscales (Lack of Confidence, Inadequate Preparation, and Decision-Making Difficulties) of the CBI-R (see Appendix A for CBI-R subscales). The Lack of Confidence subscale includes four items that relate to confidence and self-esteem, such as "Not feeling confident about my ability on the 
job" (Swanson et al., 1996, p. 225). The Inadequate Preparation subscale includes five items that relate to internal perceptions of preparedness for the demands of the job market, such as "Lacking the required skills for my job" (Swanson et al., 1996, p. 227). The Decision-Making Difficulties subscale includes eight items, such as "Not being sure how to choose a career direction" (Swanson et al., 1996, p. 227). Subscale scores are calculated by adding the points within each subscale and dividing the points by the number of items within each subscale to obtain an average score per subscale. Higher subscale average scores indicate higher perceptions of the type of career barrier measured by that subscale.

To avoid participant fatigue, three subscales of interest were specifically selected for this study based on the perception of lack of confidence, inadequate preparation, and decisionmaking difficulties as internal, psychological barriers that prevent career progress, which is consistent with the internal nature of the other variables of interest in this study, including internalization of sociocultural standards of beauty, depression, and physical appearance state anxiety (Swanson et al., 1996). Swanson and colleagues (1996) found that participants discriminate between the types of career barriers measured by the CBI-R, as evidenced by differential responding between the CBI-R subscales, which suggests that each of the selected subscales represents a unique career barrier. Furthermore, each of the selected subscales demonstrated adequate validity and reliability estimates in the initial development and revision of the measure, as discussed shortly (Swanson et al., 1996).

Internal consistency estimates of the CBI-R yielded Cronbach's alpha coefficients ranging from .64 to .85 (median $\alpha=.77$ ) in a sample of 100 undergraduate males $(n=48)$ and females $(n=52)$ (Swanson et al., 1996). Specifically, internal consistency estimates of the subscales of interest, including Lack of Confidence subscale $(\alpha=.85)$, Inadequate Preparation 
subscale $(\alpha=.85)$, and Decision-Making Difficulties subscale $(\alpha=.83)$, exceeded the acceptable standard (Swanson et al., 1996). In addition, internal consistency estimates of the subscales of interest were conducted for the participant sample in this study. The internal consistency estimates for the Lack of Confidence $(\alpha=.86)$, Inadequate Preparation $(\alpha=.84)$, and DecisionMaking $(\alpha=.90)$ subscales were consistent with previous estimates and exceeded the acceptable standard. As previously noted, Swanson et al. (1996) also found that CBI-R items were differentiated into "types" of career barriers as originally defined by the subscales. The variation of scores across and within the CBI-R validated the measurement of the subscales as both dependent (i.e., total score) and, more important to this study, independent (i.e., subscale scores) (Swanson et al., 1996).

Evidence for the construct validity of the CBI-R was established by examining demographic data of a combined data set consisting of 1,674 undergraduate males $(n=602)$ and females $(n=1074)$ (Swanson et al., 1996). Per Swanson et al. (1996), female participants consistently scored higher than male participants on seven of the $13 \mathrm{CBI}-\mathrm{R}$ subscales, including Sex Discrimination, Lack of Confidence, Multiple-Role Conflict, Conflict between Children and Career Demands, Inadequate Preparation, Decision-Making Difficulties, and Dissatisfaction with Career. Swanson and colleagues (1996) noted that the results supported research previously published in related areas by demonstrating a gender discrepancy in perception of career barriers, in which women perceived higher levels of career barriers than men, especially in relation to familial responsibility.

The CBI-R was chosen for the present study based on the definition of a career barrier as an internal or external barrier that hinders progress in a career or career goals, which is consistent with the conceptualization of career barriers in this research (Swanson et al., 1996). In addition, 
the CBI-R demonstrated adequate psychometric properties in relation to the population of interest. The Lack of Confidence, Inadequate Preparation, and Decision-Making Difficulties subscales of the CBI-R were the three outcome variables in this study.

Sociocultural Attitudes Towards Appearance Questionnaire-Internalization. The Internalization subscale of the Sociocultural Attitudes Towards Appearance Questionnaire (SATAQ-I; Appendix B), developed by Heinberg, Thompson, and Stormer (1995), measures the internalization of sociocultural standards of beauty, defined as the endorsement or acceptance of values, attitudes, and standards regarding physical characteristics deemed desirable by a specific culture (Moradi, Dirks, \& Matteson, 2005). The SATAQ-I consists of eight items (items 1-5, 7, $13,14)$ rated on a five-point Likert scale, ranging from 1 (completely disagree) to 5 (completely agree), indicating the extent to which each item describes the individual. Only item 4, "I do not wish to look like the models in the magazines," is reverse scored. Example items from the SATAQ-I scale include, "Photographs of thin women make me wish I were thin," "I often read magazines like Cosmopolitan, Vogue, and Glamour and compare my appearance to the models," and "I believe that clothes look better on thin models." The total score is derived by adding the points across all SATAQ-I items, with possible scores ranging from 8 to 40 (Heinberg et al., 1995). Higher scores indicate higher levels of internalization of sociocultural standards of beauty.

In the initial development and validation of the SATAQ, Heinberg and colleagues (1995) reported that internal consistency estimates of the SATAQ-I yielded a Cronbach's alpha coefficient of .88 in a sample of 150 female undergraduate students, ranging in age from 17 to 36. In terms of this study, internal consistency estimates yielded a Cronbach's alpha coefficient of .89 , which is consistent with previous estimates and above acceptable standards. Several 
instruments that measure constructs related to body image and/or eating disturbance were correlated with the SATAQ-I, indicating adequate convergent validity. For example, the SATAQ-I was positively correlated with the Physical Appearance State and Trait Anxiety Scale $(r=.55)$ (PASTAS; Reed, Thompson, Brannick, \& Sacco, 1991), the Eating Disorder InventoryBody Dissatisfaction ( $r=.52$ ) (EDI-BD; Garner, 1991), and the Eating Disorder Inventory-Drive for Thinness $(r=.61)($ EDI-DT; Garner, 1991).

The SATAQ-I was chosen for the present study based on the conceptualization of the internalization of sociocultural standards of beauty as the endorsement or acceptance of beauty, as defined by a culture. The SATAQ-I also demonstrated adequate psychometric properties in relation to the population of interest. It has also been correlated with a variety of instruments measuring related constructs, which is advantageous to this study based on the inclusion of several factors that are believed to be related to the internalization of sociocultural standards of beauty. Scores on the SATAQ-I were treated as a predictor variable in this study.

Center for Epidemiologic Studies Depression Scale. The Center for Epidemiologic Studies Depression Scale (CES-D; Appendix C), developed by Radloff (1977), measures the endorsement of depressive symptoms in the general population. The CES-D consists of 20 items initially derived from previously validated depression inventories, including the Beck Depression Inventory (BDI; Beck, Ward, Mendelson, Mock, \& Erbaugh, 1961), Minnesota Multiphasic Personality Inventory (MMPI; Dahlstrom \& Walsh, 1960), and Self-Rating Depression Scale (SDS; Zung, 1965). The 20 CES-D items are rated on a four-point Likert scale, ranging from 0 (rarely or none of the time [less than 1 day]) to 3 (most or all of the time [five-seven days]), indicating the frequency of the occurrence of symptoms presented within the past week (Radloff, 1977). Items 4, 8, 12, and 16 are reverse scored. Example items from the CES-D include, "I did 
not feel like eating; my appetite was poor," "I felt that I could not shake off the blues even with help from my family or friends," and "I talked less than usual" (Radloff, 1977, p. 387). The total score is derived by adding the points across all items, with possible scores ranging from 0 to 60 . Higher scores indicate a higher risk of depressive symptoms (Radloff, 1977).

In the initial development and validation of the CES-D, Radloff (1977) reported that internal consistency estimates of the CES-D yielded a Cronbach's alpha coefficient of .90 in a sample of 70 females and males who had been diagnosed with a depressive disorder and resided in a psychiatric facility. In addition, a Cronbach's alpha coefficient of .85 was found in a nonclinical sample of 4,996 females and males (Radloff, 1977). In terms of this study, the CESD yielded a Cronbach's alpha coefficient of .92, which is consistent with previous estimates and exceeds the acceptable standard. Furthermore, Radloff (1977) assessed test-retest reliability of the CES-D by submitting two different versions of the instrument at two, four, six, and eight weeks apart for 419 participants (two weeks $r=.51$, four weeks $r=.67$, six weeks $r=.59$, and eight weeks $r=.59$ ) and three, six, twelve, and twelve months for 1,541 participants (three months $r=.48$, six months $r=.54$, twelve months $r=.49$, and twelve months $r=.32$ ). The testretest reliability was stronger during the shorter test-retest period, indicating that the CES-D is more appropriate as a measurement of current depressive symptoms, as recommended by Radloff (1977).

Radloff (1977) also pointed out that the CES-D could discriminate between clinical and nonclinical populations. For example, the average score of a clinical sample on the CES-D was 24.42, as compared to a score of $9.25,8.17$, and 7.94 in three nonclinical samples (Radloff, 1977). Per Radloff (1977), over $70 \%$ of the clinical sample received a score that exceeded a cutoff score of 16, as compared to only $19 \%, 15 \%$, and $15 \%$ in the three nonclinical samples. 
Additionally, at the admission of the clinical sample into a psychiatric facility, the CES-D was found to moderately correlate with instruments measuring similar or related constructs, including the Hamilton Rating Scale for Depression $(r=.44)$ (HRSD; Hamilton, 1960), the Raskin Depression Rating Scale ( $r=.54$ ) (RDRS; Raskin, Schulterbrandt, Reatig, \& McKeon, 1969), and the Symptom Checklist-90 ( $r=.83$ ) (Derogatis, Lipman, \& Covi, 1973). The correlations between the CES-D and the HRSD and the RDRS increased in the clinical sample following four weeks of treatment (HRSD $r=.69$; RDRS $r=.75$ ) (Radloff, 1977). Radloff (1977) also reported that the CES-D was sensitive to changes in depressive symptoms. For example, a clinical sample of 35 inpatients in a psychiatric facility reported a score of 39.11 on the CES-D upon admission and a score of 20.91 following four weeks of treatment.

The CES-D was chosen for the present study based on the conceptualization of depressive symptoms as a construct that assesses depressed affect (blues, sad, crying), positive affect (hopeful, happy, enjoyment), somatic and retarded activity (disturbed appetite, sleep, effort), and interpersonal functioning (unfriendly, isolated, lonely) (Radloff, 1977). The CES-D has also demonstrated adequate psychometric properties in relation to the population of interest (Berg, Frazier, \& Sherr, 2009). Scores on the CES-D were considered a moderator variable in this study.

Physical Appearance State and Trait Anxiety Scale. The Physical Appearance State and Trait Anxiety Scale, State subscale (PASTAS-S; Appendix D), developed by Reed, Thompson, Brannick, and Sacco (1991), measures the endorsement of anxious symptoms as a state (temporary, brief, and caused by external stimuli) in relation to body image. The PASTASS consists of 16 items that are rated on a five-point Likert scale, ranging from 0 (not at all) to 4 (exceptionally so), indicating the extent to which each item creates anxious feelings at the 
current moment (Reed et al., 1991). Eight items list body parts that are related to weight, such as "my thighs," "my hips," and "my stomach," and eight items list body parts that are unrelated to weight, such as "my lips," "my ears," and "my feet” (Reed et al., 1991, p. 326). None of the items are reverse scored. The PASTAS-S yields a weight-related anxiety total subscale score, which is calculated by adding up the weight-related item points, with possible scores ranging from 0 to 32. Higher scores indicate a higher level of state physical appearance anxiety (Reed et al., 1991). Although the non-weight-related anxiety subscale items were completed by participants, the non-weight-related anxiety subscale scores were not entered into further data analyses because the subscale is not consistent with other measures in the study. For example, Reed and colleagues (1991, p. 331) found that the non-weight-related anxiety subscale was not related to measures of body image or eating disturbance and less related to anxiety than the weight-related anxiety subscale; therefore, the usage of the non-weight-related anxiety subscale was only used to reduce the transparency of the measure.

In the initial development and validation of the PASTAS-S, Reed and colleagues (1991) reported that internal consistency estimates yielded Cronbach's alpha coefficients of $.90, .90$, and .92 for weight-related high, moderate, and low state anxiety, respectively, in a sample of 205 female undergraduate students, ranging in age from 18 to 45 years $(M=22.04)$ (Reed et al., 1991). In terms of this study, the weight-related subscale from the PASTAS-S yielded a Cronbach's alpha coefficient of .93 , which is consistent with previous estimates and exceeds the acceptable standard. The test-retest reliability of the entire PASTAS-S following a two-week interval between the first and second administration was $r=.87$ in a sample of 53 female undergraduate students, ranging in age from 18 to $37(M=20.83)$. Specifically, the PASTAS-S weight-related subscale test-retest reliability was $r=.89$ (Reed et al., 1991). In addition, the 
PASTAS-S weight-related subscale has been correlated to several previously validated instruments measuring similar or related constructs, such as the EDI-BD (Garner, 1991), the EDI-DT (Garner, 1991), the Eating Disorders Inventory-Bulimia Scale (EDI-B, Garner, 1991), and the Spielberger Trait Anxiety Inventory (STAI; Spielberger, 1983).

The PASTAS-S was chosen for the present study based on the conceptualization of anxious state symptoms in relation to body weight and shape. The PASTAS-S has also demonstrated adequate psychometric properties in relation to the population of interest (Harper \& Tiggemann, 2008). Scores on the weight-related subscale of the PASTA-S served as a moderator variable in the current analyses.

Demographic questionnaire. An 11-item demographic questionnaire (Appendix E) in the current study included items that asked for participant age, gender identification, racial/ethnic identity, sexual orientation, first language, country of origin, year in school, major in school, relationship status, number of children, and total household income.

\section{Procedures}

Following approval from the WVU's Institutional Review Board (IRB), the study was created in Qualtrics and posted to the online WVU SONA system to access the psychology department subject pool. All enrolled WVU students who identified as women and were 18 years of age or older were invited to participate through their psychology courses. Prior to participation, participants were provided with the study name, study type, duration, abstract and description of the study, and researcher names and contact information. Clicking on the "participate in this online survey" link directed participants from the WVU SONA system to the study in the Qualtrics survey system. 
The informed consent document (Appendix F) detailed the rights of participants. In addition, the informed consent document notified participants that compensation will be provided by course credit in fulfillment of a course requirement for research participation or extra credit where applicable. Participants who agreed to participate were directed to the measures of the study, which included the Lack of Confidence, Inadequate Preparation, and Decision-Making Difficulties subscales of the CBI-R (Swanson \& Daniels, 1994); SATAQ-I (Heinburg et al., 1995); CES-D (Radloff, 1977); and PASTAS-S (Reed et al., 1991). The measures were counterbalanced to prevent the introduction of any confounding variables, such as order effects. Following the measures, participants were instructed to complete a demographic questionnaire. At the completion of the survey, participants were directed to a thank you page. Participants were compensated by receiving course credit in fulfillment of a course requirement for research participation or extra credit where applicable.

All responses were collected using the WVU SONA participant management system and Qualtrics. According to SONA's security statement and privacy policy, participants' responses were transmitted via a secure, encrypted connection, in which only authorized personnel (i.e., researchers) have access to participant data. To protect the confidentiality of participants, the survey was designed to collect responses anonymously. No identifying information was attached to the surveys. 


\section{CHAPTER III}

\section{Results}

This study examined the relationship between the outcome variable of perception of career barriers (i.e., lack of confidence, inadequate preparation, and decision-making difficulties) and the predictor variable of internalization sociocultural standards of beauty with state physical appearance anxiety and depression as two potential moderating variables. This was a quantitative, correlational, cross-sectional survey research design in which all participants received identical survey material with random variation in survey order. The first section of this chapter includes a brief review of the research questions and hypotheses of the study. The second section reviews the preliminary statistics of the data. The third section details the descriptive statistics for participants. Finally, the fourth section summarizes the results of the primary analyses of the study.

\section{Research Questions and Hypotheses}

Research Question 1. Is internalization of sociocultural standards of beauty related to perception of career barriers, as measured by lack of confidence, inadequate preparation, and decision-making difficulties?

Hypothesis 1: Internalization of sociocultural standards of beauty will be a significant, positive predictor of lack of confidence.

Hypothesis 2: Internalization of sociocultural standards of beauty will be a significant, positive predictor of inadequate preparation.

Hypothesis 3: Internalization of sociocultural standards of beauty will be a significant, positive predictor of decision-making difficulties. 
Research Question 2. Is the relationship between internalization of sociocultural standards of beauty and perception of career barriers, as measured by lack of confidence, inadequate preparation, and decision-making difficulties, moderated by physical appearance state anxiety?

Hypothesis 4: The significant, positive relationship between internalization of sociocultural standards of beauty and lack of confidence will be moderated by physical appearance state anxiety.

Hypothesis 5: The significant, positive relationship between internalization of sociocultural standards of beauty and inadequate preparation will be moderated by physical appearance state anxiety.

Hypothesis 6: The significant, positive relationship between internalization of sociocultural standards of beauty and decision-making difficulties will be moderated by physical appearance state anxiety.

Research Question 3. Is the relationship between internalization of sociocultural standards of beauty and perceptions of career barriers, as measured by lack of confidence, inadequate preparation, and decision-making difficulties, moderated by depression?

Hypothesis 7: The significant, positive relationship between internalization of sociocultural standards of beauty and lack of confidence will be moderated by depression.

Hypothesis 8: The significant, positive relationship between internalization of sociocultural standards of beauty and inadequate preparation will be moderated by depression. 
Hypothesis 9: The significant, positive relationship between internalization of sociocultural standards of beauty and decision-making difficulties will be moderated by depression.

\section{Preliminary Analyses}

Prior to the primary analyses, data were examined for completeness. A total of 303 cases were collected through SONA and Qualtrics to complete the initial data set. Of these, 11 cases (3.6\%) were excluded due to missing data. The 11 cases were examined to determine possible patterns within the missing data. All 11 of the cases provided consent to participate in the study but did not respond to any survey items. The cases were removed from further data analyses.

Following the removal of cases due to missing data, the remaining data were analyzed for violations of assumptions. During these preliminary analyses, all predictor and moderator variables (i.e., internalization of sociocultural standards of beauty, physical appearance state anxiety, and depression) were analyzed with lack of confidence, decision-making difficulties, and inadequate preparation as separate criterion variables. There was independence of residuals, as assessed by a Durbin-Watson statistic that was greater than 1 and less than 3. Although the Durbin-Watson statistics were closer to 1, suggesting a positive correlation, Field (2013) recommended that values less than 1 and greater than 3 are cause for concern; therefore, the values of the Durbin-Watson statistics for this study were acceptable. There was linearity and homoscedasticity, as assessed by visual inspection of a scatterplot of studentized residuals versus unstandardized predicted values. There was collinearity, as assessed by a VIF of less than 10 and a Tolerance of greater than 0.1. As recommended by Field (2013), VIF values greater than 10 and a Tolerance value below 0.1 would indicate that the assumption of multicollinearity was violated. No outliers were present, as assessed by Casewise Diagnostics, in which no case's 
standardized residual exceeded \pm 3 standard deviations. There was normality, as assessed by visual inspection of histograms and normal probability plots.

\section{Descriptive Statistics}

A total of 303 undergraduate women at WVU participated in this study. However, 11 (3.6\%) of the 303 participants were excluded due to missing data. The remaining 292 participants provided demographic information, including age, gender identification, racial/ethnic identity, sexual orientation, first language, country of origin, year in school, marital status, number of children, and total household income. Descriptive statistics were conducted to analyze participant demographic information, as seen in Table 1.

Participants ranged in age from 18 to 41 years with a mean age of 19.31 years. In terms of race/ethnicity, $84.6 \%(n=242)$ of participants identified as Caucasian or White, $3.8 \%(n=11)$ identified as Asian American or Asian, 3.4\% $(n=10)$ identified as African American or Black, $3.1 \%(n=9)$ identified as Hispanic or Latino/a, .3\% $(n=1)$ identified as Native Hawaiian or Pacific Islander, 2.4\% $(n=7)$ identified as Biracial or Multiracial, and 2.4\% $(n=7)$ identified as Other. In terms of sexual orientation, $84.9 \%(n=248)$ identified as heterosexual, $8.2 \%(n=24)$ identified as bisexual, $3.1 \%(n=9)$ identified as lesbian or gay, $2.7 \%(n=8)$ identified as questioning, .7\% $(n=2)$ identified as asexual, and .3\% $(n=1)$ identified as pansexual. Most participants identified as American (95.5\%) and native English speakers (96.2\%).

In terms of year in school, $44.5 \%(n=130)$ participants were freshmen, 35.3\% $(n=103)$ were sophomores, $14.4 \%(n=42)$ were juniors, and 5.8\% $(n=17)$ were seniors. Only $39.4 \%(n$ $=115$ ) of the participants were psychology majors. Most participants identified as single, never married (99\%) and with no children (99\%). Regarding total household income, $20.2 \%(n=59)$ reported a household income of less than $\$ 30,000$ per year, $12 \%(n=35)$ reported a household 
income between $\$ 30,000-49,999,31.5 \%(n=92)$ reported a household income between $\$ 50,000$ $\$ 99,000,30.1 \%(n=88)$ reported a household income between $\$ 100,000-\$ 249,000$, and $6.2 \%(n$ $=18$ ) reported a household income greater than $\$ 250,000$ per year.

Table 1

Descriptive Statistics of Participant Demographic Information

\begin{tabular}{lll}
\hline & $n(\%)$ & Mean (SD) \\
\hline Age & & \\
& & \\
Race/Ethnicity & & \\
Caucasian/White & $242(84.6 \%)$ & \\
Asian American/Asian & $11(3.8 \%)$ & \\
African American/Black & $10(3.4 \%)$ & \\
Hispanic/Latino/a & $9(3.1 \%)$ & \\
Native Hawaiian/Pacific Islander & $1(.3 \%)$ & \\
Biracial/Multiracial & $7(2.4 \%)$ & \\
Other & $7(2.4 \%)$ &
\end{tabular}

Sexual Orientation

Heterosexual

Bisexual

Lesbian/Gay

Questioning

$248(84.9 \%)$

Asexual

$24(8.2 \%)$

$9(3.1 \%)$

$8(2.7 \%)$

Pansexual

$2(0.7 \%)$

$1(0.3 \%)$

Nationality

American

Other

$279(95.5 \%)$

$13(4.5 \%)$

Native Language

English

Other

$281(96.2 \%)$

$11(3.8 \%)$

Year in School

Freshman

$130(44.5 \%)$

Sophomore

$103(35.3 \%)$

Junior

$42(14.4 \%)$

Senior

$17(5.8 \%)$

Major

Psychology

$115(39.4 \%)$ 


\section{Table 1, Continued:}

Other

Relationship Status

Single, Never Married

Married

Divorced

Number of Children

0

1

2

Total Household Income

Less than $\$ 30,000$

$\$ 30,000-\$ 49,999$

$\$ 50,000-\$ 99,999$

$\$ 100,000-\$ 249,999$

$\$ 250,000$ or more
$177(60.6 \%)$

$289(99 \%)$

$2(0.7 \%)$

$1(0.3 \%)$
$289(99 \%)$

$1(0.3 \%)$

$1(0.3 \%)$

Note: $n=292$

\section{Bivariate Correlation Analyses}

To test the first three study hypotheses, specifically, that internalization of sociocultural standards of beauty will be a significant, positive predictor of perception of career barriers, as measured by lack of confidence, inadequate preparation, and decision-making difficulties, Pearson bivariate correlation analyses were conducted. A bivariate correlation matrix was created to assess the relationships among all study variables.

As seen in Table 2, the first study hypothesis was supported, $(r=.23, p<.01)$, indicating that internalization of sociocultural standards of beauty is positively related to perception of lack of confidence as a career barrier. Surprisingly, lack of confidence yielded significant and positive relationships with all study variables (i.e., perceived inadequate preparation, $r=.75, p<.01$; perceived decision-making difficulties, $r=.63, p<.01$; depression, $r=.30, p<.01$; and physical appearance state anxiety, $r=.28, p<.01)$. 
As demonstrated in Table 2, the second study hypothesis was not supported, which suggests that internalization of sociocultural standards of beauty is not related to the perception of inadequate preparation as a career barrier. However, perception of inadequate preparation was significantly related to perceived lack of confidence $(r=.75, p<.01)$, perceived decisionmaking difficulties $(r=.70, p<.01)$, and depression $(r=.13, p<.05)$.

The third study hypothesis was supported $(r=.24, p<.01)$, indicating that internalization of sociocultural standards of beauty is positively related to perception of decision-making difficulties as a career barrier. Perception of decision-making difficulties was positively and significantly related to all study variables (i.e., perceived lack of confidence, $r=.63, p<.01$; perceived inadequate preparation, $r=.70, p<.01$; internalization of sociocultural standards of beauty, $r=.24, p<.01$; depression, $r=.30, p<.01$; and physical appearance state anxiety, $r=$ $.24, p<.01)$. Also of note in Table 2 , depression was significantly and positively related to all study variables (i.e., perceived lack of confidence, $r=.30, p<.01$; perceived inadequate preparation, $r=.13, p<.05$; perceived decision-making difficulties, $r=.30, p<.01$; internalization of sociocultural standards of beauty, $r=.33, p<.01$; and physical appearance state anxiety, $r=.46, p<.01)$.

Table 2

Correlations Among Possible Predictor Variables of Lack of Confidence, Inadequate Preparation, and Decision-Making Difficulties

\begin{tabular}{lrrrrrr}
\hline Variable & 1 & 2 & 3 & 4 & 5 & 6 \\
\hline 1. CBI-R-LOC & -- & & & & & \\
2. CBI-R-IP & $* * .75$ & -- & & & & \\
3. CBI-R-DMD & $* * .63$ & $* * .70$ & -- & & & \\
4. SATAQ & $* * .23$ & .11 & $* * .24$ & -- & & \\
5. CESD & $* * .30$ & $* .13$ & $* * .30$ & $* * .33$ & -- & \\
6. PASTAS & $* * .28$ & .10 & $* * .24$ & $* * .55$ & $* * .46$ & -- \\
\hline
\end{tabular}


Note. $n=292$; CBI-R-LOC $=$ Career Barriers Inventory-Revised, Lack of Confidence; CBI-R-IP $=$ Career Barriers Inventory-Revised, Inadequate Preparation; CBI-R-DMD $=$ Career Barriers Inventory-Revised, Decision-Making Difficulties; SATAQ = Sociocultural Attitude Towards Appearance Questionnaire; CESD = Center for Epidemiologic Studies Depression Scale; PASTAS $=$ Physical Appearance State and Trait Anxiety Scale.

$* p<.05 ; * * p<.01$

\section{Regression Analyses}

To test the remaining study hypotheses, specifically, that the relationship between internalization of sociocultural standards of beauty and perception of career barriers, as measured by lack of confidence, inadequate preparation, and decision-making difficulties, will be moderated by physical appearance state anxiety and depression, a series of regression analyses were conducted. For each regression analysis, the predictor variables were mean centered prior to creating an interaction term to reduce potential multicollinearity and to aid interpretation of the effect of predictor variables on the criterion variable, as recommended by Field (2013).

\section{Physical appearance state anxiety as a moderating variable and lack of confidence}

as an outcome variable. The fourth study hypothesis states that the relationship between internalization of sociocultural standards of beauty and perception of career barriers, as measured by lack of confidence, will be moderated by state physical appearance anxiety, as seen in Figure 2.

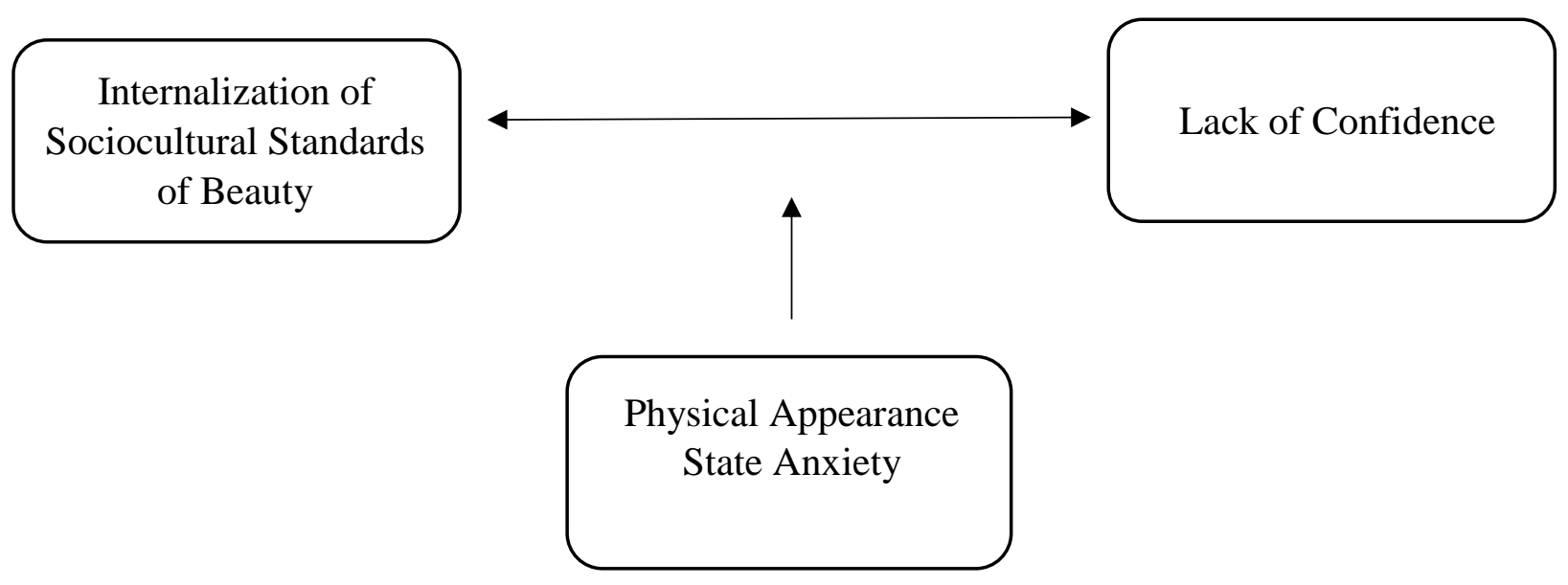


Figure 2. A conceptual model of Hypothesis 4 with physical appearance state anxiety as a moderating variable and lack of confidence as an outcome variable.

To test this hypothesis, a series of regression models were conducted, as seen in Table 3.

Table 3

Summary of Multiple Regression Analyses for Variables Predicting Lack of Confidence as a Perceived Career Barrier: Physical Appearance State Anxiety as a Moderating Variable

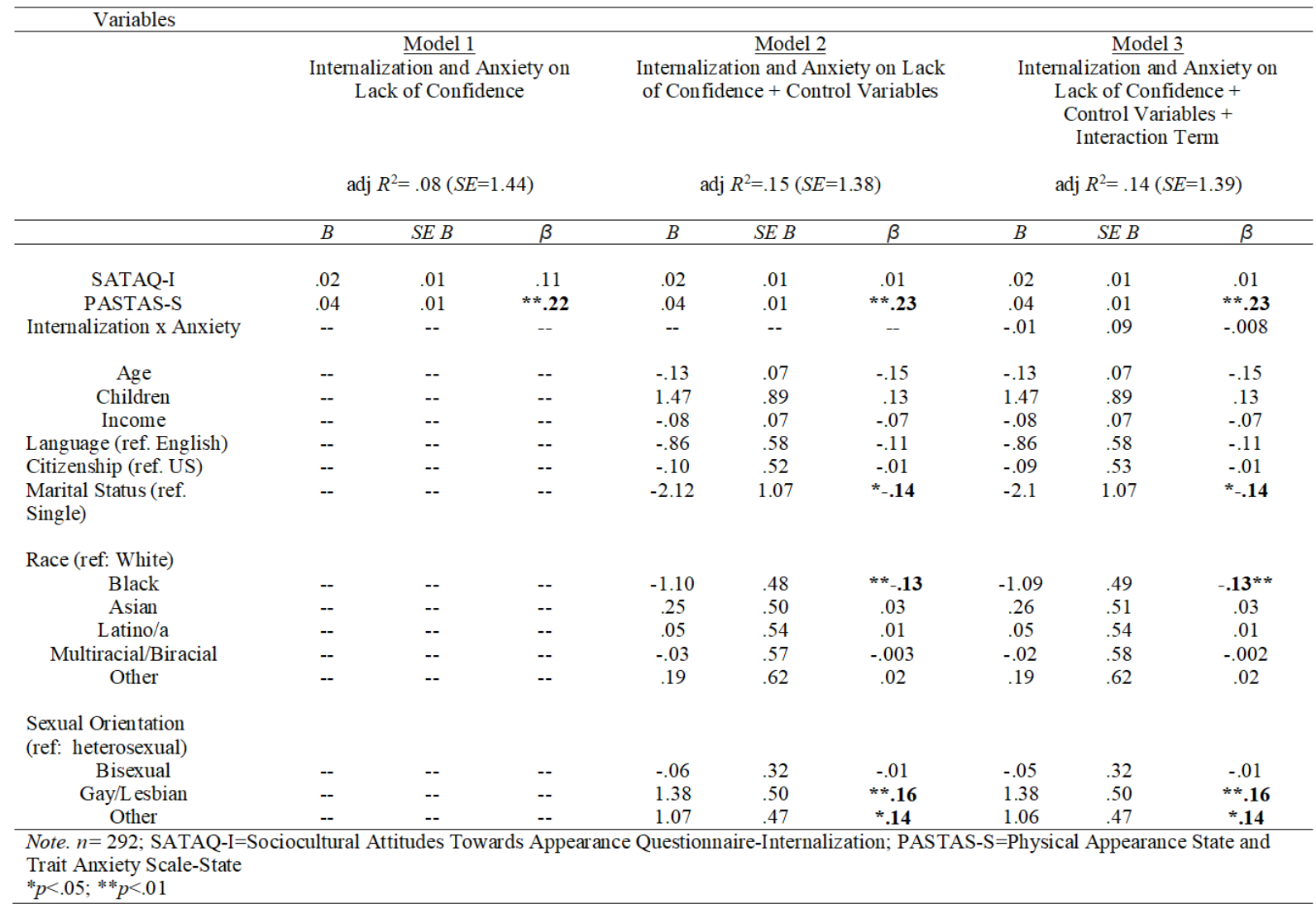

In Model 1, the two predictor variables of internalization of sociocultural standards of beauty and physical appearance state anxiety were mean centered and regressed onto the outcome variable of perceived lack of confidence. Physical appearance state anxiety was the only predictor in this model shown to be a significant predictor of perceived lack of confidence $(\beta=.22, p<.001)$. In Model 2, control variables were included to hold constant demographic variables. Physical appearance state anxiety remained the only significant predictor of perceived lack of confidence 
$(\beta=.23, p<.001)$. In terms of demographic variables, marital status $(\beta=-.14, p<.05)$, the race category of African American/Black $(\beta=-.13, p<.001)$, and the sexual orientation categories of gay/lesbian $(\beta=.16, p<.001)$ and other $(\beta=.14 ; p<.05)$ were significant predictors. In Model 3 , the interaction term of internalization of sociocultural standards of beauty x physical appearance state anxiety was added in the model. The interaction term was not a significant predictor, which suggests that physical appearance state anxiety does not moderate the relationship between internalization of sociocultural standards of beauty and perceived lack of confidence, as predicted in the fourth hypothesis of the study. However, physical appearance state anxiety is an independent positive predictor of perceived lack of confidence, as demonstrated by the regression analyses and also the significant positive correlation between the two variables $(r=.23, p<.001)$, seen in Table 2 .

Physical appearance state anxiety as a mediating variable and lack of confidence as an outcome variable. Although the fourth hypothesis of the study was not supported, the fourstep mediation protocol by Baron and Kenny (1986) was conducted to further assess the relationships among internalization of sociocultural standards of beauty, physical appearance state anxiety, and perceived lack of confidence. As seen in Table 3, internalization of sociocultural standards of beauty was a significant predictor of the outcome variable of lack of confidence $(r=.23, p<.01)$. However, internalization of sociocultural standards of beauty was not a significant predictor of lack of confidence with the addition of physical appearance state anxiety as a predictor variable of lack of confidence $(\beta=.11, p>.05)$, as seen in Table 3 . In other words, the addition of physical appearance state anxiety as a predictor variable of perceived lack of confidence markedly reduced the previously significant relationship between internalization of sociocultural standards of beauty and perceived lack of confidence. Although 
internalization of sociocultural standards of beauty did not remain a significant predictor of perceived lack of confidence, physical appearance state anxiety continued to be a significant predictor of perceived lack of confidence $(\beta=.22, p<.001)$. Therefore, the Baron and Kenny (1986) mediation protocol was conducted because previous correlation and regression analyses suggested that physical appearance state anxiety accounted for some of the relationship between internalization of sociocultural standards of beauty and perceived lack of confidence, as seen in Figure 3.

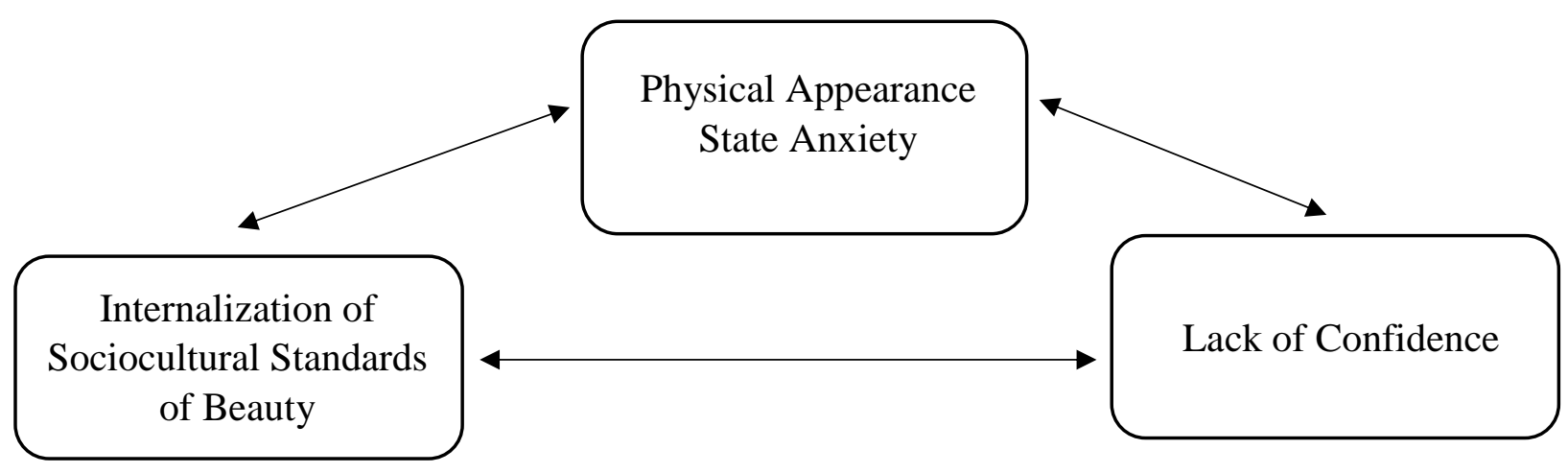

Figure 3. An alternative conceptual model of Hypothesis 4 with physical appearance state anxiety as a mediating variable and lack of confidence as an outcome variable.

Beginning with the predictor variable of internalization of sociocultural standards of beauty, the four-step Baron and Kenny (1986) mediation analysis was conducted, as seen in Table 4. 
Table 4

PASTAS-S as a Mediating Variable between Predictor Variable SATAQ-I and Outcome Variable Lack of Confidence

\begin{tabular}{|c|c|c|c|c|c|c|c|c|c|c|c|c|}
\hline \multicolumn{13}{|l|}{ Variables } \\
\hline & \multirow{4}{*}{\multicolumn{3}{|c|}{$\begin{array}{c}\text { Model 1 } \\
\text { SATAQ-I on } \\
\text { Lack of Confidence } \\
\text { adj } R^{2}=.05(S E=1.46)\end{array}$}} & \multirow{4}{*}{\multicolumn{3}{|c|}{$\begin{array}{l}\text { Model } 2 \\
\text { SATAQ-I on } \\
\text { PASTAS-S }\end{array}$}} & \multirow{3}{*}{\multicolumn{3}{|c|}{$\begin{array}{c}\text { Model } 3 \\
\text { PASTAS-S on } \\
\text { Lack of Confidence }\end{array}$}} & \multirow{4}{*}{\multicolumn{3}{|c|}{$\begin{array}{c}\text { Model } 4 \\
\text { SATAQ-I + PASTAS-S } \\
\text { on } \\
\text { Lack of Confidence } \\
\text { adj } R^{2}=.08(S E=1.44)\end{array}$}} \\
\hline & & & & & & & & & & & & \\
\hline & & & & & & & & & & & & \\
\hline & & & & & & $\operatorname{adj} R^{2}=.30(S E=7.38)$ & \multicolumn{3}{|c|}{$\operatorname{adj} R^{2}=.08(S E=1.44)$} & & & \\
\hline & $B$ & $S E B$ & $\beta$ & $B$ & $S E B$ & $\beta$ & $B$ & $S E B$ & $\beta$ & $B$ & $S E B$ & $\beta$ \\
\hline SATAQ-I & .04 & .01 & $* * .23$ & .61 & .06 & $* * .55$ & -- & -- & -- & .02 & .01 & .11 \\
\hline PASTAS-S & -- & -- & -- & -- & -- & -- & .05 & .01 & $* * 28$ & .04 & .01 & $* * .22$ \\
\hline
\end{tabular}

Note. $n=292$; SATAQ-I=Sociocultural Attitudes Towards Appearance Questionnaire-Internalization; PASTAS-S=Physical Appearance State and Trait Anxiety Scale-State ${ }^{*} p<.05 ; * * *<.01$

In Model 1, internalization of sociocultural standards of beauty was entered as a predictor variable with the outcome variable of perceived lack of confidence. Internalization of sociocultural standards of beauty was a significant predictor of perceived lack of confidence. In Model 2, internalization of sociocultural standards of beauty was entered as a predictor variable with the outcome variable of physical appearance state anxiety. Internalization of sociocultural standards of beauty was also a significant predictor of physical appearance state anxiety. In Model 3, physical appearance state anxiety was entered as a predictor variable with the outcome variable of perceived lack of confidence. Consistent with the previous regression analyses, physical appearance state anxiety was a significant predictor of perceived lack of confidence. In Model 4, internalization of sociocultural standards of beauty and physical appearance state anxiety were entered as predictor variables with the outcome variable of perceived lack of confidence. As demonstrated in Table 4, internalization of sociocultural standards of beauty was no longer significant with the addition of the predictor variable physical appearance state anxiety, which suggests that physical appearance state anxiety fully mediates the relationship 
between internalization of sociocultural standards of beauty and perceived lack of confidence (Baron \& Kenny, 1986). Therefore, the more a woman internalizes sociocultural standards of beauty, the more she experiences physical appearance state anxiety, and, in turn, the more she perceives lack of confidence as a career barrier, see Figure 4.

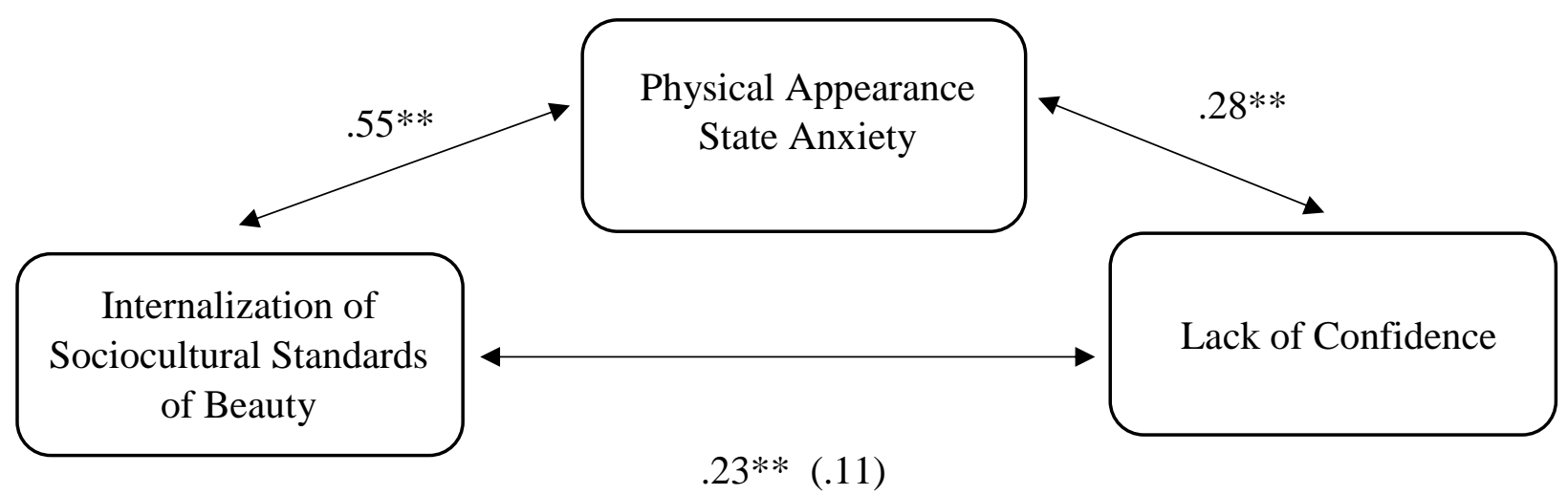

Figure 4. Standardized regression coefficients for the relationship between internalization of sociocultural standards of beauty and lack of confidence as mediated by physical appearance state anxiety. The standardized regression coefficient between internalization of sociocultural standards of beauty and lack of confidence, controlling for physical appearance state anxiety, is in parentheses.

$* p<.05 ; * * p<.01$

Physical appearance state anxiety as a moderating variable and inadequate preparation as an outcome variable. The fifth hypothesis states that the relationship between internalization of sociocultural standards of beauty and perception of career barriers, as measured by inadequate preparation, will be moderated by state physical appearance anxiety, as seen in Figure 5. 

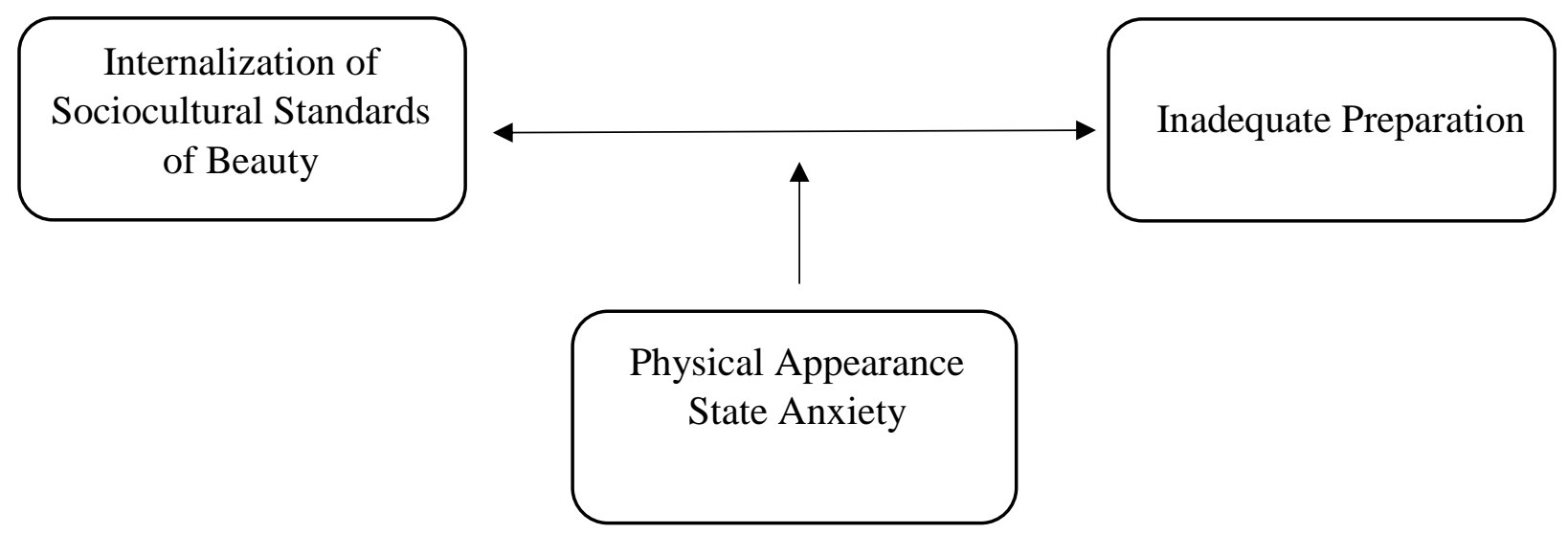

Figure 5. A conceptual model of Hypothesis 5 with physical appearance state anxiety as a moderating variable and inadequate preparation as an outcome variable.

To test this hypothesis, a series of regression models were conducted, as seen in Table 5.

Table 5

Summary of Multiple Regression Analyses for Variables Predicting Inadequate Preparation as a Perceived Career Barrier: Physical Appearance State Anxiety as a Moderating Variable

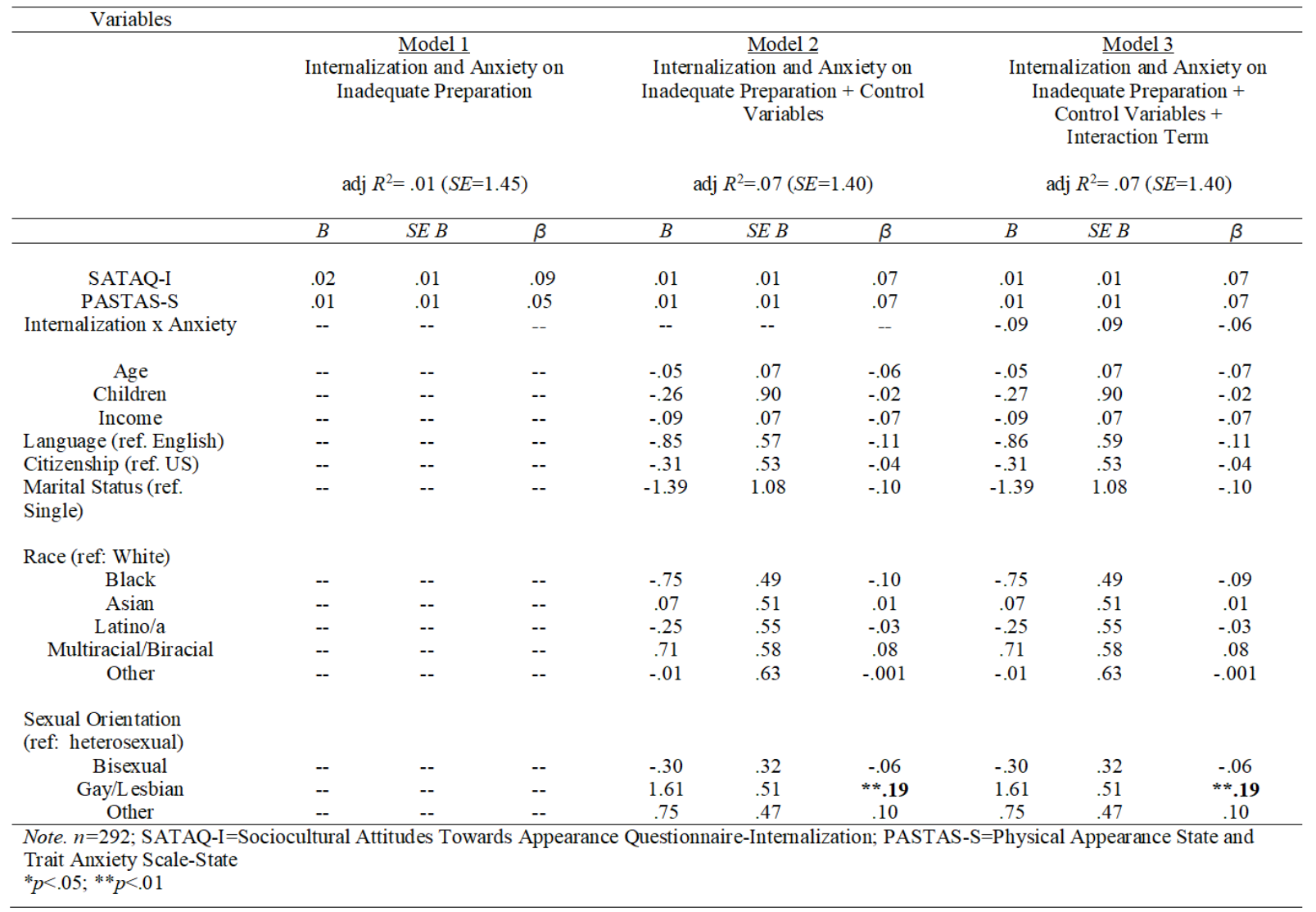


In Model 1, the two predictor variables of internalization of sociocultural standards of beauty and physical appearance state anxiety were mean centered and regressed onto the outcome variable of perceived inadequate preparation. Neither predictor variable was a significant predictor of perceived inadequate preparation. In Model 2, control variables were included to hold constant demographic variables. Again, neither predictor variable was a significant predictor of perceived inadequate preparation. In terms of demographic variables, the sexual orientation category of gay/lesbian was a significant predictor $(\beta=.19, p<.001)$. In Model 3, the interaction term of internalization of sociocultural standards of beauty x physical appearance state anxiety was added in the model. The interaction term was not a significant predictor, which suggests that physical appearance state anxiety does not moderate the relationship between internalization of sociocultural standards of beauty and perceived inadequate preparation, as hypothesized in the fifth hypothesis of the study.

\section{Physical appearance state anxiety as a moderating variable and decision-making}

difficulties as an outcome variable. The sixth hypothesis states that the relationship between internalization of sociocultural standards of beauty and perception of career barriers, as measured by decision-making difficulties, will be moderated by state physical appearance anxiety, as seen in Figure 6.

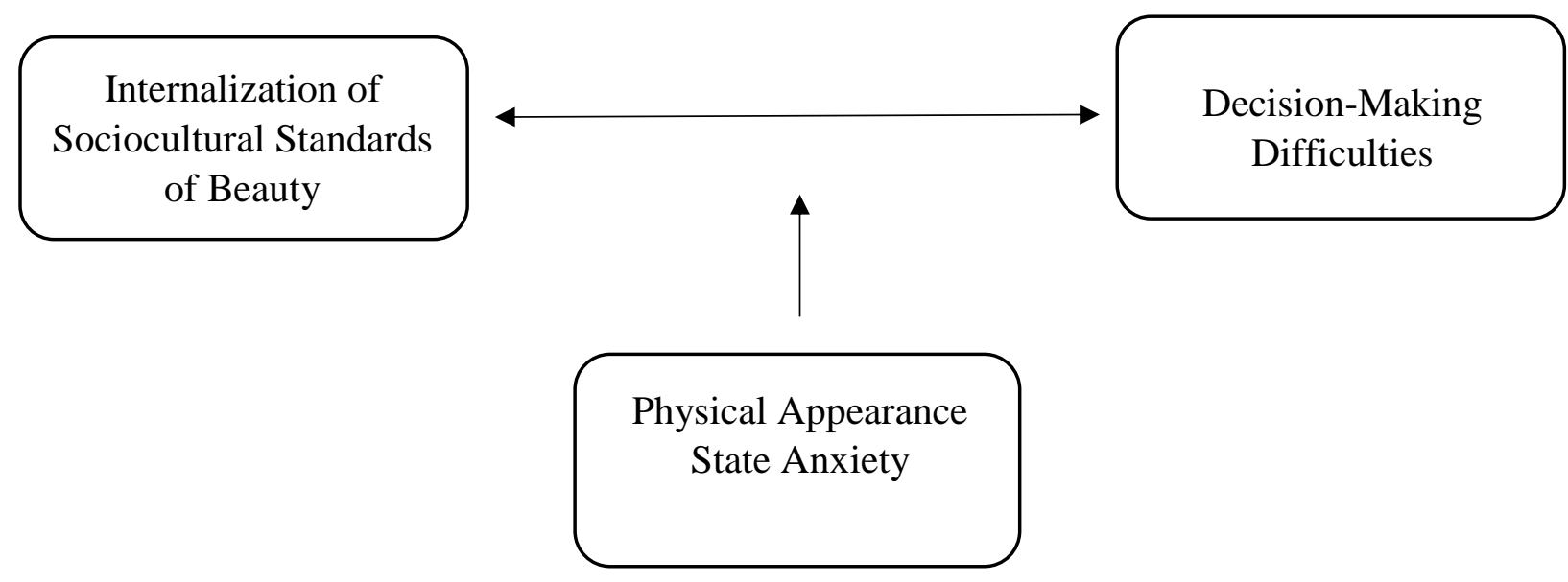


Figure 6. A conceptual model of Hypothesis 6 with physical appearance state anxiety as a moderating variable and decision-making difficulties as an outcome variable.

To test this study hypothesis, a series of regression models were conducted, as seen in Table 6.

Table 6

Summary of Multiple Regression Analyses for Variables Predicting Decision-Making Difficulties as a Perceived Career Barrier: Physical Appearance State Anxiety as a Moderating Variable

\begin{tabular}{|c|c|c|c|c|c|c|c|c|c|}
\hline \multicolumn{10}{|l|}{ Variables } \\
\hline & \multirow{3}{*}{\multicolumn{3}{|c|}{$\begin{array}{c}\text { Model 1 } \\
\text { Internalization and Anxiety on } \\
\text { Decision-Making Difficulties }\end{array}$}} & \multirow{3}{*}{\multicolumn{3}{|c|}{$\begin{array}{c}\text { Model 2 } \\
\text { Internalization and Anxiety on } \\
\text { Decision-Making Difficulties + } \\
\text { Control Variables }\end{array}$}} & \multirow{3}{*}{\multicolumn{3}{|c|}{$\begin{array}{c}\text { Model 3 } \\
\text { Internalization and Anxiety on } \\
\text { Decision-Making Difficulties + } \\
\text { Control Variables + } \\
\text { Interaction Term }\end{array}$}} \\
\hline & & & & & & & & & \\
\hline & & & & & & & & & \\
\hline & \multicolumn{3}{|c|}{$\operatorname{adj} R^{2}=.07(S E=1.16)$} & \multicolumn{3}{|c|}{$\operatorname{adj} R^{2}=.14(S E=1.11)$} & \multicolumn{3}{|c|}{$\operatorname{adj} R^{2}=.15(S E=1.11)$} \\
\hline & $B$ & $S E B$ & $\beta$ & $B$ & $S E B$ & $\beta$ & $B$ & $S E B$ & $\beta$ \\
\hline SATAQ-I & .03 & .01 & $* .17$ & .02 & .01 & $* .15$ & .02 & .01 & ${ }^{*} .15$ \\
\hline PASTAS-S & .02 & .01 & $* .14$ & .02 & .01 & $* .14$ & .02 & .01 & $* .15$ \\
\hline Internalization x Anxiety & -- & -- & -- & -- & -- & -- & -.10 & .07 & -.08 \\
\hline Age & -- & -- & -- & -.09 & .06 & -.13 & -.09 & .06 & -.13 \\
\hline Children & -- & -- & -- & -.29 & .71 & -.03 & -.30 & .71 & -.03 \\
\hline Income & -- & -- & -- & -.16 & .06 & $* *-.16$ & -.17 & .06 & $* *-17$ \\
\hline Language (ref. English) & -- & -- & -- & -.13 & .47 & -.02 & -.19 & .47 & -.03 \\
\hline Citizenship (ref. US) & -- & -- & -- & -.24 & .42 & -.04 & -.20 & .42 & -.03 \\
\hline Marital Status (ref. & -- & -- & -- & -.50 & .86 & -.04 & -.39 & .86 & -.03 \\
\hline Single) & & & & & & & & & \\
\hline \multicolumn{10}{|l|}{ Race (ref: White) } \\
\hline Black & -- & -- & -- & -.58 & .39 & -.09 & -.51 & .39 & -.08 \\
\hline Asian & -- & -- & -- & -.02 & .41 & -.003 & .01 & .41 & .001 \\
\hline Latino/a & -- & -- & -- & -.23 & .43 & -.03 & -.24 & .43 & -.03 \\
\hline Multiracial/Biracial & -- & -- & -- & -.13 & .46 & -.02 & -.03 & .46 & -.004 \\
\hline Other & -- & -- & -- & -.43 & .50 & -.06 & -.41 & .50 & -.06 \\
\hline \multicolumn{10}{|l|}{$\begin{array}{l}\text { Sexual Orientation } \\
\text { (ref: heterosexual) }\end{array}$} \\
\hline Bisexual & -- & -- & -- & -.15 & .26 & -.03 & -.10 & .26 & -.02 \\
\hline Gay/L esbian & -- & -- & -- & 1.02 & .40 & ${ }^{*} .15$ & 1.04 & .40 & ${ }^{*} .15$ \\
\hline Other & -- & -- & -- & 1.04 & .38 & $* * .17$ & .98 & .38 & $* * .16$ \\
\hline $\begin{array}{l}\text { Note. } n=292 ; \text { SATAQ-I= } \\
\text { Trait Anxiety Scale-State } \\
{ }^{*} p<.05 ;{ }^{*}{ }^{*} p<.01\end{array}$ & litur & & App & uestio & -Inte & ion; PA & $=$ Phys & 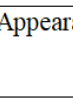 & ate and \\
\hline
\end{tabular}

In Model 1, the two predictor variables of internalization of sociocultural standards of beauty and physical appearance state anxiety were mean centered and regressed onto the outcome variable of perceived decision-making difficulties. Both internalization of sociocultural 
standards of beauty $(\beta=.17, p<.05)$ and physical appearance state anxiety $(\beta=.14, p<.05)$ were significant predictors of perceived decision-making difficulties. In Model 2, control variables were included to hold constant demographic variables. Both internalization of sociocultural standards of beauty $(\beta=.15, p<.05)$ and physical appearance state anxiety $(\beta=$ $.15, p<.05)$ remained significant predictors of perceived decision-making difficulties. In terms of demographic variables, income $(\beta=-.17, p<.001)$ and the sexual orientation categories of gay/lesbian $(\beta=.15, p<.05)$ and other $(\beta=.17, p<.001)$ were significant predictors. In Model 3 , the interaction term of internalization of sociocultural standards of beauty x physical appearance state anxiety was added in the model. The interaction term was not a significant predictor, which suggests that physical appearance state anxiety does not moderate the relationship between internalization of sociocultural standards of beauty and perceived decisionmaking difficulties, as hypothesized in the sixth hypothesis of the study. However, internalization of sociocultural standards of beauty and physical appearance state anxiety are both independent predictors of perceived decision-making difficulties, as indicated by the regression analyses and also the significant positive correlation between internalization of sociocultural standards of beauty and perceived decision-making difficulties $(r=.24, p<.001)$ and physical appearance state anxiety and perceived decision-making difficulties $(r=.24, p<$ $.001)$, as seen in Table 2 .

\section{Depression as a moderating variable and lack of confidence as an outcome variable.}

The seventh hypothesis states that the relationship between internalization of sociocultural standards of beauty and perception of career barriers, as measured by lack of confidence, will be moderated by depression, as seen in Figure 7. 


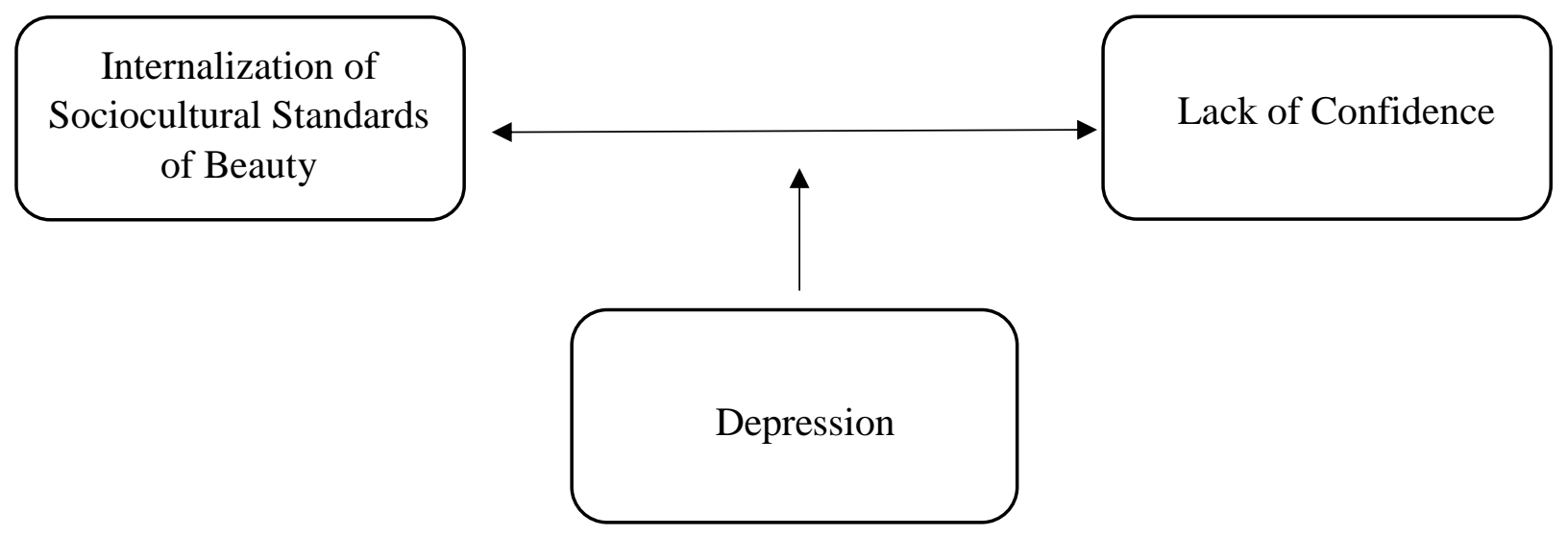

Figure 7. A conceptual model of Hypothesis 7 with depression as a moderating variable and lack of confidence as an outcome variable.

To test this hypothesis, a series of regression models were conducted, as seen in Table 7.

Table 7

Summary of Multiple Regression Analyses for Variables Predicting Lack of Confidence as a Perceived Career Barrier: Depression as a Moderating Variable

\begin{tabular}{|c|c|c|c|c|c|c|c|c|c|}
\hline \multicolumn{10}{|l|}{ Variables } \\
\hline & \multirow{2}{*}{\multicolumn{3}{|c|}{$\begin{array}{l}\text { Model } 1 \\
\text { Internalization and Depression on } \\
\text { Lack of Confidence }\end{array}$}} & \multirow{2}{*}{\multicolumn{3}{|c|}{$\begin{array}{c}\text { Model 2 } \\
\text { Internalization and Depression on } \\
\text { Lack of Confidence }+ \text { Control } \\
\text { Variables }\end{array}$}} & \multirow{2}{*}{\multicolumn{3}{|c|}{$\begin{array}{c}\underline{\text { Model } 3} \\
\text { Internalization and Depression on } \\
\text { Lack of Confidence }+ \\
\text { Control Variables }+ \\
\text { Interaction Term }\end{array}$}} \\
\hline & & & & & & & & & \\
\hline & \multicolumn{3}{|c|}{$\operatorname{adj} R^{2}=.11(S E=1.42)$} & \multicolumn{3}{|c|}{$\operatorname{adj} R^{2}=.16(S E=1.37)$} & \multicolumn{3}{|c|}{$\operatorname{adj} R^{2}=.16(S E=1.38)$} \\
\hline & $B$ & $S E B$ & $\beta$ & $B$ & $S E B$ & $\beta$ & $B$ & $S E B$ & $\beta$ \\
\hline SATAQ-I & .03 & .01 & $* .15$ & .03 & .01 & ${ }^{*} .14$ & .03 & .01 & ${ }^{*} .14$ \\
\hline CES-D & .03 & .01 & $* * .26$ & .03 & .01 & $* * .24$ & .03 & .01 & $* * 25$ \\
\hline $\begin{array}{l}\text { Internalization } \mathrm{x} \\
\text { Depression }\end{array}$ & -- & -- & -- & -- & -- & -- & -.002 & .09 & -.002 \\
\hline Age & -- & -- & -- & -.14 & .07 & *-.16 & -.14 & .07 & $*_{-.16}$ \\
\hline Children & -- & -- & -- & 1.62 & .87 & .14 & 1.62 & .87 & .14 \\
\hline Income & -- & -- & -- & -.06 & .07 & -.05 & -.06 & .07 & -.05 \\
\hline Language (ref. English) & -- & -- & -- & -1.01 & .56 & -.13 & -1.01 & .56 & -.13 \\
\hline Citizenship (ref. US) & -- & -- & -- & -.29 & .51 & -.04 & -.29 & .51 & -.04 \\
\hline Marital Status (ref. & -- & -- & -- & -1.70 & 1.04 & -.11 & -1.69 & 1.04 & -.11 \\
\hline Single) & & & & & & & & & \\
\hline \multicolumn{10}{|l|}{ Race (ref: White) } \\
\hline Black & -- & -- & -- & -.95 & .47 & $*_{-.12}$ & -.95 & .47 & $*_{-.12}$ \\
\hline Asian & -- & -- & -- & .34 & .49 & .04 & .34 & .49 & .04 \\
\hline Latino/a & -- & -- & -- & .24 & .52 & .03 & .24 & .52 & .03 \\
\hline Multiracial/Biracial & -- & -- & -- & -.12 & .55 & -.01 & -.12 & .55 & -.01 \\
\hline Other & -- & -- & -- & .23 & .60 & .03 & .23 & .60 & .03 \\
\hline \multicolumn{10}{|l|}{$\begin{array}{l}\text { Sexual Orientation } \\
\text { (ref: heterosexual) }\end{array}$} \\
\hline Bisexual & -- & -- & -- & -.22 & .31 & -.04 & -.22 & .31 & -.04 \\
\hline Gay/L esbian & -- & -- & -- & 1.20 & .49 & ${ }^{*} .14$ & 1.20 & .49 & $* .14$ \\
\hline Other & -- & -- & -- & .95 & .46 & ${ }^{*} .12$ & .95 & .46 & $* .12$ \\
\hline
\end{tabular}


In Model 1, the two predictor variables of internalization of sociocultural standards of beauty and depression were mean centered and regressed onto the outcome variable of perceived lack of confidence. Both internalization of sociocultural standards of beauty $(\beta=.15, p<.05)$ and depression $(\beta=.26, p<.001)$ were significant predictors of perceived lack of confidence. In Model 2, control variables were included to hold constant demographic variables. Both internalization of sociocultural standards of beauty $(\beta=.14, p<.05)$ and depression $(\beta=.24, p<$ .001) remained significant predictors of perceived lack of confidence. In terms of demographic variables, age $(\beta=-.16, p<.05)$, the race category of African American/Black $(\beta=-.12, p<$ $.05)$, and the sexual orientation categories of gay/lesbian $(\beta=.14, p<.05)$ and other $(\beta=.12, p<$ .05) were significant predictors. In Model 3, the interaction term of internalization of sociocultural standards of beauty $\mathrm{x}$ depression was added in the model. The interaction term was not a significant predictor, which suggests that depression does not moderate the relationship between internalization of sociocultural standards of beauty and perceived lack of confidence, as hypothesized in the seventh hypothesis of the study. However, internalization of sociocultural standards of beauty and depression are both independent predictors of perceived lack of confidence, as shown by the regression analyses and also the significant positive correlation between internalization of sociocultural standards of beauty and perceived lack of confidence $(r$ $=.23, p<.001)$ and depression and perceived lack of confidence $(r=.30, p<.001)$, as seen in Table 2 .

\section{Depression as a moderating variable and inadequate preparation as an outcome}

variable. The eighth hypothesis states that the relationship between internalization of sociocultural standards of beauty and perception of career barriers, as measured by inadequate preparation, will be moderated by depression, as seen in Figure 8. 


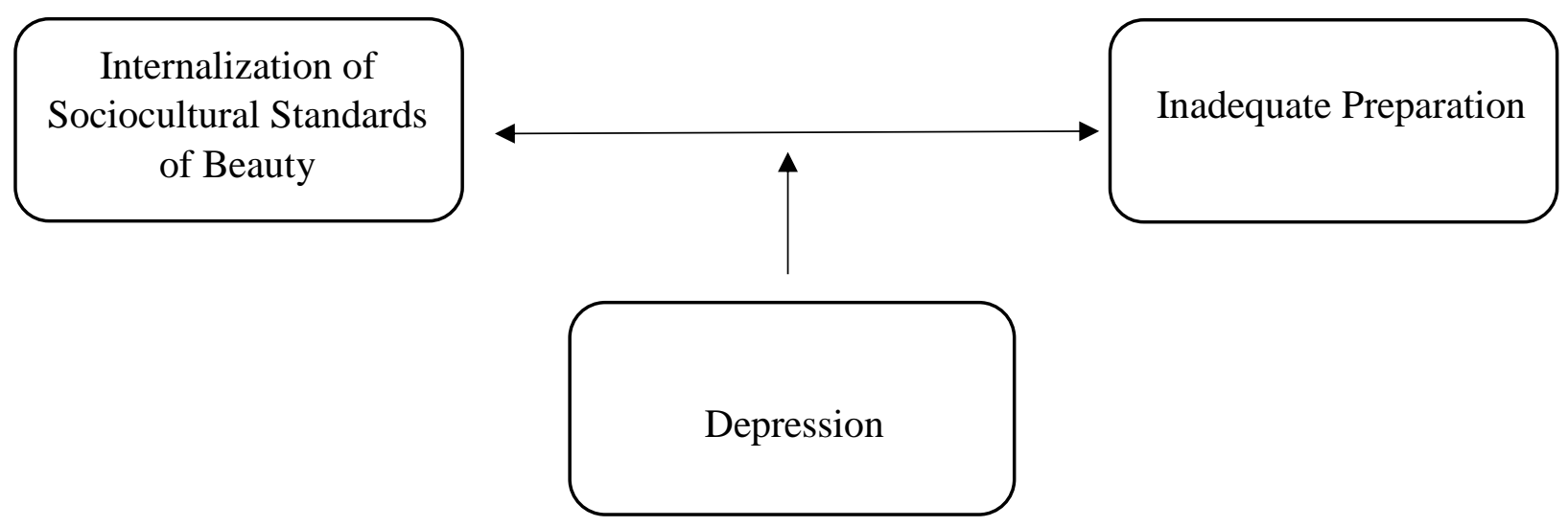

Figure 8. A conceptual model of Hypothesis 8 with depression as a moderating variable and inadequate preparation as an outcome variable.

To test this hypothesis, a series of regression models were conducted, as seen in Table 8 .

Table 8

Summary of Multiple Regression Analyses for Variables Predicting Inadequate Preparation as a Perceived Career Barrier: Depression as a Moderating Variable

\begin{tabular}{|c|c|c|c|c|c|c|c|c|c|}
\hline \multicolumn{10}{|l|}{ Variables } \\
\hline & \multirow{3}{*}{\multicolumn{3}{|c|}{$\begin{array}{c}\text { Model 1 } \\
\begin{array}{c}\text { Internalization and Depression on } \\
\text { Inadequate Preparation }\end{array}\end{array}$}} & \multirow{3}{*}{\multicolumn{3}{|c|}{$\begin{array}{c}\text { Model 2 } \\
\text { Internalization and Depression on } \\
\text { Inadequate Preparation }+ \text { Control } \\
\text { Variables }\end{array}$}} & \multirow{3}{*}{\multicolumn{3}{|c|}{$\begin{array}{c}\text { Model 3 } \\
\text { Internalization and Depression on } \\
\text { Inadequate Preparation }+ \\
\text { Control Variables }+ \\
\text { Interaction Term }\end{array}$}} \\
\hline & & & & & & & & & \\
\hline & & & & & & & & & \\
\hline & \multicolumn{3}{|c|}{$\operatorname{adj} R^{2}=.02(S E=1.44)$} & \multicolumn{3}{|c|}{$\operatorname{adj} R^{2}=.07(S E=1.40)$} & \multicolumn{3}{|c|}{$\operatorname{adj} R^{2}=.07(S E=1.40)$} \\
\hline & $B$ & $S E B$ & $\beta$ & $B$ & $S E B$ & $\beta$ & $B$ & $S E B$ & $\beta$ \\
\hline SATAQ-I & .01 & .01 & .08 & .02 & .01 & .08 & .01 & .01 & .07 \\
\hline CES-D & .01 & .01 & .11 & .01 & .01 & .09 & .01 & .01 & .11 \\
\hline Internalization $\mathrm{x}$ & - & -- & -- & -- & -- & -- & -.10 & .09 & -.07 \\
\hline \multicolumn{10}{|l|}{ Depression } \\
\hline Age & -- & -- & -- & -.05 & .07 & -.06 & -.05 & .07 & -.06 \\
\hline Children & -- & -- & -- & -.23 & .89 & -.02 & -.14 & .89 & -.01 \\
\hline Income & -- & -- & -- & -.08 & .07 & -.07 & -.08 & .07 & -.07 \\
\hline Language (ref. English) & -- & -- & -- & -.95 & .58 & -.12 & -.96 & .58 & -.13 \\
\hline Citizenship (ref. US) & -- & -- & -- & -.45 & .53 & -.06 & -.42 & .53 & -.06 \\
\hline Marital Status (ref. & -- & -- & -- & -1.34 & 1.06 & -.09 & -1.40 & 1.06 & -.10 \\
\hline \multicolumn{10}{|l|}{ Single) } \\
\hline \multicolumn{10}{|l|}{ Race (ref: White) } \\
\hline Black & -- & -- & -- & -.71 & .48 & -.09 & -.59 & .49 & -.07 \\
\hline Asian & -- & -- & -- & .09 & .50 & .01 & .07 & .50 & .01 \\
\hline Latino/a & -- & -- & -- & -.06 & .53 & -.01 & -.08 & .53 & -.01 \\
\hline Multiracial/Biracial & -- & -- & -- & .70 & .57 & .07 & .67 & .57 & .07 \\
\hline Other & -- & -- & -- & .07 & .62 & .01 & -.05 & .63 & -.01 \\
\hline \multicolumn{10}{|l|}{$\begin{array}{l}\text { Sexual Orientation } \\
\text { (ref: heterosexual) }\end{array}$} \\
\hline Bisexual & -- & -- & -- & -.36 & .32 & -.07 & -.32 & .32 & -.06 \\
\hline Gay/L esbian & -- & -- & -- & 1.58 & .50 & $* * 19$ & 1.53 & .50 & $* * 18$ \\
\hline Other & -- & -- & -- & .75 & .47 & .10 & .66 & .48 & -.07 \\
\hline \multicolumn{10}{|c|}{$\begin{array}{l}\text { Note. } n=292 \text {; SATAQ-I=Sociocultural Attitudes Towards Appearance Questionnaire-Internalization; CES-D=Center for Epidemiologic Studies- } \\
\text { Depression Scale } \\
* p<.05 ; * k<.01\end{array}$} \\
\hline
\end{tabular}


In Model 1, the two predictor variables of internalization of sociocultural standards of beauty and depression were mean centered and regressed onto the outcome variable of perceived inadequate preparation. Neither predictor variable was a significant predictor of perceived inadequate preparation. In Model 2, control variables were included to hold constant demographic variables. Like Model 1, neither predictor variable was a significant predictor of perceived inadequate preparation. In terms of demographic variables, the sexual orientation category of gay/lesbian was a significant predictor $(\beta=.19, p<.001)$. In Model 3, the interaction term of internalization of sociocultural standards of beauty $\mathrm{x}$ depression was added in the model. The interaction term was not a significant predictor, which suggests that depression does not moderate the relationship between internalization of sociocultural standards of beauty and perceived inadequate preparation, as hypothesized in the eighth hypothesis of the study.

\section{Depression as a moderating variable and decision-making difficulties as an outcome}

variable. The ninth hypothesis states that the relationship between internalization of sociocultural standards of beauty and perception of career barriers, as measured by decisionmaking difficulties, will be moderated by depression, as seen in Figure 8.

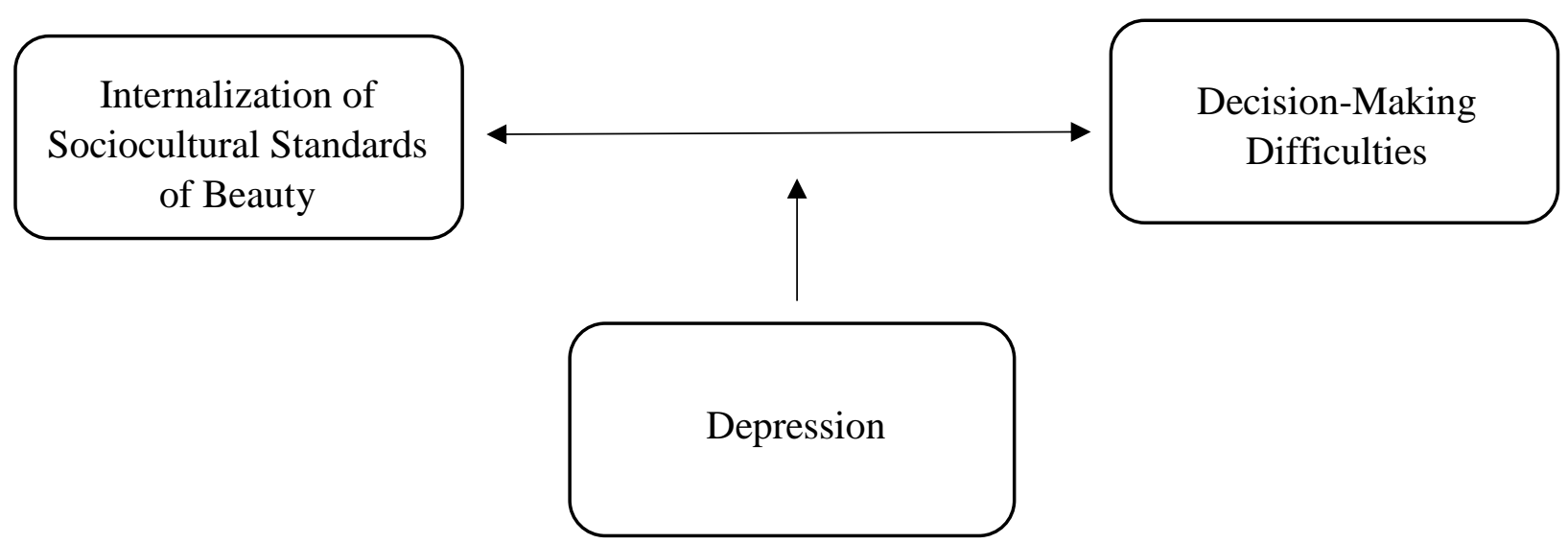

Figure 9. A conceptual model of Hypothesis 9 with depression as a moderating variable and decision-making difficulties as an outcome variable. 
To test this study hypothesis, a series of regression models were conducted, as seen in

Table 9.

Table 9

Summary of Multiple Regression Analyses for Variables Predicting Decision-Making Difficulties as a Perceived Career Barrier: Depression as a Moderating Variable

\begin{tabular}{|c|c|c|c|c|c|c|c|c|c|}
\hline \multicolumn{10}{|l|}{ Variables } \\
\hline & \multicolumn{3}{|c|}{ Model 1} & \multicolumn{3}{|c|}{ Model 2} & \multicolumn{3}{|c|}{ Model 3} \\
\hline & \multirow{2}{*}{\multicolumn{3}{|c|}{$\begin{array}{l}\text { Internalization and Depression on } \\
\text { Decision-Making Difficulties }\end{array}$}} & \multirow{2}{*}{\multicolumn{3}{|c|}{$\begin{array}{l}\text { Internalization and Depression on } \\
\text { Decision-Making Difficulties + } \\
\text { Control Variables }\end{array}$}} & \multirow{2}{*}{\multicolumn{3}{|c|}{$\begin{array}{l}\text { Internalization and Depression on } \\
\text { Decision-Making Difficulties + } \\
\text { Control Variables + } \\
\text { Interaction Term }\end{array}$}} \\
\hline & & & & & & & & & \\
\hline & \multicolumn{3}{|c|}{$\operatorname{adj} R^{2}=.11(S E=1.14)$} & \multicolumn{3}{|c|}{$\operatorname{adj} R^{2}=.17(S E=1.10)$} & \multicolumn{3}{|c|}{$\operatorname{adj} R^{2}=.17(S E=1.10)$} \\
\hline & $B$ & $S E B$ & $\beta$ & $B$ & $S E B$ & $\beta$ & $B$ & $S E B$ & $\beta$ \\
\hline SATAQ-I & .03 & .01 & $* * .16$ & .02 & .01 & $* .15$ & .02 & .01 & $* .15$ \\
\hline CES-D & .03 & .01 & $* * .25$ & .02 & .01 & $* * .22$ & .03 & .01 & $* * .24$ \\
\hline \multicolumn{10}{|l|}{ Depression } \\
\hline Age & -- & -- & -- & -.09 & .05 & -.14 & -.10 & .05 & -.14 \\
\hline Children & -- & -- & -- & -.15 & .69 & -.02 & -.09 & .69 & -.01 \\
\hline Income & -- & -- & -- & -.15 & .06 & $* *-.15$ & -.15 & .06 & *-.15 \\
\hline Language (ref. English) & -- & -- & -- & -.20 & .45 & -.03 & -.20 & .45 & -.03 \\
\hline Citizenship (ref. US) & -- & -- & -- & -.40 & .41 & -.07 & -.38 & .41 & -.06 \\
\hline Marital Status (ref. & -- & -- & -- & -.27 & .83 & -.02 & -.32 & .83 & -.03 \\
\hline \multicolumn{10}{|l|}{ Single) } \\
\hline \multicolumn{10}{|l|}{ Race (ref: White) } \\
\hline Black & -- & -- & -- & -.49 & .37 & -.07 & -.40 & .39 & -.06 \\
\hline Asian & -- & -- & -- & .05 & .39 & .01 & .03 & .39 & .01 \\
\hline Latino/a & -- & -- & -- & -.13 & .41 & -.02 & -.15 & .41 & -.02 \\
\hline Multiracial/Biracial & -- & -- & -- & -.17 & .44 & -.02 & -.19 & .44 & -.02 \\
\hline Other & -- & -- & -- & -.44 & .48 & -.06 & -.53 & .49 & -.07 \\
\hline \multicolumn{10}{|l|}{$\begin{array}{l}\text { Sexual Orientation } \\
\text { (ref: heterosexual) }\end{array}$} \\
\hline Bisexual & -- & -- & -- & -.27 & .25 & -.06 & -.24 & .25 & -.06 \\
\hline Gay/L esbian & -- & -- & -- & .90 & .39 & $* .13$ & .87 & .39 & $* .12$ \\
\hline Other & -- & -- & -- & .91 & .37 & ${ }^{*} .15$ & .84 & .37 & ${ }^{*} .13$ \\
\hline \multicolumn{10}{|c|}{$\begin{array}{l}\text { Note. } n=292 \text {; SATAQ-I=Sociocultural Attitudes Towards Appearance Questionnaire-Internalization; CES-D=Center for Epidemiologic Studies- } \\
\text { Depression Scale } \\
{ }^{*} p<.05 ; * * x<.01\end{array}$} \\
\hline
\end{tabular}

In Model 1, the two predictor variables of internalization of sociocultural standards of beauty and depression were mean centered and regressed onto the outcome variable of perceived decision-making difficulties. Both internalization of sociocultural standards of beauty $(\beta=.16, p$ $<.001)$ and depression $(\beta=.25, p<.001)$ were significant predictors of perceived decisionmaking difficulties. In Model 2, control variables were included to hold constant demographic variables. Both internalization of sociocultural standards of beauty $(\beta=.15, p<.05)$ and 
depression $(\beta=.22, p<.001)$ remained significant predictors of perceived decision-making difficulties. In terms of demographic variables, income $(\beta=-.15, p<.001)$ and the sexual orientation categories of gay/lesbian $(\beta=.13, p<.05)$ and other $(\beta=.15, p<.05)$ were significant predictors. In Model 3, the interaction term of internalization of sociocultural standards of beauty $\mathrm{x}$ depression was added in the model. The interaction term was not a significant predictor, which suggests that depression does not moderate the relationship between internalization of sociocultural standards of beauty and perceived decision-making difficulties, as hypothesized in the ninth hypothesis of the study. However, internalization of sociocultural standards of beauty and depression are both independent predictors of perceived decisionmaking difficulties, as demonstrated by the regression analyses and also the significant positive correlation between internalization of sociocultural standards of beauty and perceived decisionmaking difficulties $(r=.24, p<.001)$ and depression and perceived decision-making difficulties $(r=.30, p<.001)$, seen in Table 2.

Summary of results. In summary, the hypotheses of the study were partially supported by the results. In terms of support, the first hypothesis of the study was supported $(r=.23, p<$ .01 ), indicating that internalization of sociocultural standards of beauty is positively related to perception of lack of confidence as a career barrier. Additionally, the third hypothesis of the study was supported $(r=.24, p<.01)$, in which internalization of sociocultural standards of beauty is positively related to a perception of decision-making difficulties as a career barrier.

None of the remaining hypotheses of the study were supported. Specifically, internalization of sociocultural standards of beauty was not related to perception of inadequate preparation as a career barrier. Furthermore, no moderating effects were found. However, physical appearance state anxiety was found to fully mediate the relationship between 
internalization of sociocultural standards of beauty and perception of lack of confidence as a career barrier. 


\section{CHAPTER IV}

\section{Discussion}

The goal of this study was to explore career barriers that currently impede women's career development in the U.S. Specifically, this study examined the relationship between perception of career barriers, namely, lack of confidence, inadequate preparation, and decisionmaking difficulties, and internalization of sociocultural standards of beauty, with physical appearance state anxiety and depression as potential moderators. Bivariate correlation and multiple regression analyses were conducted to determine relationships among the variables of interest. Of note, internalization of sociocultural standards of beauty predicted perception of lack of confidence $(r=.23, p<.01)$ and decision-making difficulties as career barriers $(r=.24, p<$ .01). However, internalization of sociocultural standards of beauty was not predictive of perception of inadequate preparation as a career barrier. Furthermore, no moderating effects were found for physical appearance state anxiety or depression.

In this chapter, the results of this study are further reviewed. The limitations of this study are also addressed with suggestions for improvement. Finally, potential clinical implications and future research directions regarding the career development of women in the U.S. are proposed.

\section{Discussion of Findings}

\section{Internalization of sociocultural standards of beauty and perception of career}

barriers. The first research question of this study asked if internalization of sociocultural standards of beauty is related to perception of career barriers, as measured by lack of confidence, inadequate preparation, and decision-making difficulties. Pearson bivariate correlation analyses yielded partial support for this research question. Specifically, internalization of sociocultural standards of beauty was a significant, positive predictor of perception of lack of confidence and 
decision-making difficulties as career barriers. However, internalization of sociocultural standards of beauty was not found to be related to perception of inadequate preparation as a career barrier. Therefore, women who internalize sociocultural standards of beauty are likely to perceive lack of confidence and decision-making difficulties as career barriers that impede career development but do not perceive inadequate preparation as an obstacle to career success.

Sociocultural standards of beauty functions as an environment-person career barrier that impedes women's career development in the U.S. For example, conformity to sociocultural standards of beauty, as demonstrated by perceived physical attractiveness, is typically associated with women employees receiving more favorable evaluations from colleagues and employers based on the assumption that physical attractiveness is reflective of competence, social skill, warmth, happiness, self-confidence, honesty, intelligence, and other socially desirable personality traits (Shahani et al., 1993). Due to social desirability, conformity to sociocultural standards of beauty is a major determinant of career-related outcomes, including hiring, firing, and promotion, for women employees (Baert \& Decuypere, 2014; Bowling et al., 2004; Gilmore et al., 1986; Hosada et al., 2003; Johnson et al., 2010; Watkins \& Johnston, 2000).

However, sociocultural standards of beauty can also function as a cognitive-person variable in which women internalize, or accept and personally endorse, the feminine beauty ideal to receive the social rewards associated with conformity (Heinberg et al., 1995). Due to the dual nature of sociocultural standards of beauty, deviation from the feminine beauty ideal can result in both external (e.g., social exclusion and rejection, discrimination, harassment) and internal (e.g., depression, anxiety, anger) consequences for women (Calogero et al., 2007; Engeln-Maddox, 2006; Fredrickson et al., 1998; Moradi et al., 2005; Reed et al., 1991). Therefore, sociocultural 
standards of beauty may represent both an environment-person and cognitive-person career barrier that prevents and/or makes career progress difficult for women in the U.S.

Internalization of sociocultural standards of beauty has not been previously explored in relation to women's perception of career barriers. Despite this limitation, some research has suggested that internalization of sociocultural standards of beauty may be directly related to women's perception of career barriers. For example, experimental studies have found that girls who are exposed to appearance-focused online games or toys report no changes in perceived capacity to perform in various career types but exhibit greater preference for feminine careers (Slater, Halliwell, Jarman, \& Gaskin, 2017). Furthermore, girls who are exposed to appearancefocused stimuli report even fewer career options than boys and other girls (Sherman \& Zurbriggen, 2014). Although limited to girls, these studies suggest that exposure to an ideal body image can impact career development by constricting girls' career aspirations and, most notably, increasing girls' perception of career barriers that could impede future career success.

More specific to this study, internalization of sociocultural standards of beauty, primarily operationalized as body image, has also been found to impact career decision-making and confidence among girls and women. For example, Woodrow-Keys (2006) found that undergraduate women who expressed a positive body image were more likely to report greater career decision-making self-efficacy and assertiveness than undergraduate women who expressed a negative body image. In addition, Halliwell, Diedrichs, and Orbach (2014) asserted that internalization of sociocultural standards of beauty impacts women's career development by curtailing the performance and confidence of women. Specifically, Halliwell and colleagues (2014) explained that body weight and shape does not impact women's performance or achievement; however, negative body image decreases performance and achievement for 
women, as compared to men, due to lack of confidence and, ultimately, reduces academic- and career-related outcomes. Although limited, this research is consistent with the findings in this study and suggest that internalization of sociocultural standards of beauty may operate as a cognitive-person career barrier that impedes women's career development in the U.S.

Internalization and perception are both cognitive, or internal, processes (Moradi et al., 2005; Swanson \& Daniels, 1994; Swanson, Daniels, \& Tokar, 1996; Swanson \& Tokar, 1991a; Swanson \& Tokar, 1991b). Therefore, the significant, positive relationships between internalization of sociocultural standards of beauty and perception of lack of confidence and decision-making difficulties as career barriers suggest that women may experience each as an internal impediment to career development. Furthermore, Swanson and colleagues (1996) found that women tend to identify cognitive-person, or internal, career barriers, such as perceived lack of confidence and decision-making difficulties, as more detrimental to career development than environment-person, or external, career barriers, such as gender discrimination and job market constraints, which may explain why another internal process, internalization of sociocultural standards of beauty, would be related to women's perception of lack of confidence and decisionmaking difficulties as career barriers.

As previously noted, internalization of sociocultural standards of beauty was not a predictor of perception of inadequate preparation as a career barrier in this study. Perceived inadequate preparation was originally classified as a cognitive-person career barrier by Swanson and colleagues (1996) and was conceptualized as internal perceptions of preparedness for the demands of the job market. However, participants in this study were undergraduate women who were in the process of receiving education and experience in a specified career; therefore, perceived inadequate preparation may not have functioned as a career barrier for participants at 
the time of this study. In addition, perceived inadequate preparation may operate as an

environment-person career barrier, in which preparedness can be determined and/or modified by the external environment (e.g., performance appraisal, experiential learning). Therefore, internalization of sociocultural standards of beauty may not have been a predictor of perceived inadequate preparation because preparedness was not relevant to the participant sample and/or preparedness primarily functions as an external, rather than internal, career barrier.

\section{Internalization of sociocultural standards of beauty, physical appearance state}

anxiety, and perception of career barriers. The second research question of the study asked if the relationship between internalization of sociocultural standards of beauty and perception of career barriers, as measured by lack of confidence, inadequate preparation, and decision-making difficulties, is moderated by physical appearance state anxiety. Regression analyses did not yield any support for this research question. Specifically, physical appearance state anxiety did not moderate the relationship between internalization of sociocultural standards of beauty and perception of career barriers, as measured by lack of confidence, inadequate preparation, or decision-making difficulties. However, regression analyses that followed the Baron and Kenny (1986) mediation protocol suggested that physical appearance state anxiety fully mediated the relationship between internalization of sociocultural standards of beauty and perceived lack of confidence. In other words, women who internalize sociocultural standards of beauty are more likely to experience physical appearance state anxiety and, in turn, are more likely to perceive lack of confidence as a career barrier.

Physical appearance state anxiety is a psychological consequence commonly associated with internalization of sociocultural standards of beauty (Fredrickson et al., 1998; Grabe et al., 2008; Moradi et al., 2005). In addition, physical appearance state anxiety is related to many of 
the same psychological consequences as internalization of sociocultural standards of beauty, including negative body image, body dissatisfaction, eating disturbance, depression, and low self-esteem (Heinberg et al., 1995; Reed et al., 1991). Based on an apparent link between physical appearance state anxiety and internalization of sociocultural standards of beauty, physical appearance state anxiety was hypothesized to moderate the relationship between internalization of sociocultural standards of beauty and perception of lack of confidence, inadequate preparation, and decision-making difficulties as career barriers.

Although physical appearance state anxiety has not specifically been examined in relation to women's career development, anxiety has been found to reduce career-related outcomes due to professional burnout, absenteeism, job dissatisfaction, interpersonal conflict, and poor performance appraisal (Bianchi et al., 2015; Cropanzano, Rupp, \& Byrne, 2003; Maslach, Schaufeli, \& Leiter, 2001). Therefore, physical appearance state anxiety was considered a possible domain-specific extension of anxiety. This study provides preliminary support for this assumption and suggests that physical appearance state anxiety may function in a similar manner as anxiety to reduce career outcomes for women. For example, physical appearance state anxiety was a significant, positive predictor of perceived decision-making difficulties, which is consistent with previous research that has found a relationship between anxiety and decisionmaking difficulties (Campagna \& Curtis, 2007; Cheung, Cheung, \& Wu, 2014; Fuqua, Newman, \& Seaworth, 1988; Isik, 2012). Although physical appearance state anxiety was not a predictor of perception of inadequate preparation as a career barrier, this may, as previously discussed, reflect potential irrelevance of the career barrier to the sample or the external nature of the career barrier. It is also important to note that perception of inadequate preparation is noticeably absent in the research regarding anxiety and career development. In addition to potential irrelevance, 
perceived inadequate preparation may be conceptualized by researchers as a component of decision-making difficulties, in which decision-making difficulties may occur in response to the perception of inadequacy in relation to various careers or career types (Campagna \& Curtis, 2007).

Due to the link between anxiety and various career-related outcomes, the lack of any moderating effect of physical appearance state anxiety on the relationship between internalization of sociocultural standards of beauty and perception of lack of confidence, inadequate preparation, or decision-making difficulties as career barriers was surprising. The mediation of physical appearance state anxiety on the relationship between internalization of sociocultural standards of beauty and perception of lack of confidence as a career barrier was also unexpected. However, internalization of sociocultural standards of beauty alone may not cause any functional impairment in terms of women's career development (Halliwell et al., 2014). For example, women may internalize sociocultural standards of beauty and experience no psychological consequences as a result of succeeding or failing to meet sociocultural standards of beauty; therefore, the absence of psychological consequences may negate any potential impact of internalization of sociocultural standards on women's perception of career barriers. In other words, internalization of sociocultural standards of beauty may operate through, rather than in addition to, associated psychological consequences, such as physical appearance state anxiety, to influence women's career development.

It is important to note that no other mediation effect was discovered. Therefore, the mediation effect of physical appearance state anxiety on the relationship between internalization of sociocultural standards of beauty and perception of lack of confidence as a career barrier was unique. One explanation for this finding is that physical appearance state anxiety that stems from 
internalization of sociocultural standards of beauty undermines career-related self-efficacy and outcome expectations and, thereby, distinctively contributes to the perception of lack of confidence as a career barrier (Campagna \& Curtis, 2007; Lent et al., 2000; Motowidlo et al., 1986; Rottinghaus et al., 2009; Saunders et al., 2000; Swanson et al., 1996). This may occur because confidence overlaps in many ways with the behavioral, cognitive, and emotional correlates associated with self-efficacy beliefs and outcome expectations and is often conceptualized as a broader self-belief construct that encapsulates the domain-specific constructs of self-efficacy and outcome expectations (Stankov, Lee, Luo, \& Hogan, 2012). Therefore, physical appearance state anxiety associated with internalization of sociocultural standards of beauty may reduce career-related self-efficacy beliefs and outcome expectations, which, due to similarity in function, reduce self-confidence and increase perception of lack of confidence as a career barrier.

\section{Internalization of sociocultural standards of beauty, depression, and perception of}

career barriers. The third research question of the study asked if the relationship between internalization of sociocultural standards of beauty and perception of career barriers, as measured by lack of confidence, inadequate preparation, and decision-making difficulties, is moderated by depression. Regression analyses did not yield any support for this research question. Specifically, depression did not moderate the relationship between internalization of sociocultural standards of beauty and perception of career barriers, as measured by lack of confidence, inadequate preparation, or decision-making difficulties.

Depression is a psychological consequence typically associated with internalization of sociocultural standards of beauty and often occurs following actual or perceived failure to conform to sociocultural standards of beauty (Fredrickson et al., 1998; Grabe et al., 2008; 
Moradi et al., 2005). Similar to physical appearance state anxiety, depression reduces careerrelated outcomes due to burnout, job dissatisfaction, absenteeism, social isolation and withdrawal, job performance deficits, productivity loss, and work disengagement (Bianchi et al., 2015; Cropanzano et al., 2003; Hakanen, Schaufeli, \& Ahola, 2008; Lerner \& Henke, 2008; Maslach et al., 2001). Based on the link between depression, internalization of sociocultural standards of beauty, and various career-related outcomes, the lack of any moderating effects of depression on the relationship between internalization of sociocultural standards of beauty and perception of lack of confidence, inadequate preparation, or decision-making difficulties as career barriers was unexpected.

However, several findings in this study were consistent with previous research. For example, internalization of sociocultural standards of beauty was a significant, positive predictor of depression. As previously mentioned, depression is a psychological consequence typically associated with internalization of sociocultural standards of beauty (Fredrickson et al., 1998; Grabe et al., 2008; Moradi et al., 2005). Furthermore, depression was a significant, positive predictor of perception of career barriers, as measured by lack of confidence, inadequate preparation, and decision-making difficulties. Therefore, depression may operate by independently weakening career-related self-efficacy and outcome expectations, resulting in the development and maintenance of cognitive-person career barriers (Bianchi, et al., 2015; Rottinghaus et al., 2009; Saunders et al., 2000).

Summary of findings. Internalization of sociocultural standards of beauty was a significant, positive predictor of perception of lack of confidence and decision-making difficulties as career barriers. However, internalization of sociocultural standards of beauty was not predictive of perception of inadequate preparation as a career barrier. This suggests that 
perception of lack of confidence and decision-making difficulties and internalization of sociocultural standards of beauty may be experienced as internal impediments to career development. In contrast, perceived inadequate preparation may be experienced as an external impediment due to the impact of environment on preparation for a career.

Physical appearance state anxiety was found to fully mediate the relationship between internalization of sociocultural standards of beauty and perception of lack of confidence as a career barrier. Therefore, women who internalize sociocultural standards of beauty are more likely to experience physical appearance state anxiety and, subsequently, are more likely to perceive lack of confidence as a career barrier. However, no moderating effects were found for physical appearance state anxiety or depression. Despite the lack of any moderating effects, depression was a significant, positive and independent predictor of perception of lack of confidence, inadequate preparation, and decision-making difficulties as career barriers. In addition, physical appearance state anxiety was a significant, positive and independent predictor of perception of decision-making difficulties as a career barrier. This suggests that both depression and physical appearance state anxiety may be related to women's career development by weakening career-related self-efficacy and outcome expectations and increasing perception of various types of career barriers.

\section{Limitations}

Although the findings of this study increase understanding of the relationship between internalization of sociocultural standards of beauty and perception of career barriers among women, there are limitations that should be addressed. The first limitation of this study is the generalizability of the sample. The convenience sample was recruited from one university in the Southeastern region of the U.S. and primarily consists of young, White, heterosexual, cisgender, 
single undergraduate women with an annual household income ranging between $\$ 50,000$ $\$ 99,000$. Although the sample was consistent with the student population of the university sampled, the sample is non-representative of women in the U.S. and caution should be used in generalizing the findings of this study to undergraduate women or, more generally, women in the U.S. (West Virginia Higher Education Policy Commission, 2018).

A second limitation of this study is instrumentation. The instruments used in this study, including the CBI-R (Swanson \& Daniels, 1994), SATAQ-I (Heinberg et al., 1995), CES-D (Radloff, 1977), and PASTAS-S (Reed et al., 1991), were selected due to adequate psychometric properties with the population of interest, accessibility, and definition and measurement of constructs that are consistent with the conceptualization of each variable of interest in this study. However, the instruments are dated and may not have been as relevant to the sample as more contemporary instruments measuring the same or similar constructs. For example, the SATAQ-I (Heinberg et al., 1995) asks participants to rate the items, "I tend to compare my body to people in magazines and on TV" and "I often read magazines like Cosmopolitan, Vogue, and Glamour and compare my appearance to the models." However, women are increasingly exposed to the feminine beauty ideal via social media, as compared to magazines and television, which is not a media outlet that was assessed by the instrument, thereby, potentially reducing the accuracy of the instrument in measuring women's internalization of sociocultural standards of beauty (Fardouly, Diedrichs, Vartanian, \& Halliwell, 2015; Fardouly \& Vartanian, 2016; Perloff, 2014). Additionally, the CBI-R (Swanson et al., 1996) may not be as relevant for women in the U.S. today due to development in the 1990s. Since the 1990s, the U.S. shifted from a manufacturing to a service economy, which may have benefited women based on women's preferences for careers in the service industry, as opposed to careers in manufacturing, and, 
thereby, potentially reduced or altered women's perception of career barriers (Pew Research Center, 2016). Furthermore, women are becoming increasingly educated; choosing to postpone marriage and children; and participating in the workforce, regardless of marital or motherhood status, which may also contribute to reduced or altered perceptions of career barriers (Covert, 2017; Freedman, 2010). Although each instrument demonstrated adequate reliability with this sample and has been found to be reliable and valid instruments in previous research, instrumentation is a potential limitation of this study.

A third limitation of this study is the outcome variable of perception of career barriers. Although perception of career barriers is hypothesized to influence choice of career by constricting career options, this study did not directly measure women's career outcomes (Swanson \& Daniels, 1994; Swanson, Daniels, \& Tokar, 1996; Swanson \& Tokar, 1991a; Swanson \& Tokar, 1991b). Therefore, women's perception of career barriers may not be related to career outcomes and is potentially less relevant to career development. Due to this limitation, any conclusions drawn from this study should not assume that this study directly measures women's career outcomes.

A fourth limitation of this study is the reduction of the CBI-R (Swanson et al., 1996) to the Lack of Confidence, Inadequate Preparation, and Decision-Making Difficulties subscales. The CBI-R is comprised of 13 subscales, including Sex Discrimination, Lack of Confidence, Multiple Role Conflict, Conflict between Children and Career Demands, Racial Discrimination, Inadequate Preparation, Disapproval by Significant Others, Decision-Making Difficulties, Dissatisfaction with Career, Discouraged from Choosing Nontraditional Careers, Disability/Health Concerns, Job Market Constraints, and Difficulties with Networking/Socializing (Swanson et al., 1996). Therefore, the majority of career barriers 
identified by Swanson and colleagues (1996) as detrimental to career development were excluded and, thereby, reduced the scope of this study. Due to this limitation, this study did not fully ascertain women's perception of career barriers in the U.S., and the findings of this study, especially the findings associated with the CBI-R (Swanson et al., 1996), should be interpreted with caution.

A fifth limitation of this study is reliance on self-report instruments. Due to the potential for response bias, participants' report of internalization of sociocultural standards of beauty, perception of career barriers, depression, and/or physical appearance state anxiety may be inaccurate. For example, participants completed this study via Qualtrics, an online survey system, which does not allow for interaction between the researcher and the participants. Although this method of data collection allows for uniform assessment, participants were not able to obtain clarification on any potential questions regarding the instruments. Therefore, participants may have misunderstood instructions or instrument items, resulting in potential inaccuracy. Another form of response bias that may have occurred is positive impression management. Due to a lack of control for positive impression management, participants may have responded in a socially desirable manner to portray a positive and normative image (Field, 2013). Therefore, response bias may have impacted the findings of this study and should be considered a limitation.

A sixth limitation of this study is the correlational research design. Due to the use of correlation and regression analyses, causal inferences cannot be determined regarding the nature of the relationships between the variables of interest (Field, 2013). Despite finding significant relationships among variables of interest, a relationship cannot prove that one variable causes another variable to change. Furthermore, unknown or unmeasured variables that were not 
accounted for in this study may have contributed to the relationships that were found in this study. Therefore, interpretation of the findings of this study is limited due to reliance on a correlational research design.

\section{Study Contributions}

Despite limitations, this study also has several strengths that should be highlighted. First, this study contributes to an increased understanding of women's career development in the U.S., with a specific focus on career barriers that impede career advancement in a career or career goal(s). Although women's career development has received significant attention in the psychological community since the 1990s, this study included several variables, including internalization of sociocultural standards of beauty, depression, and physical appearance state anxiety, that have not previously been examined in relation to women's perception of career barriers. Due to the inclusion of unique variables, this study was able to build upon previous research and identify new and current career barriers to women's career development (Swanson \& Daniels, 1994; Swanson, Daniels, \& Tokar, 1996; Swanson \& Tokar, 1991a; Swanson \& Tokar, 1991b).

Second, this study emphasizes the relationships among and between external and internal variables on women's career development. Although past research has examined the impact of external variables, primarily traditional gender norms and stereotypes, on women's career development, this study demonstrates that sociocultural standards of beauty, a construct that is not typically linked to career development, has implications for women's career interests, goals, and actions (Charles, 2003; Freedman, 2010; Hodges \& Parks, 2013; Lyness \& Heilman, 2006; Swanson et al., 1996). Previously, sociocultural standards of beauty were conceptualized as an external career barrier, in which perceived physical attractiveness significantly impacted various 
career outcomes for women, including hiring, firing, and promotion (Baert \& Decuypere, 2014; Bowling et al., 2014; Depboye et al., 1977; Gilmore, Beehr, \& Love, 1986; Hosoda et al., 2003; Johnson et al., 2010; Shahani et al., 1993; Watkins \& Johnston, 2000). However, this study suggests that sociocultural standards of beauty may operate as both external and internal career barriers that influence women's career development and limit career advancement in a career or career goals.

Third, this study provides further support for the application of SCCT as a theoretical framework to understand the construct of career barriers (Lent et al., 1994; Swanson et al., 1996). SCCT is a theoretical model developed by Lent, Brown, and Hackett (1994) to conceptualize the processes that underly the formation of interests, choices, and actions in academic and career-related pursuits (Lent et al., 2000). Most notably, SCCT highlights the interaction between internal and external variables on career development. This is consistent with the findings of this study, in which an external variable, specifically, sociocultural standards of beauty, was linked to several internal variables, including internalization of sociocultural standards of beauty, physical appearance state anxiety, depression, and perception of career barriers (i.e., lack of confidence, decision-making difficulties), that play an important role in women's career development. SCCT also emphasizes the influence of objective and perceived external variables on career development (Lent et al., 2000). Although this study did not include an examination of objective external variables, this study underscores the importance of perceived external variables on women's career development. This study also found a unique perceived external variable, namely, sociocultural standards of beauty, which has not previously been identified as related to women's career development but has implications for women's 
progress in a career or career goal (Swanson \& Daniels, 1994; Swanson, Daniels, \& Tokar, 1996; Swanson \& Tokar, 1991a; Swanson \& Tokar, 1991b).

Fourth, despite using instruments that were constructed between 1977 and 1996, this study found the instruments to be reliable. Therefore, this study demonstrates the continued utility of the CBI-R (Swanson et al., 1996), SATAQ-I (Heinberg et al., 1995), CES-D (Radloff, 1977), and PASTAS-S (Reed et al., 1991), especially with college women in the U.S. Furthermore, due to the lack of contemporary instruments that measure perception of career barriers and internalization of sociocultural standards of beauty, it is recommended that these instruments, in particular, continue to be used in future research.

\section{Future Research Directions}

Women in the U.S. continue to differentially experience career barriers that impede or prevent progress in a career or career goal(s) (Charles, 2003; Correll et al., 2007; Germeijs et al., 2006; Freedman, 2010; Lopez \& Anne-Yi, 2006; Lyness \& Heilman, 2006; Newkirk et al., 2017; Phelan et al., 2008; Rudman \& Glick, 2001; Swanson et al., 1996; U.S. Bureau of Labor Statistics, 2017; Yavorsky et al., 2015). Although the discrepancy between men's and women's career development has historically been described as a byproduct of gender discrimination, this explanation is overly simplistic and does not account for other potential factors at play. To further understand this disparity, previously disconnected variables, namely, internalization of sociocultural standards of beauty, physical appearance state anxiety, and depression, were included in this study and explored in relation to women's perception of career barriers.

Although the limitations of this study reduce generalizability and applicability of the findings, the limitations also provide a strong foundation for future research to build upon. First, this study's sample was recruited from one university from the Southeastern region of the U.S. 
Therefore, future research should consider recruiting a general sample of women or a sample of undergraduate women from universities across the U.S. Researchers should also consider examining specific demographic variables, such as age, race/ethnicity, socioeconomic status, etc., in more depth due to differential career development among women in the U.S. (Lopez \& Ann-Yi, 2006; Perrone-McGovern, Wright, Howell, \& Barnum, 2014; Schneider \& Dimito, 2010). Varying the sample is important for future research endeavors because the findings of this study may be distinctive due to recruitment of undergraduate women from one university in the Southeastern region of the U.S. Therefore, future research that examines the variables of interest with different or more diverse samples may confirm the findings of this study as unique to this sample or as common patterns of experience among women in the U.S.

Second, the instruments used in this study were dated and may be inappropriate measures of the variables of interest (Heinberg et al., 1995; Radloff, 1977; Reed et al., 1991; Swanson et al., 1996). Although the instruments were found to be reliable in this study, the instruments may lack applicability and/or validity. For example, sociocultural standards of beauty are fluid and differ based on context; therefore, the feminine beauty ideal may differ from that espoused during the development of the SATAQ-I (Heinberg et al., 1995; Singh \& Singh, 2011). Additionally, changes in the economic, political, social, and cultural landscape in the U.S. may have resulted in subsequent shifts to external and internal variables that women perceive to be career barriers and may have been unintentionally excluded due to use of the CBI-R, an instrument developed in the early 1990s (Swanson \& Daniels, 1994). Finally, physical appearance state anxiety, as measured by the PASTAS-S (Reed et al., 1991), and depression, as measured by the CES-D (Radloff, 1977), appear to be consistent with current understandings of the constructs but may also be lacking due to instrument development between 1977 and 1991, 
respectively. In sum, future researchers should consider using more contemporary instruments to measure the variables of interest. Future researchers may also consider developing instruments to measure the variables of interest due to limited instrumentation, especially in relation to the measurement of perception of career barriers and internalization of sociocultural standards of beauty.

Third, perception of career barriers was measured by the CBI-R (Swanson \& Daniels, 1994) with the understanding that perception of career barriers limits career outcomes by constricting career interests, goals, and actions (Swanson et al., 1996; Swanson \& Tokar, 1991a; Swanson \& Tokar, 1991b). However, this study did not directly measure women's career outcomes. Therefore, the assumption that perception of career barriers is related to career outcomes may be inaccurate. Based on this limitation, it is recommended that future researchers develop both qualitative and quantitative studies that address the influence of perception of career barriers on women's career outcomes.

Fourth, this study reduced the CBI-R (Swanson \& Daniels, 1994) to the Lack of Confidence, Inadequate Preparation, and Decision-Making Difficulties subscales. However, the CBI-R is comprised of 13 subscales that measure a variety of career barriers that were not included in this study, such as gender and racial/ethnic discrimination, conflict between children and career demands, and discouragement from choosing nontraditional careers (Swanson \& Daniels, 1994; Swanson et al., 1996). Due to this exclusion, it is recommended that future researchers include the entirety of the CBI-R to measure perception of career barriers and obtain a more holistic understanding of the types of career barriers that women currently perceive in the U.S. (Swanson \& Daniels, 1994). It may also be beneficial for future researchers to include qualitative questions that ascertain the types of career barriers that women perceive, which may 
or may not be measured by the CBI-R due to development in the 1990s (Swanson \& Daniels, 1994; Swanson et al., 1996).

Fifth, the goal of this study was to explore career barriers that currently impede women's career development in the U.S. Although this study examined internalization of sociocultural standards of beauty, physical appearance state anxiety, and depression in relation to women's perception of career barriers, more research is necessary to further understand barriers that continue to impede women's progress in a career or career goal(s). As such, future researchers should conduct qualitative and quantitative research that builds upon this study and identifies external and/or internal variables that detrimentally impact women's career development. Although this study was primarily focused on career barriers, future research should also include a thorough examination of career supports that foster women's career development. This type of research is necessary to further promote gender equality in the U.S. by identifying potential interventions that facilitate career development and improve career outcomes for women.

Sixth, this study identified internalization of sociocultural standards of beauty as a potential barrier to women's career development in the U.S. Previously, sociocultural standards of beauty were primarily conceptualized as an objective external career barrier, in which perceived physical attractiveness was recognized as limiting to women's career development (Baert \& Decuypere, 2014; Bowling et al., 2004; Gilmore et al., 1986; Hosada et al., 2003; Johnson et al., 2010; Shahani et al., 1993; Watkins \& Johnston, 2000). However, this study conceptualized sociocultural standards of beauty as an internal career barrier, in which internalization of sociocultural standards of beauty is related to the constriction of perceived career options, resulting in reduced career interests, goals, and actions (Lent et al., 2000). As such, this is one of the first studies to examine internalization of sociocultural standards of 
beauty as a potential career barrier for women in the U.S. Therefore, it is recommended that future researchers continue to examine the impact of internalization of sociocultural standards of beauty in relation to women's career development, especially as exposure to the beauty ideal via social media, has become more predominant in U.S. culture.

\section{Counseling Psychology and Other Clinical Implications}

In addition to researchers, this study can also prove valuable for mental health clinicians. First, this study highlights barriers that women in the U.S. perceive to impede progress in a career or career goal(s). Due to the progressively narrow gap between men and women in economic, political, social, and cultural domains, mental health clinicians may mistakenly assume that the career development of men and women is the same and, thereby, discount the unique barriers that women confront when pursuing a career. As mental health clinicians providing career counseling and interventions to clients, it is vital to attend to cultural influences on career development. According to Flores and Bike (2014), culture pervades all aspects of career development, such as access to and use of career-related information and resources, perception of career barriers and supports, values and expectations, systemic oppression, etc. (Duffy \& Klingaman, 2009; Flores, 2009), and should not be neglected by mental health clinicians. Although this study was limited to the career development of women, it is recommended that mental health clinicians provide multicultural career counseling to clients and attend to the primacy of culture "in all phases of the career counseling process" (Flores \& Bike, 2014, p. 407) to facilitate the career advancement of culturally diverse clients in a predominantly White, male-dominated, "educational and occupational opportunity structure" (Diemer, 2007, p. 2). 
Second, this study calls attention to the influence of internalization of sociocultural standards of beauty on women's career development. Although internalization of sociocultural standards of beauty in the U.S. has been previously linked to a number of psychological and physiological consequences for young girls and women, including anxiety, depression, and disordered eating, career-related consequences have largely been ignored (Fredrickson et al., 1998; Grabe et al., 2008; Moradi et al., 2005). Based on the findings of this study, it is recommended that mental health clinicians provide multicultural career counseling and interventions that focus on the influence of internalization of sociocultural standards of beauty on career development, especially for young girls and women (Flores \& Bike, 2014). Furthermore, it is recommended that mental health clinicians attend to the career development of young girls and women with presenting concerns related to body image and disordered eating because internalization of sociocultural standards of beauty typically underlie these and other similar presenting concerns and may potentially result in career-related functional impairment. Despite the exclusion of men from this study, it is also important for mental health clinicians to consider the potential influence of internalization of sociocultural standards of beauty on men's career development.

Third, this study underscores the importance of mental health clinicians attending to the impact of mental health concerns on career development. Although previous research has demonstrated that mental health concerns, such as anxiety and depression, reduce career outcomes due to consequences associated with distress, including burnout, job dissatisfaction, negative performance appraisal, absenteeism, poor productivity, and social isolation and withdrawal, this study highlights the relationship between mental health concerns, namely, physical appearance state anxiety and depression, and perception of career barriers (Bianchi et 
al., 2015; Cropanzano et al., 2003; Maslach et al., 2001). Therefore, this study expands upon previous research by suggesting that mental health concerns function as career barriers that may potentially reduce career outcomes at the beginning stages of career development due to the increased rate of onset of many mental health disorders in adolescence (American Psychiatric Association, 2013). Based on the findings of this study and previous research, it is recommended that mental health clinicians attend to the influence of mental health concerns on career-related self-efficacy and outcome expectations with adolescent and adult clients to facilitate progress at each stage of career development (Campagna \& Curtis, 2007; Lent et al., 2000; Motowidlo et al., 1986; Rottinghaus et al., 2009; Saunders et al., 2000; Swanson et al., 1996).

Fourth, this study emphasizes the complex and multifaceted nature of career development. Traditionally, career development has been a focus of career counseling, and other presenting concerns, such as depression, anxiety, body image, and disordered eating, have been relegated to personal counseling (Betz \& Corning, 1993; Krumboltz, 1993). However, this study suggests that presenting concerns that have historically been excluded or disregarded in career counseling are integral to career development. Although career counseling is increasingly viewed as "inextricably intertwined" with personal counseling, career and personal counseling continue to be perceived and practiced by many mental health clinicians separately (Krumboltz, p. 143, 1993; Maxwell, 2007). Therefore, it is recommended that mental health clinicians integrate career and personal counseling because integration encourages engagement in multicultural counseling, which is essential to the therapeutic alliance and outcomes of counseling (American Psychological Association, 2019; Flores \& Bike, 2014; Hanna \& Cardona, 2013)

\section{Conclusion}


Despite significant gains in economic, political, social, and cultural domains, women continue to experience career barriers that impede or prevent progress in a career or career goal(s). Due to the potential impact of career barriers on women's career outcomes, the goal of this study was to explore career barriers that currently limit women's career development in the U.S. Historically, the differential career development of men and women was primarily explained as a function of gender discrimination; however, this study expanded upon previous research by exploring potential barriers to women's career development that have not been previously identified in the literature to date. More specifically, this study found that internalization of sociocultural standards of beauty, physical appearance state anxiety, and depression were related to women's perception of career barriers, primarily, perception of lack of confidence and decision-making difficulties as career barriers. By exploring internalization of sociocultural standards of beauty, depression, and physical appearance state anxiety in relation to perception of career barriers, this study provides multiple avenues for future researchers to build upon to further understanding of women's career development in the U.S. Furthermore, this study may also be useful to mental health clinicians by emphasizing the complexity of career development and encouraging integration of career and personal counseling into practice. 


\section{REFERENCES}

American Psychiatric Association (2013). Diagnostic and statistical manual of mental disorders ( $5^{\text {th }}$ ed.). Washington, DC: Author.

American Psychological Association (2019). APA multicultural guidelines executive summary: Ecological approach to context, identity, and intersectionality. American Psychologist, 74(2), 232-244. doi: 10.1037/amp0000382

Astin, H. S. (1984). The meaning of work in women's lives: A sociopsychological model of career choice and work behavior. The Counseling Psychologist, 12(4), 117-126. doi: $10.1177 / 0011000084124002$

Baert, S., \& Decuypere, L. (2014). Better sexy than flexy? A lab experiment assessing the impact of perceived attractiveness and personality traits on hiring decisions. Applied Economics Letters, 21(9), 597-601. doi: 10.1080/13504851.2013.877564

Bandura, A. (1977). Self-efficacy: Toward a unifying theory of behavioral change. Psychological Review, 34(2), 191-215. doi: 10.1037/0033-295X.84.2.191

Bandura, A. (1986). Social foundations of thought and action: A social cognitive theory. Englewood Cliffs, NJ: Prentice-Hall.

BarNir, A., Watson, W. E., \& Hutchins, H. M. (2011). Mediation and moderated mediation in the relationship among role models, self-efficacy, entrepreneurial career intention, and gender. Journal of Applied Social Psychology, 41(2), 270-297. doi: 10.1111/j.15591816.2010.00713.x

Baron, R. M., \& Kenny, D. A. (1986). The moderator-mediator variable distinction in social psychological research: Conceptual, strategic, and statistical considerations. Journal of Personality and Social Psychology, 51(6), 1173-1182. doi:10.1037/0022-3514.51.6.1173 Bartky, S. (1990). Femininity and domination. New York: Routledge. 
Bartlett, C. P., \& Harris, R. J. (2008). The impact of body emphasizing video games on body image concerns in men and women. Sex Roles, 59(7), 586-601. doi: 10.1007/s11199-008$9457-8$

Beck, A. T., Ward, C. H., Mendelson, M., Mock, J., \& Erbaugh, J. (1961). An inventory for measuring depression. Archives of General Psychiatry, 4(6), 561-571. doi: 10.1001/archpsyc. 1961.01710120031004

Becker, J., Milad, M., \& Klock, S. (2006). Burnout, depression, and career satisfaction: Crosssectional study of obstetrics and gynecology residents. American Journal of Obstetrics and Gynecology, 195(5), 1444-1449. doi: 10.1016/j.ajog.2006.06.075

Berg, K. C., Frazier, P., \& Sherr, L. (2009). Change in eating disorder attitudes and behavior in college women: Prevalence and predictors. Eating Behaviors, 10(3), 137-142. doi: 10.1016/j.eatbeh.2009.03.003

Betz, N. E., \& Hackett, G. (1981). The relationship of career-related self-efficacy expectations to perceived career options in college women and men. Journal of Counseling Psychology, 28(5), 399-410. doi: 10.1037/0022-0167.28.5.399

Betz, N., \& Corning, A. (1993). The inseparability of "career" and "personal" counseling. Career Development Quarterly, 42(2), 137-142. doi: 10.1002/j.2161-0045.1993.tb00426.x

Bianchi, R., Schonfeld, I. S., \& Laurent, E. (2015). Burnout-depression overlap: A review. Clinical Psychology Review, 36(1), 28-41. doi: 10.1016/j.cpr.2015.01.004

Bowling, N. A., Beehr, T. A., Johnson, A. L., Semmer, N. K., Hendricks, E. A., \& Webster, H. A. (2004). Explaining potential antecedents of workplace social support: Reciprocity or attractiveness? Journal of Occupational Health Psychology, 9(4), 339-350. doi: 10.1037/1076-8998.9.4.339 
Calogero, R. M., Boroughs, M., \& Thompson, J. K. (2007). The impact of Western beauty ideals on the lives of women and men: A sociocultural perspective. In V. Swami \& A. Furnham (Eds.), Body beautiful: Evolutionary and sociocultural perspectives (pp. 259-298). New York: Palgrave Macmillan.

Campagna, C. J., \& Curtis, G. J. (2007). So worried I don't know what to be: Anxiety is associated with increased career indecision and reduced career certainty. Journal of Psychologists and Counsellors in School, 17(1), 91-96. doi: 10.1375/ajgc.17.1.91

Cattarin, J. A., Thompson, J. K., Thomas, C., \& Williams, R. (2000). Body image, mood, and televised images of attractiveness: The role of social comparison. Journal of Social and Clinical Psychology, 19(2), 220-239. doi: 10.1521/jscp.2000.19.2.220

Charles, M. (2003). Deciphering sex segregation: Vertical and horizontal inequalities in ten national labor markets. Acta Sociologica, 46(4), 267-287. doi: $10.1177 / 0001699303464001$

Cheung, C., Cheung, H., \& Wu, J. (2014). Career unreadiness in relation to anxiety and authoritarian parenting among undergraduates. International Journal of Adolescence and Youth, 19(3), 336-349. doi: 10.1080/02673843.2014.928784

Cook, E. P., Heppner, M. J., \& O’Brien, K. M. (2002). The Career Development Quarterly, 50(4), 291-235. doi: 10.1002/j.2161-0045.2002.tb00574.x

Correll, S. J., Benard, S., \& Paik, I. (2007). Getting a job: Is there a motherhood penalty? American Journal of Sociology, 112(5), 1297-1339. doi: 10.1086/511799

Corse, S. J. (1990). Pregnant managers and their subordinates: The effects of gender expectations on hierarchical relationships. Journal of Applied Behavioral Science, 26(1), 25-48. doi: $10.1177 / 002188639002600104$ 
Covert, B. (2017). The best era for working women was 20 years ago. Ny Times. Retrieved from https://www.nytimes.com/2017/09/02/opinion/sunday/working-women-decline$\underline{\text { 1990s.html }}$

Crites, J. O. (1969). Vocational Psychology. New York: McGraw-Hill.

Cropanzano, R., Rupp, D. E., Byrne, Z. S. (2003). The relationship of emotional exhaustion to work attitudes, job performance, and organizational citizenship behaviors. Journal of Applied Psychology, 88(1), 160-169. doi: 10.1037/0021-9010.88.1.160

Cuddy, A. J. C., Fiske, S. T., \& Glick, P. (2004). When professionals become mothers, warmth doesn't cut the ice. Journal of Social Issues, 60(4), 701-718. doi: 10.1111/j.00224537.2004.00381.x

Dahling, J. J., Melloy, R., \& Thompson, M. N. (2013). Financial strain and regional unemployment as barriers to job search self-efficacy. Journal of Counseling Psychology, 60(2), 210-218. doi: 10.1037/a0031492

Dahlstrom, W., \& Walsh, G. (1960). An MMPI Handbook. University of Minnesota Press: Minneapolis.

Dakanalis, A., Clerici, M., Caslini, M., Favagrossa, L., Prunas, A., Volpato, C., ...Zanetti, M. A. (2014). Internalization of sociocultural standards of beauty and disordered eating behaviors: The role of body surveillance, shame, and social anxiety. Journal of Psychopathology, 20(1), 33-37. doi: 10.1017/ S0033291798006618

Derogatis, L., Lipman, R., \& Covi, L. (1973). SLO-90: An outpatient psychiatric scale: Preliminary report. Psychopharmacology Bulletin, 9(1), 13-27.

Diemer, M. (2007). Two worlds: African American men's negotiation of predominantly White educational and occupational worlds. Journal of Multicultural Counseling and 
Development, 35(1), 2-14. doi:10.1002/j.2161-1912.2007.tb00045.x

Dion, K. K., Berscheid, E., \& Walster, E. (1972). What is beautiful is good. Journal of Personality and Social Psychology, 24(3), 285-290. doi: 10.1037/h0033731

Dipboye, R. L., Arvey, R. D., \& Terpstra, D. E. (1977). Sex and Physical Attractiveness of Raters and Applicants as Determinants of Résumé Evaluations. Journal of Applied Psychology, 62(3), 288. doi: 10.1037/0021-9010.62.3.288

Dittmar, H., \& Howard, S. (2004). Thin-ideal internalization and social comparison tendency as moderators of media models' impact on women's body-focused anxiety. Journal of Social and Clinical Psychology, 23(6), 768-791. doi: 10.1521/jscp.23.6.768.54799

Duffy, R., \& Klingaman, E. (2009). Ethnic identity and career development among first-year college students. Journal of Career Assessment, 17(3), 286-297. doi:10.1177/1069072708330504

Eagly, A. H., Ashmore, R. D., Makhijani, M. G., Longo, L. C. (1991). What is beautiful is good, but...A meta-analytic review of research on the physical attractiveness stereotype. Psychological Bulletin, 110(1), 109-128. doi: 10.1037/0033-2909.110.1.109

Engeln-Maddox, R. (2006). Buying a beauty standard or dreaming of a new life? Expectations associated with media ideals. Psychology of Women Quarterly, 30(3), 258-266. doi: 10.1111/j.1471-6402.2006.00294.x

Fardouly, J., Diedrichs, P. C., Vartanian, L., \& Halliwell, E. (2015). Social comparisons on social media: The impact of Facebook on young women's body image concerns and mood. Body Image, 13(1), 38-45. doi: 10.1016/j.bodyim.2014.12.002

Farmer, H.S. (1976). What inhibits achievement and career motivation in women? The Counseling Psychologist, 6(2), 12-14. doi: 10.1177/001100007600600204 
Faul, F., Erdfelder, E., Buchner, A., \& Lang, A. (2009). Statistical power analyses using G*Power 3.1: Tests for correlation and regression analyses. Behavior Research Methods, 41(4), 1149-1160. doi: 10.3758/BRM.41.4.1149

Faul, F., Erdfelder, E., Lang, A., \& Buchner, A. (2007). G*Power 3: A flexible statistical power analysis program for the social, behavioral, and biomedical sciences. Behavior Research Methods, 39(2), 175-191. doi: 10.3758/BF03193146

Field, A. (2013). Discovering statistics using IBM SPSS statistics ( $4^{\text {th }}$ ed.). Las Angeles, CA: Sage Publications.

Flores, L. (2009). Empowering life choices: Career counseling in the contexts of race and class. In N. C. Gysbers, M. J. Heppner, \& J. A. Johnston (Eds.), Career counseling: Contexts, processes, and techniques (3rd ed., pp. 49-74). Alexandria, VA: American Counseling Association.

Flores, L., \& Bike, D. (2014). Multicultural Career Counseling. In F. T. L. Leong, L. ComasDiaz, H. Nagayama, C. Gordon, V. C. McLoyd, J. E. Trimble, (Eds.), APA Handbook of Multicultural Psychology, Vol. 2: Applications and Training (pp. 403-417). Washington, DC: American Psychological Association.

Freedman, J. (2010). Women in the workplace: Wages, respect, and equal rights. New York, NY: The Rosen Publishing Group, Inc.

Fredrickson, B. L., \& Roberts, T. (1997). Objectification theory: Toward understanding women's lived experiences and mental health risks. Psychology of Women Quarterly, 21(2), 173206. doi: 10.1111/j.1471-6402.1997.tb00108.x

Fredrickson, B. L., Roberts, T., Noll, S. M., Quinn, D. M., \& Twenge, J. M. (1998). That swimsuit becomes you: Sex differences in self-objectification, restrained eating, and math 
performance. Journal of Personality and Social Psychology, 75(1), 269-284. doi:

$10.1037 / 0022-3514.75 .1 .269$

Fuqua, D., Newman, J., \& Seaworth, T. (1988). Relation of state and trait anxiety to different components of career indecision. Journal of Counseling Psychology, 35(2), 154-158. doi: $10.1037 / 0022-0167.35 .2 .154$

Gaffner, D. C., \& Hazler, R. J. (2002). Factors related to indecisiveness and career indecision in undecided college students. Journal of College Student Development, 43(3), 317-326. doi: $10.1037 / 0022-0167.53 .4 .397$

Germeijs, V., Verschueren, K., \& Soenens, B. (2006). Indecisiveness and high school students' career decision-making process: Longitudinal associations and the mediational role of anxiety. Journal of Counseling Psychology, 53(4), 397-410. doi: 10.1037/00220167.53.4.397

Gervais, S. J., Vescio, T. K., \& Allen, J. (2011). When what you see is what you get: The consequences of the objectifying gaze for women and men. Psychology of Women Quarterly, 35(1), 5-17. doi: 10.1177/0361684310386121

Gilmore, D. C., Beehr, T. A., \& Love, K. G. (1986). Effects of applicant sex, applicant physical attractiveness, type of rater and type of job on interview decisions. Journal of Occupational Psychology, 59(2), 103-109. doi: 10.1111/j.2044-8325.1986.tb00217.x

Goffman, E. (1979). Gender advertisements. Cambridge, MA: Harvard University Press.

Grabe, S., Ward, L. M., \& Hyde, J. S. (2008). The role of the media in body image concerns among women: A meta-analysis of the experimental and correlational studies. Psychological Bulletin, 134(3), 460-476. doi: 10.1037/0033-2909.134.3.460

Greenhaus, J. H., Beutell, N. J. (1985). Sources of conflict between work and family roles. 
Academy of Management Review, 10(1), 76-88. doi: 10.2307/258214

Groesz, L. M., Levine, M. P., \& Murnen, S. K. (2002). The effect of experimental presentation of thin media images on body satisfaction: A meta-analytic review. International Journal of Eating Disorders, 31(1), 1-16. doi: 10.1002/eat.10005

Hackett, G., \& Betz, N. E. (1981). A self-efficacy approach to the career development of women. Journal of Vocational Behavior, 18(3), 326-339. doi: 10.1016/0001-8791(81)90019-1

Hakanen, J., Schaufeli, W., \& Ahola, K. (2008). The Job-Demands Resources model: A threeyear cross-lagged study of burnout, depression, commitment, and work engagement. Work and Stress, 22(3), 224-241. doi: 10.1080/02678370802379432

Halliwell, E., Diedrichs, P.C., \& Orbach, S. (2014). Costing the invisible: A review of the evidence examining the links between body image, aspirations, education and workplace confidence. Centre for Appearance Research, University of the West of England. Retrieved from http://eprints.uwe.ac.uk/24438/

Halpert, J. A., Wilson, M. L., \& Hickman, J. (1993). Pregnancy as a source of bias in performance appraisals. Journal of Organizational Behavior, 14(7), 649-663. doi: 10.1002/job.4030140704

Hamilton, M. (1960). A rating scale for depression. Journal of Neurological Neurosurgical Psychiatry, 23(1), 56-62. doi: 10.1136/jnnp.23.1.56

Hanna, F., \& Cardona, B. (2013). Multicultural counseling beyond the relationship: Expanding the repertoire with techniques. Journal of Counseling and Development, 91(3), 349-357. doi: 10.1002/j.1556-6676.2013.00104.x

Harmon, L. W. (1977). Career counseling for women. In E. Rawlings \& D. Carter (Eds.)., Psychotherapy for Women. Springfield, IL: Thomas. 
Harper, B., \& Tiggemann, M. (2008). The effect of thin media ideal media images on women's self-objectification, mood, and body image. Sex Roles, 58(9), 649-657. doi: $10.1007 / \mathrm{s} 11199-007-9379-\mathrm{x}$

Harrison, K. (2003). Television viewers' ideal body proportions: The case of the curvaceously thin woman. Sex Roles, 48(5), 255-264. doi: 10.1023/A:1022825421647

Heilman, M. E., Wallen, A. S., Fuchs, D., \& Tamkins, M. M. (2004). Penalties for success: Reactions to women who succeed at male gender-typed tasks. Journal of Applied Psychology, 89(3), 416-427. doi: 10.1037/0021-9010.89.3.416

Heinberg, L. J., Thompson, J. K., \& Stormer, S. (1995). Development and validation of the Sociocultural Attitudes Towards Appearance Questionnaire. International Journal of Eating Disorders, 17(1), 81-89. doi: 10.1002/1098-108X(199501)17:1<81::AIDEAT2260170111>3.0.CO;2-Y

Hodges, A. J., \& Park, B. (2013). Oppositional identities: Dissimilarities in how women and men experience parent versus professional roles. Journal of Personality and Social Psychology, 105(2), 193-216. doi: 10.1037/a0032681

Hosoda, M., Stone- Romero, E. F., \& Coats, G. (2003). The effects of physical attractiveness on job-related outcomes: A meta-analysis of experimental studies. Personnel Psychology, 56(2), 431-462. doi: 10.1111/j.1744-6570.2003.tb00157.x

Isik, E. (2012). The relationship of career decision self-efficacy, trait anxiety, and affectivity among undergraduate students. Psychological Reports: Human Resources and Marketing, 111(3), 805-813. doi: 10.2466/01.09.10.PR0.111.6.805-813

Johnson, S. K., Podratz, K. E., Dipboye, R. L., \& Gibbons, E. (2010). Physical attractiveness bias in ratings of employment suitability: Tracking down the "beauty is beastly" effect. 
Journal of Social Psychology, 150(3), 301-318. doi: 10.1080/00224540903365414

Krones, P. G., Stice, E., Batres, C., \& Orjada, K. (2005). In vivo social comparison to a thin-ideal peer promotes body dissatisfaction: A randomized experiment. International Journal of Eating Disorders, 38(2), 134-142. doi: 10.1002/eat.20171

Krumboltz, J. (1993). Integrating career and personal counseling. Career Development Quarterly, 42(2), 143-148. doi: 10.1002/j.2161-0045.1993.tb00427.x

Lent, R. W., Brown, S. D., \& Hackett, G. (1994). Toward a unifying Social Cognitive Theory of career and academic interest, choice, and performance. Journal of Vocational Behavior, 45(1), 79-122. doi: 10.1006/jvbe.1994.1027

Lent, R. W., Brown, S. D., \& Hackett, G. (2000). Contextual supports and barriers to career choice: A social cognitive analysis. Journal of Counseling Psychology, 47(1), 36-49. doi: $10.1037 / 0022-0167.47 .1 .36$

Lerner, D., \& Henke, R. (2008). What does research tell us about depression, job performance, and work productivity? Journal of Occupational and Environmental Medicine, 50(4), 401-410. doi: 10.1097/JOM.0b013e31816bae50

Lindsey, T. B. (2011). Black no more: Skin bleaching and the emergence of new negro womanhood beauty culture. Journal of Pan African Studies, 4(4), 97-116. doi: $10.1177 / 1468796814565216$

Lopez, F. G., \& Ann-Yi, S. (2006). Predictors of career indecision in three racial/ethnic groups of college women. Journal of Career Development, 33(1), 29-46. doi:

$10.1177 / 0894845306287341$

Lucas, M., Skokowski, C., \& Ancis, J. (2000). Contextual themes in career decision making of female clients who indicate depression. Journal of Counseling and Development, 78(3), 
316-325. doi: 10.1002/j.1556-6676.2000.tb01913.x

Lyness, K. S., \& Heilman, M. E. (2006). When fit is fundamental: Performance evaluations and promotions of upper-level female and male managers. Journal of Applied Psychology, 91(4), 777-785. doi: 10.1037/0021-9010.91.4.777

Maslach, C., Schaufeli, W. B., \& Leiter, M. P. (2001). Job burnout. Annual Review of Psychology, 52(1), 397-422. doi: 10.1146/annurev.psych.52.1.397

Maxwell, M. (2007). Career counseling is personal counseling: A constructivist approach to nurturing the development of gifted female adolescents. Career Development Quarterly, 55(3), 206-224. doi: 10.1002/j.2161-0045.2007.tb00078.x

Moradi, B., Dirks, D., \& Matteson, A. V. (2005). Roles of sexual objectification experiences and internalization of standards of beauty in eating disorder symptomatology: A test and extension of Objectification Theory. Journal of Counseling Psychology, 52(3), 420-428. doi: $10.1037 / 0022-0167.52 .3 .420$

Morry, M. M., \& Staska, S. L. (2001). Magazine exposure: Internalization, self-objectification, eating attitudes, and body satisfaction in male and female university students. Canadian Journal of Behavioral Science, 33(4), 269-279. doi: 10.1037/h0087148

Motowidlo, S. J., Packard, J. S., \& Manning, M. R. (1986). Occupational stress: Its causes and consequences for job performance. Journal of Applied Psychology, 71(4), 618-629. doi: $10.1037 / / 0021-9010.71 .4 .618$

Myers, T. A., \& Crowther, J. H. (2009). Social comparison as a predictor of body dissatisfaction: A meta-analytic review. Journal of Abnormal Psychology, 118(4), 683-698. doi: $10.1037 / \mathrm{a} 0016763$

National Eating Disorders Association. (2018). Media and eating disorders. Retrieved from 


\section{https://www.nationaleatingdisorders.org/media-eating-disorders}

Newkirk, K., Perry-Jenkins, M., \& Sayer, A. G. (2017). Division of household and childcare labor and relationship conflict among low-income new parents. Sex Roles, 76(5), 319333. doi: $10.1007 / \mathrm{s} 11199-016-0604-3$

Novakovic, A., \& Gnilka, P. B. (2015). Dispositional affect and career barriers: The moderating roles of gender and coping. The Career Development Quarterly, 63(4), 363-375. doi: $10.1002 /$ cdq. 12034

O’Leary, V. E. (1974). Some attitudinal barriers to occupational aspirations in women. Psychological Bulletin, 81(11), 809-826. doi: 10.1037/h0037267

O’Neil, D. A., \& Bilimoria, D. (2005). Women's career development phases: Idealism, endurance, reinvention. Career Development International, 10(3), 168-189. doi: $10.1108 / 13620430510598300$

Perloff, R. (2014). Social media effects on young women's body image concerns: Theoretical perspectives and an agenda for research. Sex Roles, 71(11-12), 363-377. doi: $10.1007 / \mathrm{s} 11199-014-0384-6$

Perrone-McGovern, K., Wright, S., Howell, D., \& Barnum, E. (2014). Contextual influences on work and family roles: Gender, culture, and socioeconomic factors. The Career Development Quarterly, 62(1), 21-28. doi: 10.1002/j.2161-0045.2014.00067.x

Pew Research Center. (2016). The state of American jobs. Retrieved from https://www.pewsocialtrends.org/2016/10/06/the-state-of-american-jobs/

Phelan, J. E., Moss-Racusin, C. A., Rudman, L. A. (2008). Competent yet out in the cold: Shifting criteria for hiring reflect backlash toward agentic women. Psychology of Women Quarterly, 32(4), 406-413. doi: 10.1111/j.1471-6402.2008.00454.x 
Radloff, L. (1977). The CES-D Scale: A self-report depression scale for research in the general population. Applied Psychological Measurement, 1(3), 385-401. doi: $10.1177 / 014662167700100306$

Raskin, A., Schulterbrandt, J., Reatig, N., \& McKeon, J. (1969). Replication of factors of psychopathology in interview, ward behavior, and self-report ratings of hospitalized depressives. Journal of Nervous and Mental Disease, 148(1), 87-96. doi: $10.1097 / 00005053-196901000-00010$

Reed, D., Thompson, J., Brannick, M., \& Sacco, W. (1991). Development and validation of the Physical Appearance State and Trait Anxiety Scale (PASTAS). Journal of Anxiety Disorders, 5(1), 323-332. doi: 10.1016/0887-6185(91)90032-O

Rivera, L. M., Chen, E. C., Flores, L. Y., Blumberg, F., \& Ponterotto, J. G. (2007). The effects of perceived barriers, role models, and acculturation on the career self-efficacy and career consideration of Hispanic women. The Career Development Quarterly, 56(1), 47-61. doi: 10.1002/j.2161-0045.2007.tb00019.x

Rottinghaus, P. J., Jenkins, N., \& Jantzer, A. M. (2009). Relation of depression and affectivity to career decision status and self-efficacy in college students. Journal of Career Assessment, 17(3), 271-285. doi: 10.1177/1069072708330463

Rudman, L. A., \& Glick, P. (2001). Prescriptive gender stereotypes and backlash toward agentic women. Journal of Social Issues, 57(4), 743-762. doi: 10.1111/0022-4537.00239

Saunders, D. E., Peterson, G. W., Sampson, J. P., \& Reardon, R. C. (2000). Relation of depression and dysfunctional career thinking to career indecision. Journal of Vocational Behavior, 56(2), 288-298. doi: 10.1006/jvbe.1999.1715

Schneider, M., \& Dimito, A. (2010). Factors influencing the career and academic choices of 
lesbian, gay, bisexual, and transgender people. Journal of Homosexuality, 57(10), 13551369. doi: $10.1080 / 00918369.2010 .517080$

Shahani, C., Dipboye, R. L., \& Gehrlein, T. M. (1993). Attractiveness bias in the interview: Exploring the boundaries of an effect. Basic and Applied Social Psychology, 14(3), 317328. doi: $10.1207 / \mathrm{s} 15324834$ basp1403_5

Sherman, A., \& Zurbriggen, E. (2014). "Boys can be anything": Effect of Barbie play on girls' career cognitions. Sex Roles, 70(5-6), 195-208. doi: 10.1007/s11199-014-0347-y

Singh, D., \& Singh, D. (2011). Shape and significance of feminine beauty: An evolutionary perspective. Sex Roles, 64(9), 723-731. doi: 10.1007/s11199-011-9938-z

Slater, A., Halliwell, E., Jarman, H., \& Gaskin, E. (2017). More than just child's play?: An experimental investigation of the impact of an appearance-focused internet game on body image and career aspirations of young girls. Journal of Youth and Adolescence, 46(9), 2047-2059. doi: 10.1007/s10964-017-0659-7

Spielberger, C. (1983). Manual for the State-Trait Anxiety Inventory (Form Y). Palo Alto: Consulting Psychologists Press.

Stankov, L., Lee, J., Luo, W., \& Hogan, D. (2012). Confidence: A better predictor of academic achievement than self-efficacy, self-concept and anxiety? Learning and Individual Differences, 22(6). doi: 10.1016/j.lindif.2012.05.013.

Stice, E., Maxfield, J., \& Wells, T. (2003). Adverse effects of social pressure to be thin on young women: An experimental investigation of the effects of "fat talk." International Journal of Eating Disorders, 34(1), 108-117. doi: 10.1002/eat.10171

Swanson, J. L., \& Daniels, K. (1994). The Career Barriers Inventory-Revised. Unpublished manuscript. Carbondale, IL: Southern Illinois University. 
Swanson, J. L., Daniels, K., \& Tokar, D. M. (1996). Assessing perceptions of career-related barriers: The Career Barriers Inventory. Journal of Career Assessment, 4(2), 219-244. doi: $10.1177 / 106907279600400207$

Swanson, J. L., \& Tokar, D. M. (1991a). College students' perceptions of barriers to career development. Journal of Vocational Behavior, 38(1), 92-106. 10.1016/00018791(91)90020-M

Swanson, J. L., \& Tokar, D. M. (1991b). Development and initial validation of the Career Barriers Inventory. Journal of Vocational Behavior, 39(3), 344-361. doi: 10.1016/00018791(91)90043-L

Sweeney, M., \& Schill, T. (1998). The association between self-defeating personality characteristics, career indecision, and vocational identity. Journal of Career Assessment, 6(1), 69-81. doi: 10.1177/106907279800600105

Swim, J., Hyers, L., Cohen, L., \& Ferguson, M. (2001). Everyday sexism: Evidence for its incidence, nature, and psychological impact from three daily diary studies. Journal of Social Issues, 57(1), 31-53. doi: 10.1111/0022-4537.00200

Taylor, K. M., \& Betz, N. E. (1983). Applications of self-efficacy theory to the understanding and treatment of career indecision. Journal of Vocational Behavior, 22(1), 63-81. doi: $10.1016 / 0001-8791(83) 90006-4$

Tiggemann, M., \& Slater, A. (2004). Thin ideals in music television: A source of social comparison and body dissatisfaction. International Journal of Eating Disorders, 35(1), 48-58. doi: 10.1002/eat.10214

U.S. Bureau of Labor Statistics. (2017). Women in the labor force: A databook (Report 1071). Retrieved from https://www.bls.gov/opub/reports/womens-databook/2017/pdf/home.pdf 
Vondracek, F. W., Lerner, R. M., \& Schulenberg, J. E. (1986). Career development: A life-span developmental approach. Hillsdale, NJ: Erlbaum.

Vuori, J., Toppinen-Tanner, S. (2015). Enhancing career management preparedness and mental health. In J. Vuori, R. Blonk, and R. Price (Eds.), Sustainable working lives: Aligning perspectives on health, safety, and well-being. New York: NY: Springer.

Walker, J., \& Peterson, J. (2012). Career thoughts, indecision, and depression: Implications for mental health assessment in career counseling. Journal of Career Assessment, 20(4), $497-$ 506. doi: $10.1177 / 1069072712450010$

Watkins, L. M., \& Johnston, L. (2000). Screening job applicants: The impact of physical attractiveness and application quality. International Journal of Selection and Assessment, 8(2), 76-84. doi: 10.1111/1468-2389.00135

Watts, L. L., Frame, M. C., Moffett, R. G., Van Hein, J. L., \& Hein, M. (2015). The relationship between gender, perceived career barriers, and occupational aspirations. Journal of Applied Social Psychology, 45(1), 10-22. doi: 10.1111/jasp.12271

West Virginia Higher Education Policy Commission. (2018). Reports and publications. Retrieved from http://www.wvhepc.edu/resources/reports-and-publications/.

Woodrow-Keys, E. (2006). The effects of body image on career decision making self-efficacy and assertiveness in female athletes and non athletes (Unpublished master's thesis). Marshall University, Huntington, WV.

Yavorsky, J. E., Kamp Dush, C. M., \& Schoppe-Sullivan, S. J. (2015). The production of inequality: The gender division of labor across the transition to parenthood. Journal of Marriage and Family, 77(3), 662-679. doi: 10.1111/jomf.12189

Zung, W. (1965). A self-rating depression scale. Archives of General Psychiatry, 12(1), 63-70. 
doi: 10.1001/archpsyc. 1965.01720310065008 


\section{Appendix A}

\section{CAREER BARRIERS INVENTORY-REVISED}

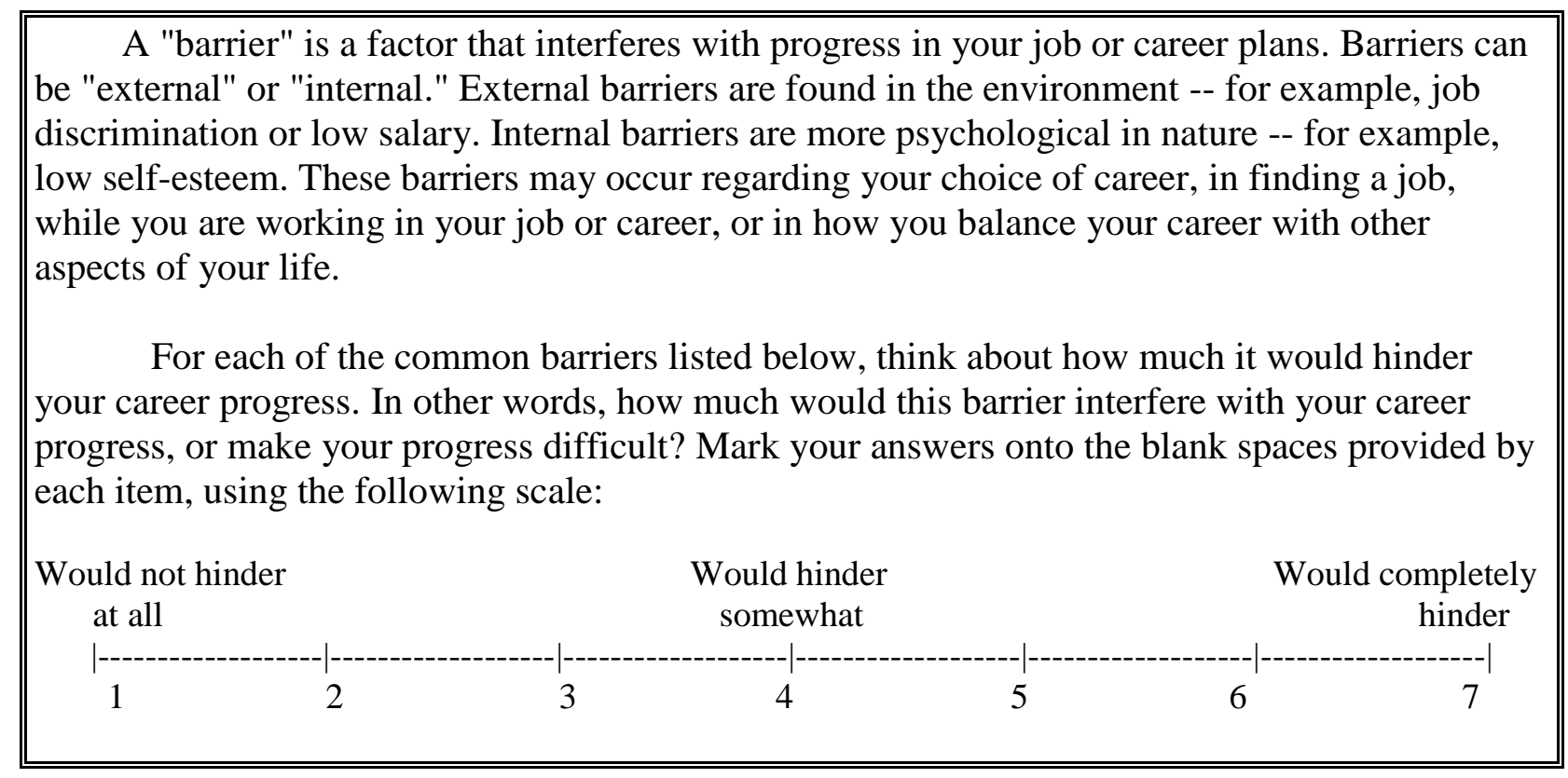

1. Unsure of my career goals.

2. Changing my mind again and again about my career plans

3. Unsure of how to "sell myself" to an employer

4. Unsure of my work-related values

5. Not feeling confident about my ability on the job

6. Not feeling confident about myself in general

7. Being undecided about what job/career I would like

8. Lacking the required skills for my job (e.g., communications, leadership)

9. Not being sure how to choose a career direction

10. Unsure of what my career alternatives are

11. Lack of maturity interferes with my career 
12. Having low self-esteem

13. Lacking information about possible jobs/careers

14. Unable to deal with the physical or emotional demands of my job

15. Unsure of what I want out of life

16. Lacking the necessary educational background for the job I want

17. Lacking the necessary hands-on experience for the job I want 


\section{Appendix B}

\section{SOCIOCULTURAL ATTITUDES TOWARDS APPEARANCE QUESTIONNAIRE}

Please read each of the following items and circle the number that best reflects your agreement with the statement.

1. Women who appear in TV shows and movies project the type of appearance that I see as my goal.

\begin{tabular}{ccccc}
1 & 2 & 3 & 4 & 5 \\
\hline $\begin{array}{c}\text { Completely } \\
\text { disagree }\end{array}$ & & $\begin{array}{c}\text { Neither agree } \\
\text { nor disagree }\end{array}$ & $\begin{array}{c}\text { Completely } \\
\text { agree }\end{array}$
\end{tabular}

2. I believe that clothes look better on thin models.

\begin{tabular}{ccccc}
1 & 2 & 3 & 4 & 5 \\
\hline $\begin{array}{c}\text { Completely } \\
\text { disagree }\end{array}$ & & $\begin{array}{c}\text { Neither agree } \\
\text { nor disagree }\end{array}$ & $\begin{array}{c}\text { Completely } \\
\text { agree }\end{array}$
\end{tabular}

3. Music videos that show thin women make me wish that I were thin.

\begin{tabular}{ccccc}
1 & 2 & 3 & 4 & 5 \\
\hline $\begin{array}{c}\text { Completely } \\
\text { disagree }\end{array}$ & & $\begin{array}{c}\text { Neither agree } \\
\text { nor disagree }\end{array}$ & $\begin{array}{c}\text { Completely } \\
\text { agree }\end{array}$
\end{tabular}

4. I do not wish to look like the models in the magazines.

\begin{tabular}{ccccc}
1 & 2 & 3 & 4 & 5 \\
\hline $\begin{array}{c}\text { Completely } \\
\text { disagree }\end{array}$ & & $\begin{array}{c}\text { Neither agree } \\
\text { nor disagree }\end{array}$ & $\begin{array}{c}\text { Completely } \\
\text { agree }\end{array}$
\end{tabular}


5. I tend to compare my body to people in magazines and on TV.

\begin{tabular}{ccccc}
1 & 2 & 3 & 4 & 5 \\
\hline $\begin{array}{c}\text { Completely } \\
\text { disagree }\end{array}$ & & $\begin{array}{c}\text { Neither agree } \\
\text { nor disagree }\end{array}$ & $\begin{array}{c}\text { Completely } \\
\text { agree }\end{array}$
\end{tabular}

6. Photographs of thin women make me wish that I were thin.

\begin{tabular}{ccccc}
1 & 2 & 3 & 4 & 5 \\
\hline $\begin{array}{c}\text { Completely } \\
\text { disagree }\end{array}$ & & $\begin{array}{c}\text { Neither agree } \\
\text { nor disagree }\end{array}$ & $\begin{array}{c}\text { Completely } \\
\text { agree }\end{array}$
\end{tabular}

7. I wish I looked like a swimsuit model.

\begin{tabular}{ccccc}
1 & 2 & 3 & 4 & 5 \\
\hline $\begin{array}{c}\text { Completely } \\
\text { disagree }\end{array}$ & & $\begin{array}{c}\text { Neither agree } \\
\text { nor disagree }\end{array}$ & $\begin{array}{c}\text { Completely } \\
\text { agree }\end{array}$
\end{tabular}

8. I often read magazines like Cosmopolitan, Vogue, and Glamour and compare my appearance to the models.

\begin{tabular}{ccccc}
1 & 2 & 3 & 4 & 5 \\
\hline $\begin{array}{c}\text { Completely } \\
\text { disagree }\end{array}$ & & $\begin{array}{c}\text { Neither agree } \\
\text { nor disagree }\end{array}$ & & $\begin{array}{c}\text { Completely } \\
\text { agree }\end{array}$
\end{tabular}




\section{Appendix C}

\section{CENTER FOR EPIDEMIOLOGIC STUDIES DEPRESSION SCALE}

Below is a list of some ways you may have felt or behaved. Please indicate how often you have felt this way during the last week by checking the appropriate space. Please only provide one answer to each question.

\begin{tabular}{|c|l|l|l|l|l|}
\hline & \multicolumn{1}{|c|}{ During the past week: } & $\begin{array}{c}\text { Rarely or none of } \\
\text { the time (less than } \\
1 \text { day) }\end{array}$ & $\begin{array}{c}\text { Some or a little of } \\
\text { the time (1-2 } \\
\text { days) }\end{array}$ & $\begin{array}{c}\text { Occasionally or a } \\
\text { moderate amount } \\
\text { of the time (3-4 } \\
\text { days) }\end{array}$ & $\begin{array}{c}\text { Most or all of the } \\
\text { time (5-7 days) }\end{array}$ \\
\hline 1. & $\begin{array}{l}\text { I was bothered by things that } \\
\text { usually don't bother me. }\end{array}$ & & & & \\
\hline 2. & $\begin{array}{l}\text { I did not feel like eating; my } \\
\text { appetite was poor. }\end{array}$ & & & & \\
\hline 3. & $\begin{array}{l}\text { I felt that I could not shake } \\
\text { off the blues even with help } \\
\text { from my family or friends. }\end{array}$ & & & & \\
\hline 4. & $\begin{array}{l}\text { I felt I was just as good as } \\
\text { other people. }\end{array}$ & & & \\
\hline 5. & $\begin{array}{l}\text { I had trouble keeping my } \\
\text { mind on what I was doing. }\end{array}$ & & & \\
\hline 6. & I felt depressed. & & & \\
\hline 7. & $\begin{array}{l}\text { I felt that everything I did } \\
\text { was an effort. }\end{array}$ & & & & \\
\hline 8. & I felt hopeful about the future. & & & & \\
\hline 9. & $\begin{array}{l}\text { I thought my life had been a } \\
\text { failure. }\end{array}$ & & & & \\
\hline 10 & I felt fearful. & & & \\
\hline 11. & My sleep was restless. & & & & \\
\hline 12. & I was happy. & & & & \\
\hline 13. & I talked less than usual. & & & & \\
\hline 14. & I felt lonely. & & & & \\
\hline 15. & People were unfriendly. & & & & \\
\hline 16. & I enjoyed life. & & & & \\
\hline 17. & I had crying spells. & & & & \\
\hline 18. & I felt sad. & & & & \\
\hline 19. & I felt that people disliked me. & & & & \\
\hline 20. & I could not get going. & & & & \\
\hline & & & & & \\
\hline
\end{tabular}




\section{Appendix D}

\section{PHYSICAL APPEARANCE STATE AND TRAIT ANXIETY SCALE}

The statements listed below are used to describe how anxious, tense, or nervous you feel Right Now about your body.

Use the following scale:

\begin{tabular}{|c|c|c|c|c||}
\hline \hline Not at All & Slightly & Moderately & Very Much So & Exceptionally So \\
0 & 1 & 2 & 3 & 4 \\
\hline
\end{tabular}

Right now, I feel anxious, tense, or nervous about:

1. The extent to which I look overweight. $\quad \begin{array}{llllll}0 & 1 & 2 & 3 & 4\end{array}$

2. My ears.

3. My thighs.

4. My lips.

5. My wrists.

6. My buttocks.

7. My hands.

8. My forehead.

9. My hips.

10. My neck.

11. My stomach (abdomen).

12. My chin.

13. My legs.

14. My feet.

15. My waist.

16. My muscle tone.

$\begin{array}{lllll}0 & 1 & 2 & 3 & 4\end{array}$

$\begin{array}{lllll}0 & 1 & 2 & 3 & 4\end{array}$

$\begin{array}{lllll}0 & 1 & 2 & 3 & 4\end{array}$

$\begin{array}{lllll}0 & 1 & 2 & 3 & 4\end{array}$

$\begin{array}{lllll}0 & 1 & 2 & 3 & 4\end{array}$

$\begin{array}{lllll}0 & 1 & 2 & 3 & 4\end{array}$

$\begin{array}{lllll}0 & 1 & 2 & 3 & 4\end{array}$

$\begin{array}{lllll}0 & 1 & 2 & 3 & 4\end{array}$

$\begin{array}{lllll}0 & 1 & 2 & 3 & 4\end{array}$

$\begin{array}{lllll}0 & 1 & 2 & 3 & 4\end{array}$

$\begin{array}{lllll}0 & 1 & 2 & 3 & 4\end{array}$

$\begin{array}{lllll}0 & 1 & 2 & 3 & 4\end{array}$

$\begin{array}{lllll}0 & 1 & 2 & 3 & 4\end{array}$

$\begin{array}{lllll}0 & 1 & 2 & 3 & 4\end{array}$

$\begin{array}{lllll}0 & 1 & 2 & 3 & 4\end{array}$




\section{DEMOGRAPHIC QUESTIONNAIRE}

1. What is your age in years?

2. What is your sex (or gender)?

Male

Female

Transgender

Gender Non-Conforming

Other

3. What is your racial/ethnic identity?

African American or Black

American Indian or Alaskan Native

Asian American or Asian

Hispanic or Latino/a

Native Hawaiian or Pacific Islander

Biracial or Multiracial

Caucasian or White

Other

4. What is your sexual orientation?

Heterosexual

Bisexual

Lesbian or Gay 
Asexual

Pansexual

Questioning

Other

5. What is your first (or native) language?

6. What country were you born in?

7. What is your current year in school?

First Year

Sophomore

Junior

Senior

Graduate

8. What is your marital status?

Single, Never Married

Married

Divorced

Widowed

9. How many children do you have?

10. What is your total household income? (If you are being supported with the help of your family, what is the total household income of your family as a whole?) 
Less than $\$ 30,000$

$\$ 30,000$ - $\$ 49,999$

$\$ 50,000$ - \$99,999

$\$ 100,000$ - \$249,999

$\$ 250,000$ or more

11. What is your major in school? 


\section{Only Minimal Risk Consent Information Form (without HIPAA)}

Principal Investigator

Department

Protocol Number

Study Title

Co-Investigator(s)

Sponsor (if any)
Lisa Platt, Ph.D.

Department of Counseling, Rehabilitation Counseling, and Counseling Psychology

Internalization of Sociocultural Standards of Beauty, Perception of Career Barriers, Depression, and State Physical Appearance Anxiety Among College Women

None

\section{Contact Persons}

In the event you experience any side effects or injury or have any questions, concerns, or complains related to this research, you should contact Dr. Lisa Platt at (304) 293-2176.

For information regarding your rights as a research subject, to discuss problems, concerns, or suggestions related to the research, to obtain information or offer input about the research, contact the Office of Research Integrity and Compliance at (304) 293-7073.

In addition, if you would like to discuss problems, concerns, have suggestions related to research, or would like to offer input about the research, contact the Office of Research Integrity and Compliance at (304) 293-7073.

\section{Introduction}

You have been asked to participate in this research study. This study is being conducted by Dr. Lisa Platt and Adrionia Molder, M.S., in the Department of Counseling, Rehabilitation Counseling, and Counseling Psychology at West Virginia University.

Phone: 304-293-7073

Fax: 304-293-3098 http://oric.research.wvu.edu
Chestnut Ridge Research Building

886 Chestnut Ridge Road

PO Box 6845

Morgantown, WV 26506-6845

$P$ a g e | 1 


\section{Purpose(s) of the Study}

The purpose of this study is to understand the relationship between internalization of the sociocultural standards of beauty, depression, state physical appearance anxiety, and perception of career barriers among college women.

\section{Description of Procedures}

This study involves the completion of surveys measuring perception of career barriers, internalization of sociocultural standards of beauty, depression, and state physical appearance anxiety. A demographic questionnaire will also be included. This will take approximately 15-20 minutes for you to complete. You do not have to answer all the questions. You will have the opportunity to see the surveys and questionnaire before signing this consent form.

\section{Discomforts}

There are no known or expected risks from participating in this study, except for the mild frustration associated with answering the questions.

\section{Benefits}

By participating in this study, you will be providing information that will not only contribute to research on college women's career development, but you will also further aid in understanding gender inequality in the United States. You will be compensated by course credit in fulfillment of a course requirement for research participation or extra credit where applicable.

\section{Financial Considerations}

There are no special fees for participating in this study.

\section{Confidentiality}

Any information about you that is obtained as a result of your participation in this research will be kept as confidential as legally possible. Your research records and test results, just like hospital records, may be subpoenaed by court order or may be inspected by the study sponsor or federal regulatory authorities (including the FDA if applicable) without your additional consent.

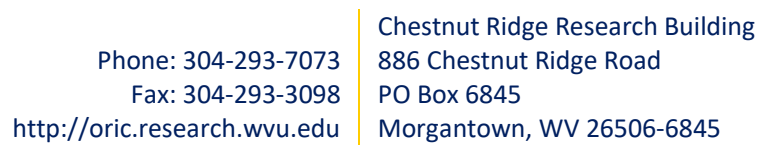

Morgantown, WV 26506-6845
$P$ a g e $\mid 2$ 
In addition, there are certain instances where the researcher is legally required to give information to the appropriate authorities. These would include mandatory reporting of infectious diseases, mandatory reporting of information about behavior that is imminently dangerous to your child or to others, such as suicide, child abuse, etc.

In any publications that result from this research, neither your name nor any information from which you might be identified will be published without your consent.

\section{Voluntary Participation}

Participation in this study is voluntary. You are free to withdraw your consent to participate in this study at any time.

Refusal to participate or withdrawal will not affect you and will involve no penalty to you. Refusal to participate or withdrawal will not affect your future care at West Virginia University.

In the event new information becomes available that may affect your willingness to participate in this study, this information will be given to you so that you can make an informed decision about whether or not to continue your participation.

You have been given the opportunity to ask questions about the research, and you have received answers concerning areas you did not understand.

I willingly agree to be in the study.

$\circ$ Yes $\quad \circ$ No

Phone: 304-293-7073

Chestnut Ridge Research Building

$P$ a g e | 3

Fax: 304-293-3098

886 Chestnut Ridge Road

PO Box 6845

http://oric.research.wvu.edu

Morgantown, WV 26506-6845 